Une déclaration d'un comité consultatif (DCC)

https://doi.org/10.14745/ccdr.v39i00a03f

Groupe de travail pour l'élimination de la rougeole et de la rubéole (GTERR)

(1) Avis : Nouvelles recommandations sur la prophylaxie post-exposition contre la rougeole

Le chapitre sur la prophylaxie post-exposition des Lignes directrices pour la prévention et le contrôle des éclosions de rougeole au Canada est actuellement en processus de révision. Ceci est nécessaire en raison d'un changement récent des recommandations du Comité consultatif national de l'immunisation (CCNI) en ce qui concerne les indications, le dosage et l'administration d'immunoglobuline (Ig) humaine pour la prophylaxie post-exposition contre la rougeole.

Consultez les Nouvelles recommandations du CCNI en matière de prophylaxie post-exposition contre la rougeole publiées en septembre 2018 dans le Relevé des maladies transmissibles au Canada (RMTC).

\title{
LIGNES DIRECTRICES POUR LA PRÉVENTION ET LE CONTRÔLE DES ÉCLOSIONS DE ROUGEOLE AU CANADA
}

APPROUVÉ PAR LE CONSEIL DES MÉDECINS HYGIÉNISTES EN CHEF (CMHC) LE 2 NOVEMBRE 2012

\section{TABLE DES MATIÈRES}

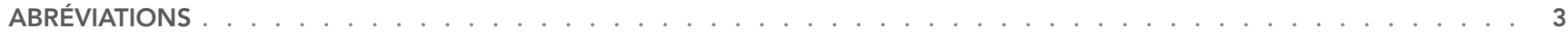

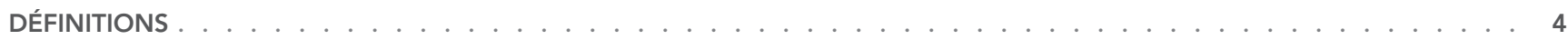

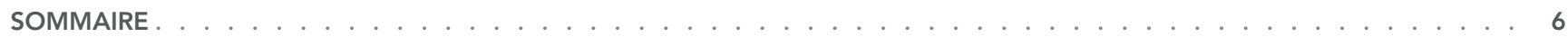

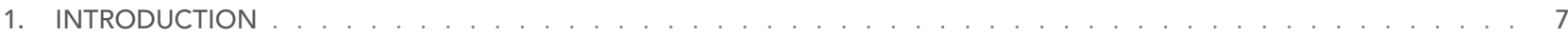

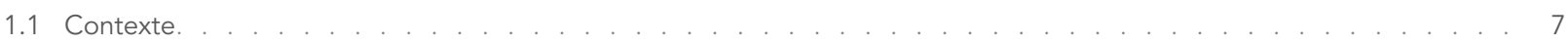

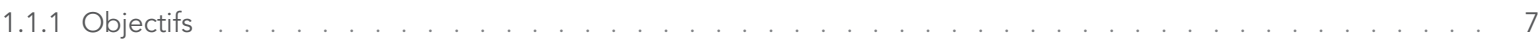

2. É́PIDÉMIOLOGIE DE LA ROUGEOLE AU CANADA $\ldots \ldots \ldots \ldots$

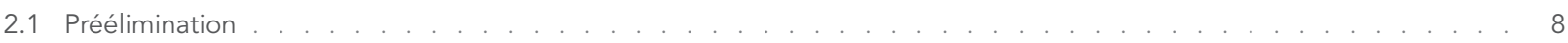

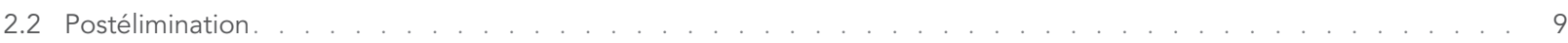

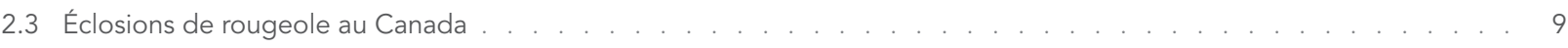

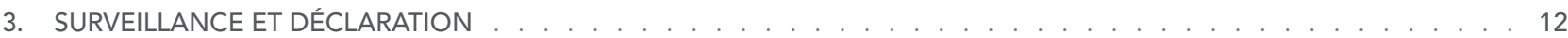

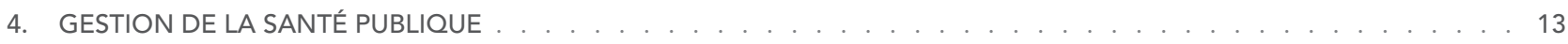

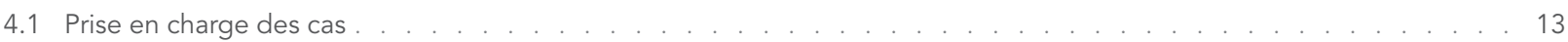

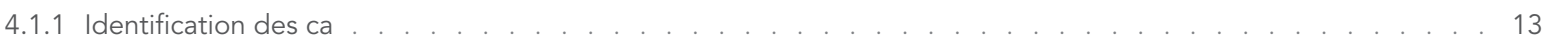

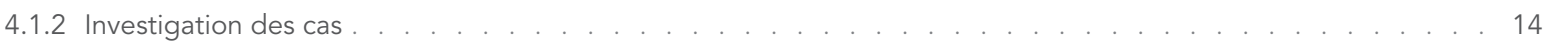

4.1 .3 Collecte de données . . . . . . . . . . . . . . . . . . . 14

4.1 .4 Prise en charge des cas . . . . . . . . . . . . . . . . . . . . . . . . . . . . . . . . . . . . . . . 14

4.1 .5 Retrait de la société des cas confirmés. . . . . . . . . . . . . . . . . . . . . . . . . . . . . . . . 14

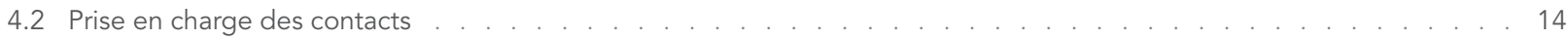

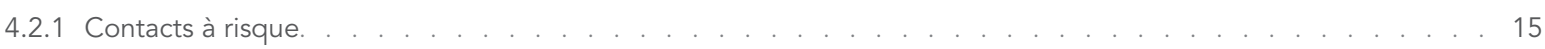

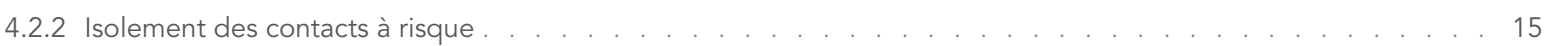

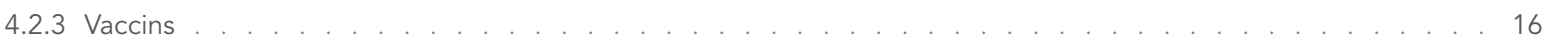

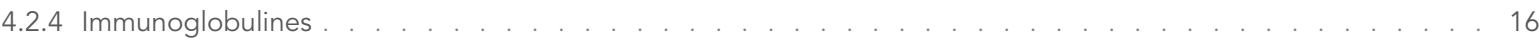




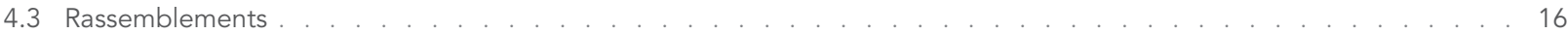

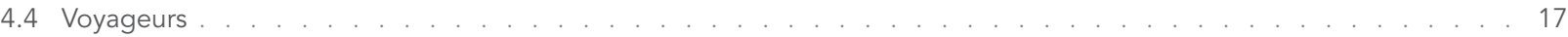

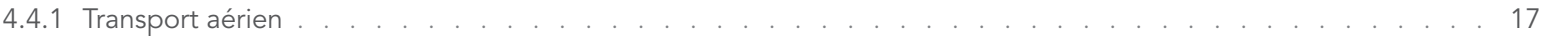

4.4 .2 Voyage en mer sur navire de croisière . . . . . . . . . . . . . . . . . . . . . . . . . . . . . . . . . 18

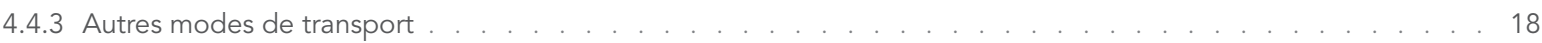

5. MILIEUX DE SOINS . . . . . . . . . . . . . . . . . . . . . . . . . . . . . . . . . . . . . . . . . . . . 19

5.1 Mesures de prévention et de contrôle de l'infection dans les cas suspects ou confi més de rougeole . . . . . . . . . 19

5.1 .1 Prise en charge des travailleurs de la santé exposés à des cas . . . . . . . . . . . . . . . . . . . . 20

5.1 .2 Prise en charge des patients exposés à des cas. . . . . . . . . . . . . . . . . . . . . . . . . . . . 21

6. LIGNES DIRECTRICES POUR LE DIAGNOSTIC DE LA ROUGEOLE EN LABORATOIRE . . . . . . . . . . . . . . . . . . 22

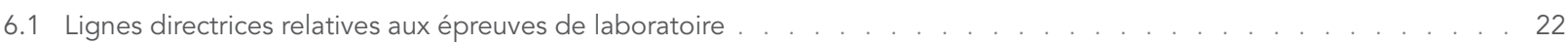

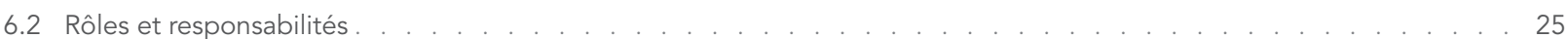

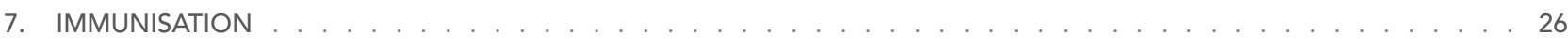

7.1 Recommandations du Comité consultatif national de l'immunisation relatives à l'utilisation du vaccin contre la rougeole. 26

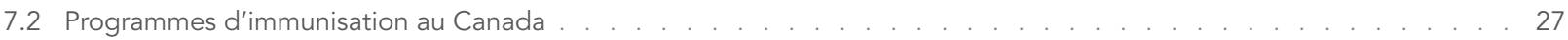

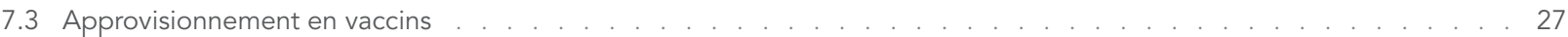

7.3.1 Vaccin contenant le virus de la rougeole au Canada. . . . . . . . . . . . . . . . . . . . . . . . . . . 28

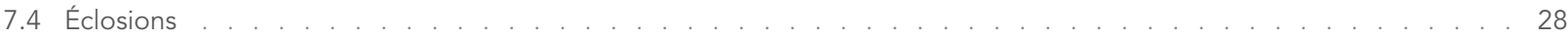

8. CADRE DE COMMUNICATION STRATÉGIQUE DES RISQUES . . . . . . . . . . . . . . . . . . . . . . 29

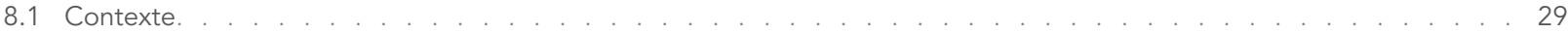

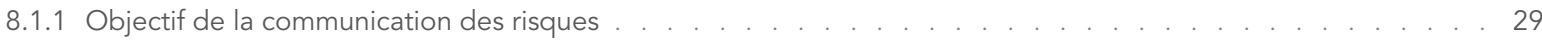

8.2 Protocoles de communication fédéraux-provinciaux-territoriaux . . . . . . . . . . . . . . . . . . . . . . . 29

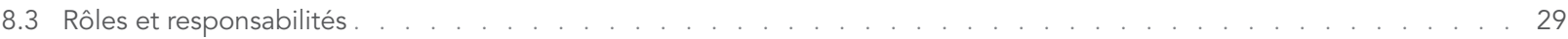

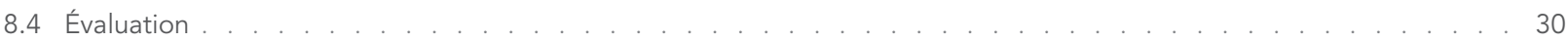

8.5 Principes clés de la communication des risques . . . . . . . . . . . . . . . . . . . . . . . . . . . . . . 30

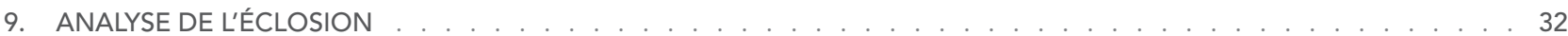

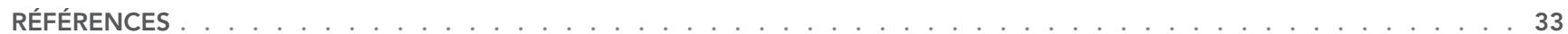

ANNEXE A. PARTICIPANTS À L'ÉLABORATION DES LIGNES DIRECTRICES . . . . . . . . . . . . . . . . . . . . . . 35

ANNEXE B. LOIS PROVINCIALES ET TERRITORIALES RELATIVES À LA DÉCLARATION DES MALADIES TRANSMISSIBLES. . . . . . 36

ANNEXE C. EXIGENCES FÉDÉRALES, PROVINCIALES ET TERRITORIALES RELATIVES

À LA DÉCLARATION DES CAS DE ROUGEOLE. . . . . . . . . . . . . . . . . . . . . . . . . . . . . . . . 37

ANNEXE D. FORMULAIRE NATIONAL DE DÉCLARATION DE CAS DE ROUGEOLE. . . . . . . . . . . . . . . . . . . . . . . 39

ANNEXE E. FORMULAIRE D'ANALYSE D'ÉCHANTILLON DE CAS DE ROUGEOLE . . . . . . . . . . . . . . . . . . . . . 40

ANNEXE F. RECOMMANDATIONS POUR LA PRISE EN CHARGE DES CAS DE ROUGEOLE DANS LES MILIEUX DE SOINS . . . . . 44

ANNEXE G. ALGORITHMES POUR MILIEUX DE SOINS . . . . . . . . . . . . . . . . . . . . . . . . . . 48

ANNEXE H. LIGNES DIRECTRICES POUR LE DIAGNOSTIC DE LA ROUGEOLE EN LABORATOIRE. . . . . . . . . . . . . . . . . 51

ANNEXE I. CARTE DES PARTIES CONCERNÉES . . . . . . . . . . . . . . . . . . . . . . . . . . . . . 57

ANNEXE J. EXEMPLE DE COMPOSITION D’UN MESSAGE . . . . . . . . . . . . . . . . . . . . . . . . . . . 58 


\section{ABRÉVIATIONS}

\begin{tabular}{|c|c|}
\hline ASPC & Agence de la santé publique du Canada (l'agence) \\
\hline CCNI & Comité consultatif national de l'immunisation \\
\hline CDMTI & Comité directeur sur les maladies transmissibles et infectieuses \\
\hline CCE & Comité consultatif de l'épidémiologie \\
\hline CIITA & chambre d'isolement pour infections à transmission aérienne \\
\hline CIMRI & Centre de l'immunisation et des maladies respiratoires infectieuses \\
\hline $\mathrm{CMHC}$ & Conseil des médecins hygiénistes en chef \\
\hline CRSP & Conseil du réseau pancanadien de santé publique \\
\hline DGPCMI & Direction générale de la prévention et du contrôle des maladies infectieuses \\
\hline EIA & épreuve immunoenzymatique \\
\hline FPT & fédéral-provincial-territorial \\
\hline $\mathrm{GCl}$ & Guide canadien d'immunisation \\
\hline GTERR & Groupe de travail pour l'élimination de la rougeole et de la rubéole \\
\hline $\lg$ & immunoglobuline \\
\hline $\lg G$ & immunoglobuline G \\
\hline $\lg M$ & immunoglobuline $\mathrm{M}$ \\
\hline LCR & liquide céphalorachidien \\
\hline LNM & Laboratoire national de microbiologie \\
\hline mIU & milli-unité internationale \\
\hline MTV & milieu de transport viral \\
\hline OMS & Organisation mondiale de la Santé \\
\hline OPS & Organisation panaméricaine de la santé \\
\hline $\mathrm{PCl}$ & prévention et contrôle des infections \\
\hline PT & province ou territoire \\
\hline PCET & Programme canadien d'épidémiologie de terrain \\
\hline PSS & panencéphalite sclérosante subaiguë \\
\hline $\mathrm{RCP}$ & réaction en chaîne de la polymérase \\
\hline RCRSP & Réseau canadien de renseignements sur la santé publique \\
\hline RRO & rougeole, rubéole et oreillons \\
\hline RROV & rougeole, rubéole, oreillons et varicelle \\
\hline RSI & règlement sanitaire international \\
\hline RT-PCR & transcription inverse suivie d'une réaction en chaîne de la polymérase \\
\hline SCSMDO & Système canadien de surveillance des maladies à déclaration obligatoire \\
\hline SCSRR & Système canadien de surveillance de la rougeole et de la rubéole \\
\hline SRC/IRC & syndrome de rubéole congénitale/infection rubéoleuse congénitale \\
\hline TMD & transport de marchandises dangereuses \\
\hline TS & travailleur de la santé \\
\hline TSNRP & test de séro-neutralisation par réduction des plages \\
\hline UI & unité internationale \\
\hline
\end{tabular}




\section{DÉFINITIONS}

\section{CAS DE SOURCE INCONNUE}

Cas confirmé dont la source d'infection n'a pas

été établie.

\section{CAS ENDÉMIQUE}

Un cas de rougeole est considéré endémique lorsque

la chaîne de transmission continue d'être ininterrompue pendant une période de plus de 12 mois.

\section{CAS IMPORTÉ}

Cas confirmé qui, selon des données épidémiologiques et virologiques, a été exposé au virus de la rougeole à l'extérieur du Canada au cours des 7 à 18 jours précédant l'apparition de la fièvre ou des 7 à 21 jours précédant I'apparition d'une éruption cutanée généralisée.

\section{CAS LIÉ À UN CAS IMPORTÉ}

Infection acquise localement survenant dans le cadre d'une chaîne de transmission provenant d'un cas importé, comme le suggèrent des données épidémiologiques ou virologiques, ou les deux.

\section{CONTACT}

Par « contact», on entend toute personne ayant :

- passé un certain laps de temps dans une pièce ou un espace clos avec un cas confirmé de rougeole, pendant la période infectieuse de celui-ci (c.-à-d. approximativement de quatre jours précédant l'apparition de l'éruption cutanée à quatre jours suivant l'apparition de l'éruption cutanée); ou

- passé un certain laps de temps dans une pièce précédemment occupée par un cas de rougeole, pendant la période infectieuse de celui-ci, dans les deux heures suivant le départ du cas de la pièce ou l'espace.

\section{ÉCLOSION DE ROUGEOLE}

Étant donné que la rougeole a été éliminée au Canada, un seul cas serait considéré comme inhabituel ou inopiné. Cependant, tant que l'activité associée à la rougeole demeure élevée dans d'autres régions de l'Organisation mondiale de la Santé, les cas importés peuvent continuer de survenir. Voici une définition ad hoc d'une éclosion de rougeole:
" deux cas confirmés ou plus liés sur le plan épidémiologique ou virologique, ou les deux.

\section{FIN D'UNE ÉCLOSION}

Une éclosion peut être considérée comme terminée au plus tôt le 32e jour1 suivant la date de l'apparition de l'éruption cutanée du dernier cas associé à l'éclosion afin de tenir compte des retards dans le signalement de cas, des cas subcliniques ou des cas non diagnostiqués.

\section{LIEN ÉPIDÉMIOLOGIQUE}

Un cas présente un lien épidémiologique s'il répond à un ou plusieurs des critères suivants :

- contact avec un cas confirmé de rougeole;

- voyage, au cours des 21 jours précédant l'apparition de l'éruption cutanée, dans une région géographique où la rougeole est endémique ou qui connaît une éclosion de la rougeole;

- appartenance à un groupe à risque défini pendant une éclosion.

\section{MILIEU DE SOINS}

Aux fins du présent document, un milieu de soins est un établissement ou un lieu où des soins de santé sont dispensés, notamment des soins d'urgence, des soins préhospitaliers, des soins de courte durée, des soins de longue durée, des soins aux malades chroniques, des soins complexes, des soins à domicile, des soins ambulatoires ainsi qu'un établissement ou un lieu communautaire où des soins sont dispensés (p. ex. les infirmeries scolaires ou les établissements résidentiels(1)).

\section{PATIENT}

Par « patient », on entend notamment les patients hospitalisés, les patients externes, les résidents d'établissements de soins de longue durée ou de soins aux malades chroniques, ainsi que les patients qui reçoivent des soins dans les milieux résidentiels et communautaires.

\footnotetext{
Cette durée correspond à deux périodes d'incubation (14 jours entre l'exposition au virus et l'éruption cutanée) plus la période maximale de transmissibilité de quatre jours après l'apparition de l'éruption cutanée(10).
} 


\section{PERSONNE À RISOUE}

Une personne considérée comme étant à risque à la rougeole qui répond aux critères suivants :

- ne dispose pas de preuve qu'elle a été vaccinée après son premier anniversaire, puis au moins quatre semaines plus tard s'il s'agit du vaccin RRO ou six semaines plus tard s'il s'agit du vaccin RROV (une dose pour les adultes de 18 ans et plus nés en 1970 ou après; deux doses pour les enfants ayant entre 12 mois et 17 ans);

- ne dispose pas de preuve fournie par un laboratoire attestant qu'elle a déjà été atteinte de la rougeole; et

- ne dispose pas de preuve d'immunité fournie par un laboratoire (c.-à-d. anticorps IgG antirougeoleux " réactifs » ou « positifs » ou un titre d'anticorps antirougeoleux antérieur de $\geq 200 \mathrm{mUI}$ par ml)(2).

\section{TERRITOIRES}

Éclosion dont l'infection s'est répandue sur plus d'un territoire de compétence (plusieurs provinces et territoires ou pays) ou gestion d'une éclosion à laquelle participent plusieurs organismes.

\section{TRAVAILLEUR DE LA SANTÉ}

Les travailleurs de la santé sont notamment les personnes qui dispensent des soins de santé ou des services de soutien, comme les infirmières, les médecins, les dentistes, les infirmières praticiennes, les ambulanciers paramédicaux et, parfois, les premiers intervenants, les professionnels paramédicaux, les fournisseurs de soins de santé non réglementés, les enseignants cliniques et les étudiants, les bénévoles et le personnel d'entretien(1). 


\section{SOMMAIRE}

La rougeole au Canada : II n'y a pas eu de rougeole endémique au Canada depuis 1998. Toutefois, des cas continueront de se manifester tant que les gens voyageront entre le Canada et des pays où la maladie est active. Le maintien de l'état d'élimination de cette maladie nécessite une surveillance accrue, la détermination des populations réceptives et I'amélioration de l'immunisation de ces populations, ainsi que l'éducation du public et des professionnels de la santé quant à l'importance de l'immunisation.

Historique des directives : En 1991, le Comité consultatif de l'épidémiologie (CCE) a publié les Directives canadiennes pour la lutte contre la rougeole. Ces directives présentaient une approche concertée de la lutte antirougeoleuse fondée sur une large couverture vaccinale, une surveillance nationale à l'aide de définitions de cas normalisées et des interventions ciblées lors d'éclosions. Cette approche a cependant été critiquée, car elle nécessitait des ressources importantes et ses résultats étaient discutables. À la demande du CCE, une Conférence de concertation sur la rougeole a alors eu lieu à la fin de 1992 et ses actes ont été publiés en mai 1993. En 1995, le CCE a publié les Directives pour la lutte contre les épidémies de rougeole au Canada, révision faite à partir des recommandations de la Conférence de concertation.

Directives mises à jour : Dans le cadre de la campagne d'élimination de la rougeole et de la rubéole dans les Amériques de l'Organisation panaméricaine de la santé (OPS), et en réponse à une éclosion prolongée de la rougeole au Québec en 2011, le document Directives pour la lutte contre les épidémies de rougeole au Canada de 1995 a été mis à jour.
La révision des directives a été menée par le Groupe de travail pour l'élimination de la rougeole et de la rubéole (GTERR), et facilitée et encouragée par l'Agence de la santé publique du Canada (l'Agence). Le groupe de travail est composé de nombreux spécialistes de divers domaines qui sont rattachés à des instances locales, provinciales, territoriales et fédérales.

Les directives mises à jour ont été rédigées pour aider les autorités canadiennes de santé publique dans l'examen et la gestion des éclosions de rougeole afin de prévenir les complications des infections par le virus et de restreindre la propagation secondaire de la maladie en cas d'éclosion.

Voici quelques-uns des principaux changements et mises à jour des Lignes directrices pour la prévention et le contrôle des éclosions de rougeole au Canada (2012) :

- Mise à jour des renseignements en matière de vaccination pour refléter les recommandations actuelles du Comité consultatif national de l'immunisation (CCNI)

- Modifications des critères de réceptivité des travailleurs de la santé selon le Guide canadien d'immunisation mis à jour (disponible en ligne)

- Recommandation pour les autorités de publier un résumé des éclosions dans l'année suivant la fin d'une éclosion

- Recommandations des laboratoires de faire des diagnostics cliniques des sérologies

- Outil d'évaluation (algorithmes) pour les milieux de soins 


\section{INTRODUCTION}

\subsection{CONTEXTE}

La rougeole est une maladie respiratoire virale extrêmement grave et contagieuse qui se caractérise par de la fièvre et des éruptions maculopapulaires et exanthémateuses généralisées. Les symptômes sont notamment la toux, le coryza et la conjonctivite. L'infection par le virus de la rougeole peut entraîner de graves complications comme la cécité, une encéphalite ou des infections respiratoires aiguës (p. ex. la pneumonie).

Avant l'immunisation à grande échelle en 1980, la rougeole était la cause d'environ 2,6 millions de décès chaque année dans le monde. Malgré l'accès à de vaccins sécuritaires et efficaces, la rougeole demeure l'une des principales causes de décès parmi les jeunes enfants de partout dans le monde, selon l'Organisation mondiale de la Santé (OMS).

En 1994, la Région des Amériques, de l'Organisation panaméricaine de la santé (OPS), établissait l'objectif d'éliminer la rougeole pour l'an 2000. L'OPS définit l'élimination comme l'absence de génotype endémique en circulation depuis au moins un an et le maintien de l'immunité de $95 \%$ de la population par une dose du vaccin contenant le virus de la rougeole et la possibilité d'administrer une seconde dose.

Le Canada n'a pas connu d'endémies rougeoleuses depuis 1998. Au Canada, des programmes d'immunisation financés par l'État ont permis d'immuniser un pourcentage élevé de la population, et du coup, réduire les taux d'incidence de la rougeole. Une surveillance active et passive est mise en place au Canada depuis des années, ce qui permet d'intervenir rapidement là où des cas sont signalés. Des cas continueront d'apparaître au Canada tant que des personnes arrivent au Canada d'un pays où la maladie est active, et il y aura toujours des personnes et des communautés à risque qui ne sont pas immunisées ou qui sont sous-immunisées. Le maintien de l'état d'élimination de cette maladie exigera d'assurer une surveillance accrue, d'accroître les taux de couverture vaccinale des populations à risque et d'informer tant le public que les professionnels de la santé sur l'importance d'être immunisé.
Dans le cadre de la campagne d'élimination de la rougeole et de la rubéole dans les Amériques de l'OPS, et en réponse à une éclosion prolongée de la rougeole au Québec en 2011, le document Directives pour la lutte contre les épidémies de rougeole au Canada de 1995 a été mis à jour. Les lignes directrices ont été révisées de manière à aider les représentants de la santé publique et les médecins à gérer les cas de rougeole et leurs contacts pendant les éclosions, ainsi que pour limiter la probabilité que la rougeole redevienne une maladie endémique au Canada.

\subsubsection{OBJECTIFS}

Les lignes directrices ont été principalement rédigées pour aider les autorités de santé publique du Canada dans l'investigation et la gestion des éclosions de rougeole pour :

- prévenir les complications d'une infection par le virus de la rougeole;

- restreindre la propagation secondaire de la rougeole pendant une éclosion.

Il se peut que les autorités de santé publique doivent adapter les lignes directrices et les recommandations importantes aux protocoles et aux interventions de la santé publique de leur région. 


\section{2. ÉPIDÉMIOLOGIE DE LA ROUGEOLE AU CANADA}

\subsection{PRÉÉLIMINATION}

Au Canada, le nombre de cas de rougeole et les taux d'incidence de cas déclarés chaque année ont considérablement diminué depuis que la rougeole fait partie des maladies à déclaration obligatoire à l'échelle nationale, c'est-à-dire en 1924 (Figure 1). Entre 1924 et 1958, en moyenne 45000 cas (étendue : de 13471 à

83 127) ont été déclarés chaque année. Une diminution du nombre de cas a été constatée dans les années 1970, avec une moyenne de 9863 cas (étendue : de 934 à 25 137) déclarés chaque année entre 1969 et 1983. À la suite de la mise en œuvre de programmes d'immunisation systématique financés par l'État pour les enfants âgés d'un an par l'administration d'une dose du vaccin contre la rougeole, la rubéole et les oreillons (RRO) en 1983, le nombre annuel moyen de cas de rougeole a chuté à 4096 (étendue : de 187 à 14 941). En 1996-1997, les calendriers d'immunisation prévoyant deux doses du vaccin RRO ont été mis en place partout au Canada. La seconde dose était administrée à 18 mois ou à l'entrée à l'école, en association avec les campagnes de rattrapage qui se sont tenues dans plusieurs provinces. Cette mesure a entraîné d'autres baisses du nombre et du taux d'incidence de cas de rougeole déclarés au Canada.

FIGURE 1 : Nombre de cas et taux d'incidence déclarés de rougeole au Canada, de 1924 à 2011

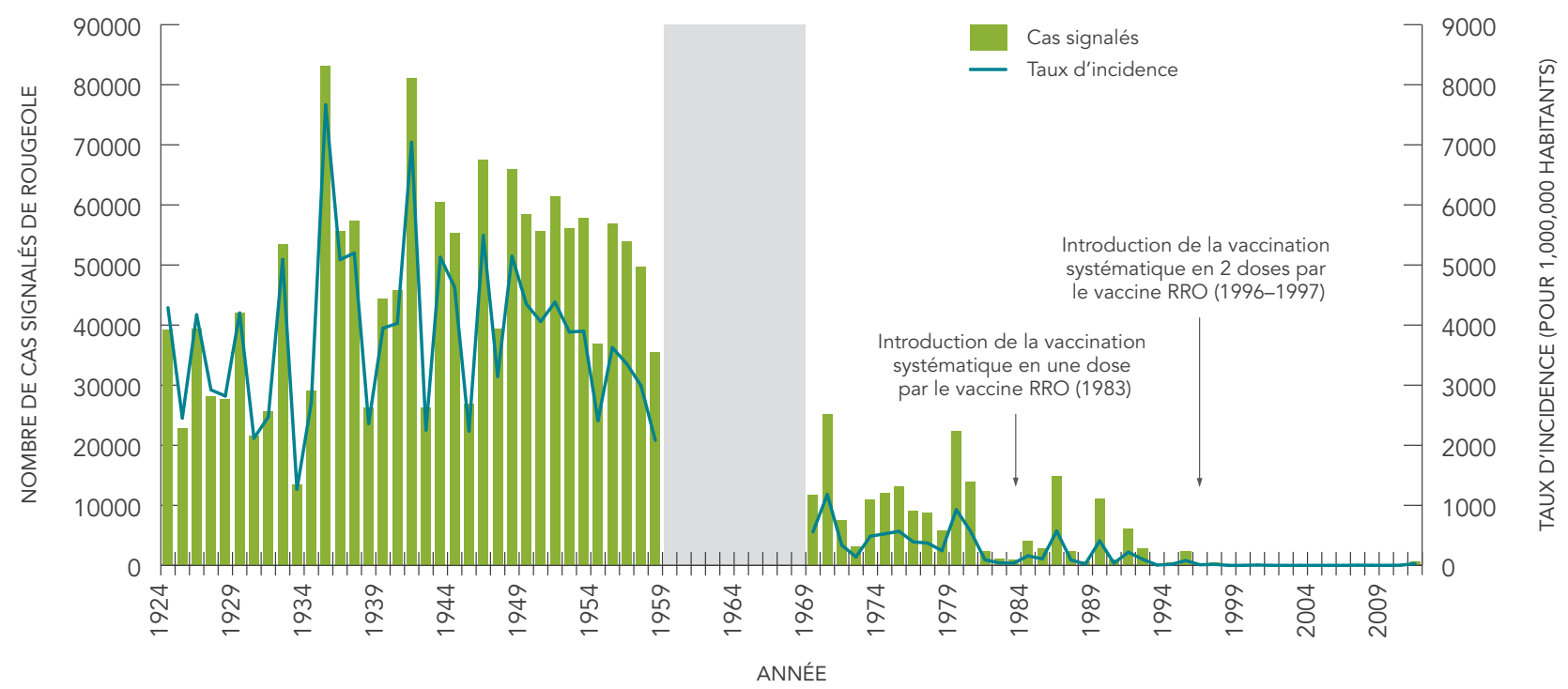


FIGURE 2 : Nombre de cas et taux d'incidence déclarés de rougeole au Canada, de 1998 à 2011

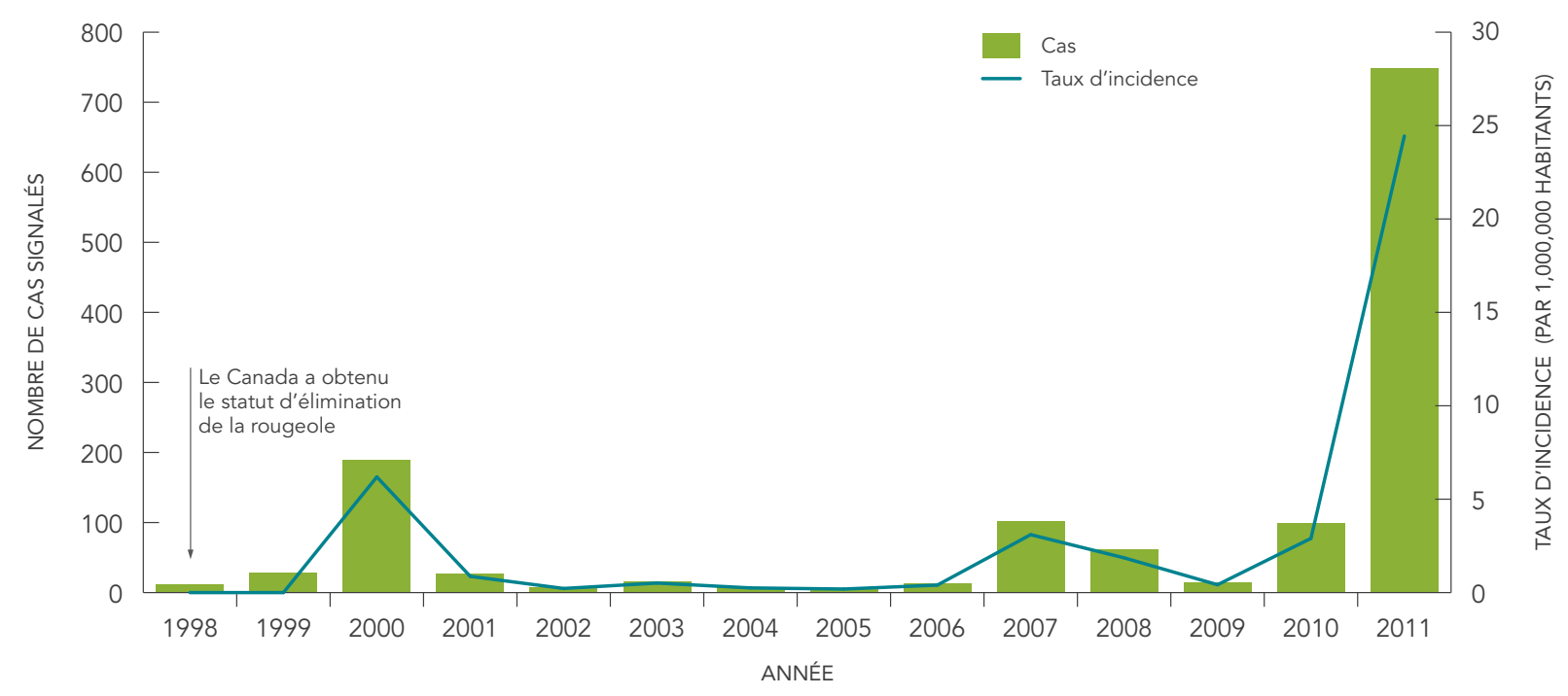

\subsection{POSTÉLIMINATION}

L'interruption de la transmission de la rougeole endémique au Canada a eu lieu en 1998. Les cas déclarés depuis ce temps ont été des cas importés d'autres pays (Figure 2). Entre 1998 et 2005, en moyenne 37 cas (étendue : de 6 à 190; médiane $=14$ ) ont été déclarés chaque année. Le nombre moyen est faussé en raison d'une forte éclosion survenue en Alberta en 2000 où 123 cas ont été déclarés. Entre 2006 et 2010, le nombre moyen de cas de rougeole déclarés a augmenté à 58 cas (étendue : de 13 à 102; médiane $=62$ ). Cette augmentation peut être attribuable aux éclosions qui sont survenues en 2007, 2008 et 2010.
La province de Québec a connu une épidémie de rougeole en 2011, avec un total de 725 cas confirmés signalés pour cette année.

\section{3 ÉCLOSIONS DE ROUGEOLE AU CANADA}

Le Canada a connu plusieurs éclosions de rougeole depuis que le virus a été éliminé. Les éclosions qui comportaient plus de cinq cas qui sont survenues au cours des cinq dernières années sont indiquées dans le Tableau 1. Quatre de ces cas sont brièvement décrits ci-dessous.

TABLEAU 1 : Éclosions de rougeole au Canada, par province, entre 2007 et 2011

\begin{tabular}{l|l|l|l|l}
\hline PROVINCE & ANNÉE & NOMBRE DE CAS & DURÉE (EN SEMAINES) & SOUCHE \\
\hline Québec & 2007 & 94 & 24 & D4 \\
\hline Ontario & 2008 & 53 & 11 & D8 \\
\hline Colombie-Britannique & 2010 & 82 & 7 & D8 ${ }^{2}$ t H1 \\
\hline Québec $^{3}$ & 2011 & 20 & 11 & D4 \\
\hline Québec $^{4}$ & 2011 & 678 & 33 & D4 \\
\hline
\end{tabular}

\footnotetext{
2 Deux souches D8 uniques circulaient pendant cette éclosion.

3 L'éclosion a débuté au mois de février 2011.

${ }^{4}$ L'éclosion a débuté au mois d'avril 2011. Ce nombre inclut un cas associé à une éclosion déclaré au Nouveau-Brunswick.
} 
Le Québec a connu une éclosion de rougeole comportant 94 cas du 19 avril ou 26 septembre 2007. II s'agissait d'une éclosion en milieu scolaire et communautaire au sein d'une population insuffisamment immunisée pour son âge. La souche virale à l'origine de cette éclosion était la souche D4(3).

L'Ontario a signalé une éclosion de la rougeole en milieu communautaire comportant 53 cas entre le 12 mars et le 22 mai 2008. Les cas faisant partie des cohortes de naissance de 1970 à 1979 et celles de 1996 aux années ultérieures ont été les plus gravement atteints. Même si la source de l'éclosion n'a pas été confirmée, les données de l'investigation suggèrent que le cas de référence a contracté l'infection d'un cas importé non diagnostiqué dans une destination touristique populaire de l'Ontario. La souche virale à l'origine de cette éclosion était la souche D8.
Un grand nombre de cas de rougeole ont été signalés en Colombie-Britannique à la suite des Jeux olympiques et des Jeux paralympiques. Un total de 78 cas ont été déclarés entre le 9 mars et le 28 avril 2010. La source de ces cas demeure inconnue, mais deux différentes souches ont été relevées pendant cette période (la H1 et a D8). On soupçonne que la propagation du virus à partir de deux cas de référence non trouvés a été à l'origine de ces éclosions.

En 2011, le Canada a connu le plus grand nombre de cas de rougeole déclarés depuis 1995. Cette éclosion de rougeole a été la plus importante de la Région des Amériques depuis l'élimination du virus en 2002. Sept cent cinquante-deux cas confirmés ont été déclarés au Canada en 2011, dont 678 (93,5\%) étaient des cas associés à une forte éclosion au Québec (Figure 3). Ce nombre représente $56 \%$ de tous les cas de rougeole déclarés au Canada depuis 1998.

FIGURE 3 : Répartition des cas confi més de rougeole, par semaine épidémiologique et par province, au Canada, en 2011

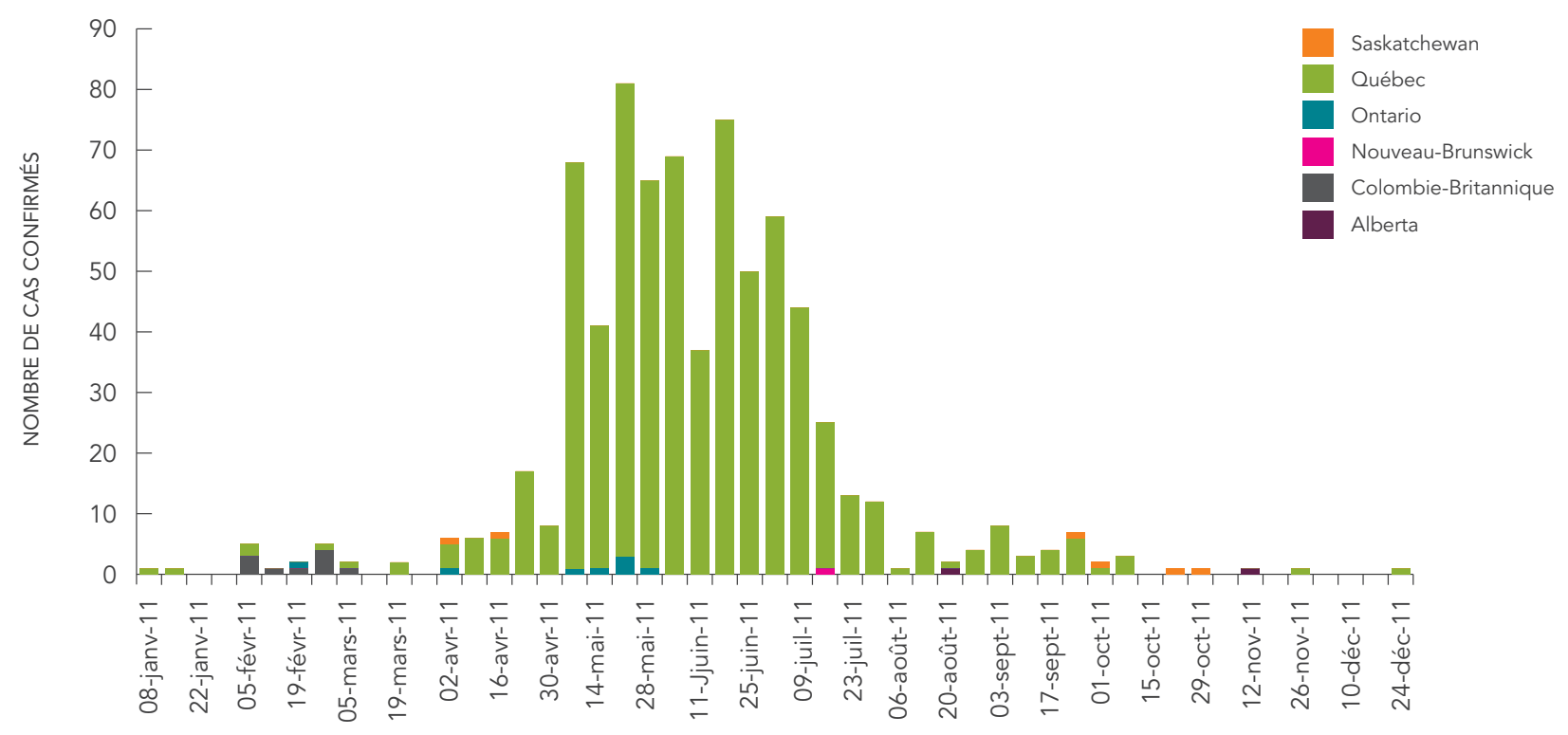

SEMAINE D'APPARITION DE L'ÉRUPTION 
L'éclosion a duré 27 semaines, soit du 7 avril au 10 octobre 2011. Le cas de référence était un intervenant du milieu scolaire qui avait reçu une dose du vaccin contenant le virus de la rougeole et qui aurait été exposé au virus de la rougeole à l'aéroport international de Montréal. L'éclosion est survenue dans une école et s'est ensuite propagée dans la communauté. La transmission accrue dans les écoles est reflétée dans la répartition des cas par âge, dont ceux qui sont âgés entre 10 et 19 ans représentant $66 \%$ de l'ensemble des cas.
La souche virale de l'éclosion qui a eu lieu au Québec en 2011 était caractérisée par le génotype D4 qui était la même souche D4 qui circulait en Europe, en 2011, où plus de 30000 cas ont été déclarés. 


\section{SURVEILLANCE ET DÉCLARATION}

Au Canada, le signalement des maladies à déclaration obligatoire est exigé par les lois et les règlements provinciaux ou territoriaux. La liste des maladies qui doivent être signalées varie légèrement d'une province ou d'un territoire à l'autre. Le signalement provincial ou territorial des maladies à déclaration obligatoire à l'échelle nationale est volontaire. Même si le Système canadien de surveillance des maladies à déclaration obligatoire (SSMDO) comporte la surveillance passive à l'échelle nationale de plus de 50 maladies à déclaration obligatoire, la quantité limitée de données recueillies pour ce système ne suffit pas à assurer la surveillance d'une maladie dans un contexte d'élimination, telle que la rougeole..

À la suite de la mise en œuvre de l'immunisation systématique au moyen de deux doses du vaccin RRO à l'échelle nationale en 1996-1997, une surveillance nationale accrue des cas confirmés de rougeole a été mise en place en 1998 afin de détecter les cas et intervenir rapidement, pour assurer une investigation épidémiologique et en laboratoire minutieuse des cas de rougeole, ainsi que pour consigner les progrès réalisés vers l'atteinte de l'élimination de la rougeole au Canada(4). La surveillance nationale conjointe de la rougeole et de la rubéole au moyen du Système canadien de surveillance de la rougeole et de la rubéole (SCSRR) a commencé par l'ajout successif de la rubéole et du syndrome de rubéole congénitale/infection rubéoleuse congénitale (SRC/IRC) au système de surveillance nationale accrue de la rougeole en 2006 et 2007, respectivement. Le SCSRR surveille constamment
I'élimination de ces maladies à l'échelle nationale par une analyse hebdomadaire des rapports des cas confirmés reçus par les provinces et les territoires, même en l'absence de cas. L'Agence signale ensuite tous les cas confirmés à l'échelle nationale à l'Organisation panaméricaine de la santé (OPS) une fois par semaine. Tous les cas signalés sont examinés afin de s'assurer qu'ils répondent aux critères de la définition d'un cas confirmé avant d'être inclus à la base de données nationale. Les données de surveillance sont utilisées pour répondre aux obligations relatives au signalement systématique des cas à l'échelle nationale et internationale, pour déterminer les lacunes dans la surveillance nationale et pour guider les stratégies nationales d'immunisation.

II est essentiel de respecter les calendriers de signalement pendant toute la durée de l'éclosion. Étant donné que le virus a été éliminé dans la Région des Amériques, une activité accrue est d'un grand intérêt pour l'OPS et d'autres pays des Amériques. II faut tout mettre en œuvre pour s'assurer que le signalement hebdomadaire des cas confirmés se poursuive, tel qu'il est précisé dans le protocole du SCSRR. Si un territoire de compétence touché en fait la demande, I'ASPC peut le soutenir en fournissant des preuves, des conseils et des ressources humaines.

Les cas de rougeole qui sont confirmés selon la définition d'un cas d'éclosion devraient continuer de faire partie du signalement systématique des cas de rougeole à l'échelle provinciale, territoriale et nationale. 


\section{GESTION DE LA SANTÉ PUBLIQUE}

\subsection{PRISE EN CHARGE DES CAS}

\subsubsection{IDENTIFICATION DES CAS}

Tous les cas confirmés, probables ou suspects de rougeole devraient faire l'objet d'une investigation le plus rapidement possible, conformément aux lignes directrices provinciales et territoriales (se reporter à l'Annexe B et à
I'Annexe C), et le formulaire de signalement d'un cas au SCSRR devrait être rempli (se reporter à l'Annexe D). La définition nationale des cas de rougeole a été révisée en 2009 et se trouve à l'adresse www.phac-aspc.gc.ca/ publicat/ccdr-rmtc/09vol35/35s2/index-fra.php(5). Même si les définitions d'un cas confirmé et d'un cas probable sont fournies, seuls les cas confirmés sont signalés à l'Agence de la santé publique du Canada (ASPC).

\section{DÉFINITION}

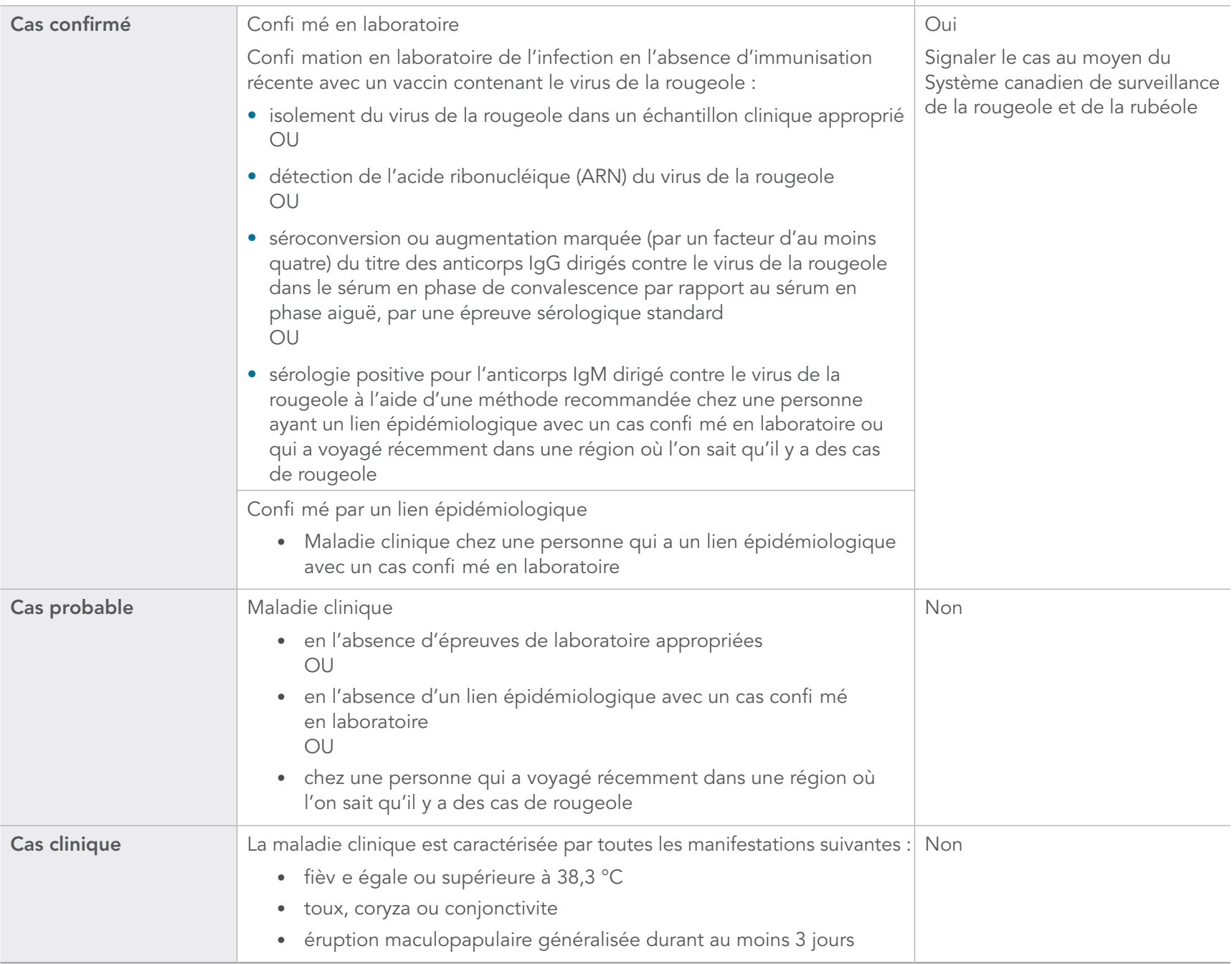

DOIT ÊTRE SIGNALÉ À L'AGENCE DE LA SANTÉ PUBLIQUE DU CANADA

Ou Système canadien de surveillance

\section{DEFINITION} récente avec un vaccin contenant le virus de la rougeole

isolement du virus de la rougeole dans un échantillon clinique approprié

détection de l'acide ribonucléique (ARN) du virus de la rougeole OU quatre) du titre des anticorps lgG dirigés contre le virus de la rougeol dans le sérum en phase de convalescence par rapport au sérum en phase aiguë, par une épreuve sérologique standard rougeole à l'aide d'une méthode recommandée chez une personne ayant un lien épidémiologique avec un cas confi mé en laboratoire ou qui a voyagé récemment dans une région où l'on sait qu'il y a des cas de rougeole

- Maladie clinique chez une personr

Maladie clinique chez une personne qui a un lien épidémiologique avec un cas confi mé en laboratoire

en l'absence d'épreuves de laboratoire appropriées

en l'absence d'un lien épidémiologique avec un cas confi mé en laboratoire

(1)

l'on sait qu'il y a des cas de rougeole

- fièv e égale ou supérieure à $38,3^{\circ} \mathrm{C}$

- éruption maculopapulaire généralisée durant au moins 3 jours 


\subsubsection{INVESTIGATION DES CAS}

Les autorités de santé publique devraient être informées des cas de rougeole le plus rapidement possible (se reporter à I'Annexe B et à I'Annexe C). Actuellement, une petite partie des cas suspects et probables ayant fait l'objet d'une investigation sont des cas confirmés de rougeole. Cependant, I'investigation des cas ne devrait pas être retardée en attendant les résultats d'analyse du laboratoire. Tous les signalements de cas suspect de la rougeole devraient être étudiés sans tarder.

Il est important de recueillir les données sur le cas et les personnes qui auraient été exposées afin de déterminer la période de transmissibilité et de fournir les services d'intervention appropriés. Les étapes essentielles de I'investigation d'un cas sont le diagnostic, l'obtention des antécédents d'immunisation, la localisation des sources d'infection et l'évaluation du risque de transmission.

\subsubsection{COLLECTE DE DONNÉES}

Les données épidémiologiques devraient être recueillies pour permettre aux professionnels de la santé publique d'établir l'épidémiologie descriptive et analytique. Les données suivantes devraient être recueillies durant un épisode ou une éclosion de rougeole :

- données démographiques;

- données cliniques, notamment sur l'apparition de l'éruption cutanée, les complications et les résultats;

- données de laboratoire;

- données sur les antécédents d'immunisation et de voyage;

- données sur les contacts familiaux et les autres contacts;

- données épidémiologiques telles que le contexte de transmission possible, la source de l'exposition et l'emploi.

Les lignes directrices provinciales et territoriales prévoient généralement des formulaires de collecte de données que l'on utilise pour l'investigation des cas. Un formulaire amélioré pour l'investigation des cas de rougeole, semblable au formulaire qui figure à l'Annexe E, peut servir à recueillir les données. D'autres données peuvent également être recueillies, et ce, à la discrétion de l'autorité de santé publique.

\subsubsection{PRISE EN CHARGE DES CAS}

II n'existe pas de traitement spécifique contre la rougeole; néanmoins, de graves complications de la rougeole peuvent être évitées par des soins de soutien qui favorisent une bonne alimentation et un apport hydrique adéquat(6). Les conseils en matière de santé publique à l'égard des cas suspects, probables et confirmés comprennent les suivants : se laver ou se désinfecter souvent les mains, éviter de partager des verres ou des ustensiles et utiliser un mouchoir ou I'avant-bras pour se couvrir la bouche au moment d'éternuer et de tousser. II revient à l'autorité de santé publique de déterminer s'il y a lieu d'émettre des avis publics quant au moment de demander des soins.

\subsubsection{RETRAIT DE LA SOCIÉTÉ DES CAS CONFIRMÉS}

Il faut conseiller aux personnes ayant reçu le diagnostic de la rougeole de rester à la maison (et de se tenir à l'écart des garderies, des écoles, des établissements postsecondaires, des lieux de travail, des milieux de soins et des autres milieux de regroupement, ainsi que des contacts non familiaux) pendant les quatre jours qui suivent l'apparition de l'éruption cutanée. Cette mesure s'applique même si le cas a déjà été vacciné. L'autoisolement aidera à prévenir la transmission du virus.

\subsection{PRISE EN CHARGE DES CONTACTS}

Dans les 24 heures suivant le signalement d'un cas suspect de rougeole, tous les contacts devraient être identifiés et définis comme à risque ou non à risque (se reporter à la section Définitions). L'état d'immunisation des contacts communautaires des cas devrait être vérifié pour en déterminer la réceptivité au virus de la rougeole.

Les autorités de santé publique devraient déterminer l'étendue de la recherche de contacts qui doit être effectuée au moment d'une éclosion, selon le contexte de l'éclosion et les ressources disponibles. Les groupes et les personnes suivantes pourraient être considérés comme des contacts pendant une éclosion :

1. les contacts familiaux; 
2. tous les employés, bénévoles, élèves, conducteurs d'autobus et membres d'équipe ou d'un club sportif d'une garderie ou d'un établissement d'enseignement;

3. les personnes qui, dans un milieu de travail, partagent le même horaire ou le même emplacement de bureau que le cas;

4. les personnes qui, dans un établissement de soins, partagent la même chambre, salle d'attente ou salle d'examen, sans protection adéquate.

\subsubsection{CONTACTS À RISOUE}

La transmission de la rougeole dépend de plusieurs facteurs, notamment des taux de couverture vaccinale de la population(9). Les personnes qui n'ont pas d'antécédents d'immunité naturelle ou qui ne sont pas immunisées contre la rougeole sont considérées présenter un risque accru de contracter la maladie. Les complications de la rougeole touchent, de façon disproportionnelle, les personnes qui souffrent de malnutrition ou d'une immunodéficience, ainsi que les femmes enceintes(10). Les adultes nés avant 1970 présentent un moindre risque de contracter l'infection par le virus de la rougeole en raison de leur immunité naturelle présumée contre la rougeole(11). De plus, les enfants nés d'une mère ayant acquis l'immunité de façon naturelle héritent de son immunité pendant de plus longues périodes que les enfants nés d'une mère ayant acquis l'immunité par l'immunisation(7). Les Canadiens qui voyagent dans des régions où la rougeole est endémique, les travailleurs de la santé, les militaires et les étudiants d'établissements postsecondaires présentent un risque plus élevé d'être exposés à la rougeole.

Un contact à risque élevé est un contact qui présente un risque élevé de souffrir de complications de la rougeole(10). Ces contacts répondent aux critères qui s'appliquent aux personnes à risque, mais sont également répartis entre les groupes suivants:

- les femmes enceintes;

- les nourrissons;

- les personnes immunovulnérables.

Même si aucune preuve n'indique qu'une infection maternelle par le virus de la rougeole pendant le premier trimestre de sa grossesse peut être à l'origine d'un syndrome congénital chez le nourrisson, l'infection par le virus de la rougeole pendant la grossesse peut entraîner des complications(12). Une étude menée de 1988 à 1990 sur 12 femmes hospitalisées pour motif de rougeole pendant leur grossesse a révélé des complications telles que la pneumonite (58 \%), I'hépatite (58 \%) et le travail précoce (33\%)(13). Bien que l'infection par le virus de la rougeole survienne tard dans la grossesse, l'infection congénitale n'est pas écartée.

Les personnes immunovulnérables sont plus à risque à l'infection que les personnes immunocompétentes. Des atteintes du système immunitaire acquis peuvent être présentes, ce qui pourrait se traduire par une capacité réduite d'éliminer le virus et une augmentation de la gravité et de la durée de l'infection(14). Il y a également une probabilité accrue d'acquisition nosocomiale(15).

\subsubsection{ISOLEMENT DES CONTACTS À RISQUE}

À la discrétion du médecin hygiéniste, l'accès aux garderies, aux écoles et aux établissements postsecondaires peut être refusé aux contacts à risque qui refusent ou qui ne peuvent recevoir le vaccin ou les immunoglobulines RRO. On pourrait également demander aux contacts à risque d'éviter les lieux de travail ou d'autres milieux de regroupement et de s'abstenir de voyager. En cas d'isolement, la période d'isolement devrait commencer cinq jours après la première exposition et se terminer le $21^{\text {e }}$ jour suivant la dernière exposition ou jusqu'à ce que les personnes:

- aient été adéquatement vaccinées (documents attestant l'administration d'au moins une dose récente du vaccin contenant le virus de la rougeole); ou

- aient démontré leur immunité à l'aide d'un test sérologique; ou

- aient reçu l'immunoglobuline (lg) (si elles sont admissibles - se reporter à la section 4.2.3).

Il faut tenir compte du nombre de contacts à risque dans le milieu; la présence de personnes à risque élevé, de nourrissons à risque ou de personnes immunovulnérables ainsi que la fiabilité des personnes en période d'incubation de se conformer aux mesures de détection précoce et d'isolement.

En collaboration avec les autorités de santé publique, il est recommandé que les écoles et les établissements d'enseignement se dotent d'un mécanisme permettant l'identification rapide des élèves à risque. 


\subsubsection{VACCINS}

L'immunisation des personnes à risque constitue une stratégie importante de réduction du risque. Une couverture vaccinale élevée est nécessaire pour assurer I'élimination de la rougeole(4). Au Canada, un calendrier d'immunisation qui prévoit l'administration de deux doses du vaccin est recommandé dans l'immunisation systématique des enfants(2). Ce calendrier recommandé vise à obtenir des niveaux élevés d'immunité personnelle en réduisant les probabilités d'échec d'immunisation(7). Un système de surveillance robuste permet d'évaluer l'incidence de l'immunisation dans les populations et de détecter rapidement les éclosions.

Les personnes à risque et immunocompétentes âgées de 12 mois et plus qui ont été exposées à la rougeole peuvent être protégées de la maladie si elles reçoivent une injection du vaccin RRO dans les 72 heures suivant I'exposition. Il peut être recommandé d'administrer le vaccin RRO aux enfants âgés de six mois à douze mois qui ont été exposés à la rougeole, à condition qu'il soit administré dans les 72 heures suivant l'exposition; par contre, deux autres doses d'un vaccin contenant le virus de la rougeole doivent être administrées après le premier anniversaire de ces enfants (et au minimum 28 jours après l'administration de la première dose) pour assurer une immunité à long terme contre la maladie. II n'existe pas de données sur l'utilisation du vaccin RROV chez les enfants ou les adultes réceptifs dans des situations de postexposition ou d'éclosion concernant les virus de la rougeole de type sauvage, des oreillons et de la varicelle; cependant, le vaccin RROV ne serait pas nécessaire dans le cas d'éclosions ou d'expositions à un agent pathogène viral unique, où le vaccin RRO ou un vaccin monovalent contre la varicelle pourrait être utilisé(8).

\subsubsection{IMMUNOGLOBULINES}

L'efficacité de l'usage prophylactique de ces produits a été démontrée pour la modification et la prévention de la maladie. Les personnes à risque qui se présentent trois jours (72 heures) après avoir été exposées à la maladie, c'est-à-dire lorsque le vaccin RRO ne procure plus de protection après l'exposition, mais moins de six jours après l'exposition (lorsque les immunoglobulines peuvent encore offrir une protection après l'exposition) peuvent recevoir des immunoglobulines(8). L'administration des Ig à des personnes réceptives qui ont été exposées à la rougeole est une solution envisageable (voir la section 4.2.1), particulièrement s'il s'agit de personnes immunovulnérables ou de femmes enceintes pour qui le vaccin contenant la rougeole est contre-indiqué ou d'enfants de moins de 6 mois. Les enfants de moins de six mois sont normalement considérés comme étant immunisés grâce à des anticorps transférés à partir de la mère. Si, toutefois, la mère contracte le virus de la rougeole, ou si on sait qu'elle n'est pas immunisée contre celui-ci, il faut administrer des immunoglobulines humaines à l'enfant.

Le titre d'anticorps antirougeoleux diminue plus rapidement chez les enfants infectés par le VIH que chez les enfants non infectés. Il est donc recommandé, après une exposition documentée à un cas confirmé de rougeole, d'administrer une dose d'immunoglobuline en prophylaxie aux enfants porteurs du VIH, même à ceux qui ont déjà reçu le vaccin RRO.

GamaSTAN® S/D (Immunoglobulines humaines) Grifols Therapeutics inc. (fabricant), Grifols Therapeutics Ltée (distributeur), (lg) est une solution stérile concentrée qui contient de $15 \%$ à $18 \%$ d'immunoglobulines.

La dose recommandée de GamaSTAN@ S/D pour les personnes en santé qui ont été exposées à la rougeole est de $0,25 \mathrm{ml} / \mathrm{kg}$ de poids corporel. La dose pour les sujets souffrant d'une affection maligne sous-jacente ou d'un déficit immunitaire est de $0,5 \mathrm{~mL} / \mathrm{kg}$. La dose maximale ne devrait pas être plus de $15 \mathrm{~mL}$. Ce produit devrait être administré uniquement par voie intramusculaire. Pour obtenir les renseignements thérapeutiques complets, consultez le feuillet du produit ou l'information contenue dans la monographie de produits autorisée, accessibles par la Base de données des produits pharmaceutiques de Santé Canada à I'adresse http://webprod5.hc-sc.gc.ca/dpd-bdpp/ language-langage.do?lang=fra\&url=t.search.recherche

\subsection{RASSEMBLEMENTS}

Les rassemblements englobent les événements de toute envergure, dans des lieux privés et publics. Les réceptions ou les cérémonies religieuses, les activités sportives, les excursions organisées de magasinage, les concerts, les conférences, les réunions de même que les transports publics sont des exemples de rassemblements. Pendant une éclosion, il n'est pas nécessaire d'annuler les 
événements, bien que certains territoires de compétence puissent envisager de reporter des rassemblements qui peuvent comporter un risque de transmission ou exposer des populations vulnérables (p. ex. les consultations pédiatriques).

Par prudence, les organisateurs devraient saisir ces occasions pour informer les participants du risque de contagion de la maladie et des méthodes pour en réduire la propagation, entre autres se faire vacciner, se laver les mains fréquemment, éviter de partager des verres ou des ustensiles, se couvrir la bouche avec un mouchoir ou l'avant-bras lorsqu'on tousse et éternue et rester à la maison si on est malade. Si une éclosion survient pendant un rassemblement, les autorités de santé publique devraient communiquer l'information sur les lieux où l'on risque d'être exposé.

\subsection{VOYAGEURS}

Lorsqu'un cas de rougeole fait l'objet d'une investigation, il faut examiner les voyages effectués dans le passé à l'intérieur et à l'extérieur du Canada qui pourraient constituer un facteur de risque potentiel. Les autorités de santé publique à l'échelle provinciale ou territoriale qui déterminent qu'un voyageur est contagieux devraient aviser les autorités de santé publique de la province ou du territoire de résidence du cas et de ses contacts connus, de sorte qu'un suivi puisse être effectué en conséquence. La province ou le territoire déclarant devrait également signaler le cas au Centre de l'immunisation et des maladies respiratoires infectieuses (CIMRI) de I'ASPC.

Lorsque des cas ou des contacts proviennent d'un autre pays, les autorités de santé publique provinciale ou territoriale qui les ont identifiés devraient aviser le Centre de l'immunisation et des maladies respiratoires infectieuses (CIMRI), de l'Agence de la santé publique du Canada (l'Agence), qui communiquera avec les autorités compétentes dans le pays concerné par l'intermédiaire du point de contact du Règlement sanitaire international du Canada. Si des voyageurs internationaux liés à des cas de rougeole ou à des contacts sont identifiés par l'agent de quarantaine d'un point d'entrée international, le Bureau des services de la quarantaine de l'Agence avisera les autorités de la santé publique provinciale ou territoriale ou internationale compétentes.
Lorsque plusieurs provinces ou pays sont concernés, I'instance qui devrait signaler un cas n'est pas toujours clairement indiquée. La déclaration des cas est importante parce qu'elle permet de décrire et de surveiller l'épidémiologie, l'impact et la propagation d'une éclosion.

Par conséquent, durant les éclosions, la première province ou territoire à identifier le cas devrait se charger de signaler le cas. Cette règle est souple et devrait être évaluée au cas par cas, en tenant compte du lieu de résidence, de l'itinéraire de voyage et de la réponse ou de l'intervention en santé publique qui a été mise en œuvre.

\subsubsection{TRANSPORT AÉRIEN}

Si l'on soupçonne en plein vol qu'une maladie contagieuse telle que la rougeole est présente à bord de l'avion, les membres de l'équipage doivent suivre les procédures de signalement à l'autorité aéroportuaire, laquelle avisera à son tour l'agent de quarantaine qui sera présent à l'arrivée de l'avion. Si la rougeole est soupçonnée, l'agent de quarantaine recueillera les coordonnées des voyageurs qui étaient assis dans un rayon de deux rangées de sièges autour du cas suspect. Si la rougeole est confirmée, l'agent de quarantaine veillera à en aviser les autorités de santé publique au point d'entrée et du territoire de compétence où réside le cas et à leur fournir les coordonnées des voyageurs qui ont potentiellement été exposés.

Les autorités de santé publique doivent être consultées si un cas de rougeole a voyagé par avion pendant la période infectieuse (de quatre jours avant l'apparition des symptômes à quatre jours suivant l'apparition de l'éruption cutanée). La liste des passagers peut servir à la recherche des contacts pour informer d'autres voyageurs qu'ils ont potentiellement été exposés, quoiqu'il n'y ait pas suffisamment de données pour recommander ce type de recherche de contact pour tous les cas au Canada. Une grande majorité de Canadiens sont considérés comme immunisés contre la rougeole, soit après avoir développé une immunité naturelle ou après avoir été vaccinés. Bien qu'il y ait eu plusieurs cas de rougeole qui étaient contagieux pendant des vols au Canada, aucun cas de transmission de la rougeole n'a été documenté au cours de ces vols. 
Une approche fondée sur le risque qui tient compte des symptômes respiratoires chez le cas et de la durée du vol devrait être utilisée pour déterminer si le risque posé par le voyageur est suffisamment élevé pour justifier une recherche des contacts.

Le Bureau des services de la quarantaine de l'Agence peut aider les autorités de santé publique à obtenir la liste des passagers, mais faut-il savoir que ces listes ne sont pas conservées indéfiniment et ne contiennent pas les coordonnées de tous les voyageurs. Si la recherche des contacts n'est pas possible, l'émission d'un avis public visant à informer la population de l'exposition potentielle peut être envisagée.

Les autorités de santé publique chargées de la supervision devraient envisager de communiquer l'itinéraire du voyageur aux autres territoires de compétence afin qu'ils soient informés de l'exposition potentielle, car leurs protocoles pourraient être différents ou parce qu'ils pourraient constater des changements dans l'activité de la rougeole au sein de leur population. Les données non nominatives sur le voyage devraient être communiquées aux professionnels de la santé publique de tout le pays à l'aide du système Alertes de santé publique du Réseau canadien de renseignements sur la santé publique (RCRSP) (www.cnphi-rcrsp.ca), une application web sécuritaire. Au Canada, les transporteurs aériens peuvent refuser l'accès à bord des personnes qui semblent atteintes d'une maladie infectieuse.

\subsubsection{VOYAGE EN MER SUR NAVIRE DE CROISIÈRE}

Advenant une éclosion de rougeole sur un navire de croisière, les services de santé du navire de croisière sont responsables de la santé des voyageurs durant la croisière et devraient effectuer un suivi des contacts conformément à la politique du transporteur.
Au moins vingt-quatre heures avant leur arrivée au port, les navires doivent signaler aux autorités portuaires canadiennes la présence de toute personne qui pourrait être atteinte d'une maladie contagieuse à bord et les informer de son état de santé. L'autorité portuaire avisera à son tour l'agent de quarantaine qui sera présent à l'arrivée du navire. Si la rougeole est confirmée, l'agent de quarantaine veillera à en aviser les autorités de santé publique au point d'entrée et du territoire de compétence où réside le cas.

Si un cas qui était contagieux alors qu'il était à bord d'un navire de croisière est détecté à la suite du voyage, le transporteur pourrait aider à informer les autres passagers et les membres de l'équipage qui ont potentiellement été exposés. L'émission d'un avis public peut également être envisagée.

Au Canada, les croisiéristes peuvent refuser l'accès à bord des personnes qui semblent atteintes d'une maladie infectieuse.

\subsubsection{AUTRES MODES DE TRANSPORT}

La recherche des contacts qui auraient été exposés à la rougeole dans d'autres moyens de transport comme les autobus, les trains ou les traversiers peut être souhaitable; toutefois, il existe rarement des listes de passagers pour ces types de moyen de transport. Dans de tels cas, une approche fondée sur le risque qui tient compte des symptômes respiratoires chez le cas et de la durée du voyage peut servir à déterminer si un avis public pour avertir les autres voyageurs qu'ils ont potentiellement été exposés est nécessaire. 


\section{MILIEUX DE SOINS}

Les éclosions de rougeole dans les milieux communautaires ont une grande incidence sur la capacité à fournir des soins de santé en raison de la nature extrêmement contagieuse de la rougeole et du potentiel de transmission de la maladie dans les milieux de soins. Le virus de la rougeole fait partie des agents microbiens les plus facilement transmissibles d'une personne à une autre $(2,16)$. Le virus peut survivre au moins deux heures sous forme de fines particules de gouttelettes évaporées qui sont disséminées dans l'air en milieux clos(17), y compris les milieux de soins(18-28). La transmission dans les milieux de soins peut survenir même lorsque les cas de référence ont quitté les lieux(20,21), étant donné que le virus survit dans I'air ou sur les surfaces de l'environnement. Durant les éclosions communautaires, les travailleurs de la santé peuvent non seulement être exposés à la rougeole au sein de la collectivité, mais aussi dans les milieux de soins.

Pour prévenir la transmission de la rougeole dans les milieux de soins, I'accent doit être mis sur l'évaluation de l'immunité des employés contre la rougeole avant l'emploi et l'administration de deux doses du vaccin contre la rougeole, la rubéole et les oreillons (RRO) aux travailleurs de la santé qui ne sont pas suffisamment immunisés avant qu'une éclosion ne survienne(2,16,29). L'immunité à la rougeole doit être une condition d'emploi de tout nouveau travailleur de la santé $(1,10,29)$. Ces deux stratégies permettront de minimiser les perturbations à fournir des soins pendant les éclosions de rougeole en milieu communautaire.

Le Comité consultatif national de l'immunisation (CCNI) répond aux questions relatives à l'immunisation des travailleurs de la santé dans la version la plus récente du Guide canadien d'immunisation(8). Les travailleurs de la santé qui n'ont pas les documents attestant qu'ils ont reçu deux doses du vaccin contenant le virus de la rougeole le jour de leur premier anniversaire ou après celui-ci, ou qui ne possèdent pas une preuve d'immunité fournie par un laboratoire ou n'ont pas d'antécédents de rougeole confirmés en laboratoire, devraient recevoir, quelle que soit leur année de naissance, deux doses du vaccin RRO, à moins d'une contre-indication à l'immunisation contre la rougeole (c.-à-d. une réaction anaphylactique dans le passé à la suite de l'administration du produit, une hypersensibilité immédiate ou anaphylactique établie à I'un ou l'autre des composants du produit [à l'exception des personnes allergiques aux œufs] ou de son contenant, une grossesse ou une immunodéficience préexistante). Les travailleurs de la santé qui n'ont reçu qu'une dose du vaccin et dont l'immunité à la rougeole n'est pas démontrée devraient recevoir une dose supplémentaire. Un résultat positif au test d'lgG indique l'immunité.

En plus des recommandations pour la prise en charge des cas de rougeole dans les milieux de soins (se reporter à l'Annexe F), des algorithmes d'évaluation de la réceptivité des travailleurs de la santé au virus de la rougeole (algorithme A), de prise en charge des travailleurs de la santé en contact direct avec un cas de rougeole (algorithme B) et de prise en charge des patients en contact direct avec un cas de rougeole (algorithme C) sont présentés à l'Annexe G.

\subsection{MESURES DE PRÉVENTION ET DE CONTRÔLE DE L'INFECTION DANS LES CAS SUSPECTS OU CONFIRMÉS DE ROUGEOLE}

Les milieux de soins devraient être avisés lorsque des cas de rougeole sont présents dans la collectivité et informés des cas reconnus sur le plan clinique et diagnostiqués en laboratoire. Les services d'urgence et les milieux de soins ambulatoires devraient être avisés de procéder au triage des cas suspects le plus rapidement possible et de les transférer dans une chambre d'isolement (CITTA) pour infections à transmission aérienne pour éviter l'exposition d'autres personnes qui se trouvent dans les salles d'attente. Les cliniques de consultation externe et les organismes de soins à domicile devraient être dotés d'un système d'identification des cas suspects ou confirmés de rougeole. Les rendez-vous pris pour des cas suspects ou confirmés de rougeole devraient être reportés, à moins qu'ils soient nécessaires sur le plan médical, jusqu'à ce qu'une CIITA puisse accueillir les cas et que les précautions à prendre avant leur isolement dans la 
chambre soient en place. Les patients de soins à domicile qui sont des cas suspects ou confirmés de rougeole ne devraient être soignés que par des travailleurs de la santé immunisés contre la rougeole.

Les cas suspects ou confirmés de rougeole qui sont hospitalisés devraient être traités dans une CIITA dès l'apparition des symptômes (fièvre, éruption maculopapulaire, toux, coryza et conjonctivite) pendant les quatre jours suivant l'apparition de l'éruption maculopapulaire $(1,10,16,29)$. Si aucune CIITA n'est disponible (comme dans les milieux de soins de longue durée), le patient devrait être placé dans une chambre individuelle, loin des patients à risque, jusqu'à son transfert dans un milieu doté d'une CIITA(1).

Les patients immunovulnérables peuvent excréter le virus pendant de longues périodes et être contagieux tant qu'ils sont malades. II est fort probable que des précautions supplémentaires doivent être prises plus longtemps pour ces patients(16). Le rôle des études virologiques pour déterminer le moment où les patients immunovulnérables peuvent cesser de faire l'objet de précautions n'a pas été défini. L'approche conservatrice consiste à maintenir en place les précautions à l'égard des patients jusqu'à ce que leurs symptômes aient disparu.

Les travailleurs de la santé à risque ne devraient pas entrer dans la chambre d'un cas suspect ou confirmé de rougeole ni dans la chambre d'un patient en phase contagieuse. Lorsqu'un travailleur de la santé ne peut éviter d'entrer dans la chambre, il devrait porter un appareil de protection respiratoire. Les travailleurs de la santé immunisés n'ont pas besoin de prendre de précautions supplémentaires (c.-à-d. port d'un appareil de protection respiratoire) pour entrer dans la CIITA d'un cas suspect ou confirmé de rougeole(1,29).

Les spécifications techniques pour le fonctionnement et la surveillance appropriés des chambres d'isolement pour infections à transmission aérienne devraient être établies et suivies(30,31).

\subsubsection{PRISE EN CHARGE DES TRAVAILLEURS DE LA SANTÉ EXPOSÉS À DES CAS}

La prise en charge des travailleurs de la santé qui ont exposés devrait être effectuée en consultation avec les autorités responsables de la santé au travail et de la santé publique de la région.

Les travailleurs de la santé qui ont été exposés à un cas confirmé de rougeole devraient faire réévaluer leur immunité(29). Si les travailleurs de la santé qui ont reçu deux doses du vaccin contenant le virus de la rougeole ou les documents attestant la présence d'anticorps antirougeoleux, ils peuvent être considérés comme immunisés $(8,29)$ et peuvent retourner au travail. Si les travailleurs de la santé ont une preuve de n'avoir reçu qu'une dose du vaccin contenant le virus de la rougeole, sans preuve d'immunité fournie par un laboratoire ou d'antécédents de rougeole confirmés en laboratoire, il est recommandé de leur faire subir un test de détection $d^{\prime}$ anticorps IgG et de leur administrer une dose du vaccin RRO immédiatement. En attendant les résultats du test sérologique, le travail devrait être interdit aux travailleurs de la santé à compter du cinquième jour, et ce, jusqu'au 21e jour suivant la dernière exposition $(1,10,16)$. Si les résultats des tests d'anticorps lgG antirougeoleux sont positifs, ils peuvent être considérés comme immunisés et peuvent retourner au travail. Si les résultats des tests d'anticorps lgG antirougeoleux sont négatifs, ils devraient être considérés comme étant à risque. Les travailleurs de la santé à risque devraient recevoir une deuxième dose du vaccin RRO 28 jours après la première dose, et l'interdiction au travail devrait se maintenir à compter du cinquième jour, et ce, jusqu'au 21e jour suivant la dernière exposition, même s'ils ont reçu le vaccin ou les immunoglobulines après leur exposition $(1,10,16)$. 


\subsubsection{PRISE EN CHARGE DES PATIENTS EXPOSÉS À DES CAS}

La prise en charge des patients qui ont été exposés au virus de la rougeole devrait être effectuée par les professionnels en prévention des infections ( $\mathrm{PCl})$ de l'organisme de soins de santé ou le délégué, en consultation avec les autorités responsables de la santé publique de la région.

Les patients qui ont été exposés à un cas confirmé de rougeole devraient faire réévaluer leur immunité(1,8). Les patients de 18 ans et plus ayant reçu une dose, les enfants de 12 mois à 17 ans ayant reçu deux doses et les personnes nées avant 1970 ou ayant une preuve d'avoir reçu deux doses du vaccin contenant le virus de la rougeole ou un document attestant la présence d'anticorps antirougeoleux peuvent être considérés comme immunisés $(1,8)$. Si les patients ont une preuve d'avoir reçu une dose du vaccin contenant le virus de la rougeole ou s'ils n'ont pas de preuve d'immunité fournie par un laboratoire ou d'antécédents de rougeole confirmés en laboratoire, il est recommandé de leur faire subir un test de détection d'anticorps lgG et de leur administrer une dose du vaccin RRO immédiatement. En attendant les résultats du test sérologique, les patients devraient être isolés dans une CIITA à compter du cinquième jour, et ce, jusqu'au $21^{e}$ jour suivant la dernière exposition(1). Si les résultats des tests d'anticorps IgG antirougeoleux sont positifs, ils peuvent être considérés comme immunisés et placés dans une chambre ordinaire. Si les résultats des tests d'anticorps IgG antirougeoleux sont négatifs, ils devraient être considérés comme à risque. Les patients à risque devraient recevoir une deuxième dose du vaccin RRO 28 jours après la première dose, et l'interdiction au travail devrait se maintenir à compter du cinquième jour, et ce, jusqu'au $21^{\text {e }}$ jour suivant la dernière exposition, même s'ils ont reçu le vaccin ou les immunoglobulines après leur exposition(1). 


\section{LIGNES DIRECTRICES POUR LE DIAGNOSTIC DE LA ROUGEOLE EN LABORATOIRE}

\subsection{LIGNES DIRECTRICES RELATIVES AUX ÉPREUVES DE LABORATOIRE}

Le diagnostic de la rougeole exige une évaluation minutieuse des données cliniques, épidémiologiques et laboratoires et peut parfois s'avérer difficile. Comme la transmission endémique a été interrompue dans la Région des Amériques, l'incidence de la rougeole est faible, et les cas sporadiques qui surviennent à la suite d'un voyage devraient être soigneusement examinés.

L'incidence très faible de la rougeole dans les contextes d'élimination se traduit par une réduction de la valeur prédictive positive des tests sérologiques, ce qui complique l'interprétation des résultats des tests sérologiques d'lgM positifs des cas suspects auxquels un lien épidémiologique à un cas confirmé est absent(32). Au sein d'une population affichant un taux élevé d'immunisation, des cas peuvent survenir chez des personnes qui ont déjà été vaccinées et pour lesquelles la sérologie peut donner des résultats contradictoires.

La détection par test moléculaire du virus est par conséquent la méthode privilégiée pour confirmer le diagnostic des cas suspects. Le prélèvement des échantillons appropriés en temps opportun de chaque cas suspect de rougeole est essentiel. Un diagnostic exact est très important non seulement pour soigner adéquatement le patient et les contacts, mais aussi pour surveiller les efforts déployés dans l'éradication de la rougeole dans la Région des Amériques.
La présente section a été rédigée à partir des expériences récentes dans les diagnostics de la rougeole à l'échelle mondiale et suit les principes directeurs du réseau de laboratoires pour la surveillance de la rougeole et de la rubéole de l'OMS(33) (disponibles à l'adresse www.who.int/immunization_monitoring/laboratory_ measles_resources/en/index.html).

Une description complète des diagnostics de la rougeole est fournie dans le Manual of Clinical Microbiology(34,35), et les précisions techniques sur les tests sont fournies dans le Tableau 2. Les lignes directrices détaillées qui s'appliquent aux tests en laboratoires pour le diagnostic de la rougeole figurent à l'Annexe $\mathrm{H}$. 
TABLEAU 2 : Sommaire des diagnostics de la rougeole en laboratoire

\begin{tabular}{|c|c|}
\hline $\begin{array}{l}\text { ÉLÉMENT DE DIAGNOSTIC } \\
\text { LABORATOIRE }\end{array}$ & DESCRIPTION \\
\hline \multirow[t]{6}{*}{ Prélèvement } & $\begin{array}{l}\text { Lorsque les médecins soupçonnent la présence de la rougeole, ils devraient immédiatement } \\
\text { faire un prélèvement pour un test sérologique et pour la détection du virus afin d'obtenir la confirmation } \\
\text { d'un laboratoire. }\end{array}$ \\
\hline & $\begin{array}{l}\text { Pour la détection du virus, les sécrétions nasopharyngiennes (préférablement) ou un échantillon de } \\
\text { la gorge (ou par lavage de la gorge) devraient être prélevés le plus tôt possible sans dépasser quatre jours } \\
\text { suivant l'apparition de l'éruption cutanée. Le virus de la rougeole peut encore être détecté sept jours } \\
\text { après l'apparition de l'éruption, mais perd rapidement de sa sensibilité. Les échantillons devraient être } \\
\text { prélevés au moyen d'un écouvillon approuvé pour l'isolement du virus et placé dans un milieu de } \\
\text { transport viral. }\end{array}$ \\
\hline & $\begin{array}{l}\text { Bien que les échantillons de sécrétions nasopharyngiennes soient préférables, le virus de la rougeole peut } \\
\text { également être détecté dans l'urine, laquelle doit être prélevée dans les sept jours suivant l'apparition de } \\
\text { l'éruption cutanée afin d'obtenir une sensibilité maximale }\end{array}$ \\
\hline & $\begin{array}{l}\text { Pour un test sérologique, un échantillon de sérum devrait être prélevé le plus rapidement possible, lorsque } \\
\text { le patient est vu pour la première fois. }\end{array}$ \\
\hline & $\begin{array}{l}\text { Pour le test sérologique d'IgM, un échantillon prélevé entre trois jours avant l'apparition de l'éruption } \\
\text { cutanée et } 28 \text { jours suivant l'apparition de l'éruption cutanée peut entraîner de faux résultats négatifs. }\end{array}$ \\
\hline & $\begin{array}{l}\text { Pour un test sérologique d'lgG, le premier échantillon (en phase aiguë) devrait être prélevé au plus tard } \\
\text { le septième jour suivant l'apparition de l'éruption cutanée, puis un deuxième échantillon (en phase de } \\
\text { convalescence), entre le } 10^{\mathrm{e}} \text { et le } 30^{\mathrm{e}} \text { jour suivant le premier. }\end{array}$ \\
\hline \multirow[t]{10}{*}{ Sérologie } & $\begin{array}{l}\text { La présence d'anticorps de classe lgM propres à la rougeole indique une infection aiguë par le virus de la } \\
\text { rougeole lorsqu'une éruption est observée et que le cas a été exposé à la rougeole lors d'un voyage dans } \\
\text { une région endémique ou lorsqu'un lien épidémiologique à un cas confi mé est établi. }\end{array}$ \\
\hline & $\begin{array}{l}\text { Les résultats positifs au test de détection d'anticorps lgM qui ne sont pas associés à une infection aiguë au } \\
\text { virus de la rougeole pourraient être attribuables aux facteurs suivants: }\end{array}$ \\
\hline & $\begin{array}{l}\text { - un résultat positif au test de détection d'anticorps IgM dans un cas d'éruption sporadique qui n'a pas } \\
\text { été exposé est potentiellement un faux résultat positif et devrait être soigneusement examiné. }\end{array}$ \\
\hline & $\begin{array}{l}\text { - Le titre d'anticorps IgM antirougeoleux est souvent élevé chez les patients qui ont reçu le vaccin RRO } \\
\text { dans les six semaines précédant l'apparition de l'éruption cutanée. }\end{array}$ \\
\hline & $\begin{array}{l}\text { L'obtention des résultats de détection d'anticorps lgM négatifs chez un vrai cas de rougeole peut } \\
\text { également se produire dans les situations suivantes: }\end{array}$ \\
\hline & $\begin{array}{l}\text { - l'échantillon est prélevé du patient avant le troisième jour précédent l'apparition de l'éruption } \\
\text { ou après le } 28^{e} \text { jour suivant l'apparition de l'éruption. }\end{array}$ \\
\hline & $\begin{array}{l}\text { - Les cas de rougeole chez les patients qui ont déjà été vaccinés peuvent ne pas être accompagnés d'une } \\
\text { élaboration d'anticorps lgM étant donné que les infections s'étant manifestées ne sont pas } \\
\text { principalement causées par une exposition à la rougeole. }\end{array}$ \\
\hline & $\begin{array}{l}\text { La séroconversion (c.-à-d. le passage de résultats négatifs à des résultats positifs) ou une augmentation du } \\
\text { titre d'anticorps IgG qui a quadruplé ou davantage entre le sérum prélevé en phase aiguë et le sérum } \\
\text { prélevé en phase de convalescence indique la présence d'une infection aiguë par le virus de la rougeole. } \\
\text { Les personnes qui ont déjà été immunisées (échec de l'immunisation secondaire) peuvent représenter une } \\
\text { exception, car une augmentation rapide du titre d'IgG antirougeoleux prévue entraînerait des résultats } \\
\text { fortement positifs au test de détection d'lgG antirougeoleux dans le sérum prélevé en phase aiguë et } \\
\text { l'absence probable d'un titre d'anticorps lgG antirougeoleux quatre fois plus élevé dans le sérum prélevé } \\
\text { en phase de convalescence }(36,37) \text {. }\end{array}$ \\
\hline & $\begin{array}{l}\text { La présence d'anticorps IgG propres à la rougeole, déterminée par une épreuve immunoenzymatique (EIA), } \\
\text { indique une immunisation contre la maladie, mais n'a pas nécessairement de lien direct avec la présence } \\
\text { d'anticorps protecteurs et neutralisants quantifiés par l'étalon de éférence, le test de séro-neutralisation par } \\
\text { réduction des plages (TSNRP)(38). L'absence d'IgG antirougeoleux détectables au moyen de l'EIA peut } \\
\text { refléter la plus faible sensibilité de l'EIA comparativement à une ép euve plus sensible, particulièrement } \\
\text { chez les jeunes enfants. }\end{array}$ \\
\hline & $\begin{array}{l}\text { Le titre d'anticorps IgG antirougeoleux protecteur estimé se situerait entre 120(39) et } 200 \text { mUI(40), } \\
\text { mais il n'est pas connu avec précision. }\end{array}$ \\
\hline
\end{tabular}




\begin{tabular}{|c|c|}
\hline $\begin{array}{l}\text { ÉLÉMENT DE DIAGNOSTIC } \\
\text { LABORATOIRE }\end{array}$ & DESCRIPTION \\
\hline \multirow{2}{*}{$\begin{array}{l}\text { Diagnostic de } \\
\text { panencéphalite } \\
\text { sclérosante subaiguë }\end{array}$} & $\begin{array}{l}\text { La panencéphalite sclérosante subaiguë (PSS) est une complication rare d'une infection par le virus de la } \\
\text { rougeole persistante du système nerveux central. }\end{array}$ \\
\hline & $\begin{array}{l}\text { En présence des symptômes cliniques, neurologiques et pathologiques caractéristiques, le diagnostic peut } \\
\text { être confi mé par la détection d'une augmentation du titre d'anticorps lgG antirougeoleux dans le liquide } \\
\text { céphalorachidien (LCR) par rapport au titre d'anticorps dans le sérum. }\end{array}$ \\
\hline \multirow[t]{5}{*}{$\begin{array}{l}\text { Détection du virus } \\
\text { de la rougeole }\end{array}$} & $\begin{array}{l}\text { La technique de transcription inverse suivie d'une réaction en chaîne de la polymérase (RT-PCR) est le test } \\
\text { le plus fiable pour confirmer un diagnostic d'une infection par le virus de la rougeole, mais sa sensibilité } \\
\text { peut être influencée par les facteurs suivants }\end{array}$ \\
\hline & - moment du prélèvement de l'échantillon; \\
\hline & - intégrité de l'échantillon (traitement rapide de l'échantillon) et conditions d'entreposage; \\
\hline & - antécédents d'immunisation. \\
\hline & $\begin{array}{l}\text { L'isolement du virus de la rougeole en culture est également un test très spécifique (lorsque les ésultats } \\
\text { sont confi més par une immunofluo escence ou par une RT-PCR), mais cette épreuve est moins sensible } \\
\text { que la RT-PCR et dépend grandement sur le moment du prélèvement et l'intégrité de l'échantillon. }\end{array}$ \\
\hline \multirow[t]{3}{*}{ Génotypage } & $\begin{array}{l}\text { Le génotypage du virus de la rougeole est nécessaire pour distinguer une éruption cutanée } \\
\text { postimmunisation d'une infection par un virus sauvage. }\end{array}$ \\
\hline & $\begin{array}{l}\text { Le génotypage du virus est utile pour lier des cas, lier des éclosions et localiser les importations. L'OPS } \\
\text { exige les données des génotypes pour surveiller les efforts déployés dans l'éradication de la rougeole. II } \\
\text { est recommandé d'obtenir le génotype du plus grand nombre de cas de rougeole possible, idéalement de } \\
\text { tous les cas sporadiques et représentatifs de toutes les éclosions. Le Laboratoire national de microbiologie } \\
\text { (LMN) fait le génotypage des cas de rougeole au Canada et accepte tous les échantillons appropriés. }\end{array}$ \\
\hline & Le génotypage nécessite le même type d'échantillon qui est utilisé dans la RT-PCR. \\
\hline \multirow[t]{5}{*}{$\begin{array}{l}\text { Interprétation des résultats } \\
\text { des analyses de laboratoire }\end{array}$} & $\begin{array}{l}\text { Pour correctement interpréter les résultats des analyses de laboratoire et pour évaluer la justesse des } \\
\text { méthodes de diagnostic de la rougeole, les données cliniques et épidémiologiques doivent être examinées } \\
\text { en parallèle avec les données du laboratoire (p. ex. les antécédents d'immunisation, les antécédents de } \\
\text { voyage et le moment du prélèvement de l'échantillon par rapport à l'apparition des symptômes). Par } \\
\text { conséquent, la communication des données entre la santé publique et le laboratoire est essentielle. }\end{array}$ \\
\hline & $\begin{array}{l}\text { Un résultat positif à la RT-PCR ou un résultat positif au test de détection d'lgM chez un patient qui } \\
\text { présente une éruption cutanée et qui a voyagé dans une région où la rougeole est endémique ou qui } \\
\text { a un lien épidémiologique avec un cas confi mé sont des critères qui permettent de poser le diagnostic } \\
\text { d'une infection par le virus de la rougeole. }\end{array}$ \\
\hline & $\begin{array}{l}\text { La séroconversion ou un titre d'anticorps IgG quatre fois plus élevé chez un patient qui présente une } \\
\text { éruption cutanée et qui n'a pas récemment reçu le vaccin RRO sont également des critères qui } \\
\text { permettent de poser le diagnostic. }\end{array}$ \\
\hline & $\begin{array}{l}\text { Un résultat négatif à la RT-PCR et un résultat négatif au test de détection d'anticorps de classe lgM } \\
\text { pourraient ne pas suffi e à écarter l'infection par le virus de la rougeole dans certains cas, particulièrement } \\
\text { si l'échantillon utilisé pour la réaction en chaîne par polymérase a été prélevé après le septième jour } \\
\text { suivant l'apparition des symptômes. }\end{array}$ \\
\hline & $\begin{array}{l}\text { Le résultat du test sérologique chez les personnes qui ont déjà été vaccinées (échec de l'immunisation } \\
\text { secondaire) ne s'inscrira probablement pas dans le paradigme associé à la présence d'une infection } \\
\text { aiguë chez les personnes qui n'ont pas été immunisées. La réponse des anticorps IgM antirougeoleux peut } \\
\text { être faible ou indétectable, et une augmentation rapide du titre d'anticorps lgG antirougeoleux prévue } \\
\text { entraînerait des résultats fortement positifs au test de détection d'IgG antirougeoleux dans le sérum prélevé } \\
\text { en phase aiguë et l'absence probable d'un titre d'anticorps lgG quatre fois plus élevé dans le sérum prélevé } \\
\text { en phase de convalescence( } 36,37) \text {. Chez ces personnes, le prélèvement en temps opportun de l'échantillon } \\
\text { pour détecter le virus de la rougeole (par RT-PCR) est recommandé. }\end{array}$ \\
\hline
\end{tabular}




\subsection{RÔLES ET RESPONSABILITÉS}

Les provinces et les territoires ont généralement la responsabilité de fournir les ressources de première ligne nécessaires pour le diagnostic des cas suspects de rougeole. L'organisme de la santé publique de la province ou du territoire devrait être doté d'une méthode pour informer et tenir au courant les médecins et les autorités sanitaires régionales des questions qui touchent l'examen des cas de rougeole en laboratoire, particulièrement en ce qui a trait au prélèvement et à la manipulation adéquats des échantillons. Les autorités de santé publique devraient également veiller à ce qu'une procédure soit en place pour recueillir les données cliniques et sur les patients pertinentes qui doivent accompagner les échantillons et pour assurer le transport sécuritaire et efficace des échantillons au laboratoire chargé d'effectuer les tests.

Les laboratoires provinciaux et territoriaux devraient s'assurer que les professionnels de la santé soient informés du moment approprié pour prélever les échantillons ainsi que des conditions de conservation et de transport adéquates des échantillons qui leur sont envoyés pour le diagnostic de la rougeole. Ces laboratoires font généralement les tests sérologiques pour la détection d'anticorps IgM et lgG et devraient s'assurer de communiquer les résultats dans un délai d'au plus 72 heures. Ils devraient s'assurer que leurs méthodes d'analyse soient accréditées et de participer régulièrement à des programmes d'essai des compétences. Les tests de détection d'anticorps contre la rubéole et le parvovirus B19 devraient également être offerts. Les laboratoires provinciaux et territoriaux suivent une logistique pour I'envoi au LMN des échantillons en vue d'un test moléculaire (s'il n'est pas fait sur place) et d'un génotypage.
Le Laboratoire national de microbiologie (LNM) est un laboratoire de référence régionale de l'Organisation mondiale de la santé pour la rougeole et la rubéole et fournit le génotypage idéalement pour tous les cas de rougeole au Canada. La séquence du génome des virus de la rougeole est versée dans les bases de données de I'OPS et de I'OMS. Le LMN fournit également les tests sérologiques pour les cas de rougeole et des épreuves de compétences moléculaires aux laboratoires provinciaux et territoriaux. Le LMN aide également les laboratoires provinciaux et territoriaux en ce qui a trait à l'évaluation des tests, aux problèmes techniques et aux tests de spécialité, notamment les tests sérologiques dans les cas de panencéphalites sclérosantes subaiguës. 


\section{IMMUNISATION}

\subsection{RECOMMANDATIONS DU COMITÉ CONSULTATIF NATIONAL DE L'IMMUNISATION RELATIVES À L'UTILISATION DU VACCIN CONTRE LA ROUGEOLE}

Au Canada, l'immunisation est une responsabilité partagée entre les gouvernements fédéral, provinciaux et territoriaux. L'approbation des produits d'immunisation et les recommandations relatives à I'utilisation des vaccins proviennent du gouvernement fédéral. Les provinces et les territoires sont responsables de planifier, de financer et d'offrir les programmes d'immunisation de leur territoire de compétence.

Les recommandations sur l'utilisation de vaccins particuliers sont fournies par le Comité consultatif national de l'immunisation. Le CCNI est un groupe consultatif d'experts en immunisation au travers le Canada qui fournit de façon continue et en temps voulu à l'Agence des conseils médicaux, scientifiques ou de santé publique ayant trait aux vaccins dont la vente est autorisée au Canada. Le Comité consultatif national de l'immunisation publie ses recommandations détaillées sur I'utilisation des vaccins au Canada. Ces recommandations sont expliquées dans le Guide canadien d'immunisation, disponible à l'adresse www.phac-aspc.gc.ca/publicat/ cig-gci/index-fra.php. Les recommandations actuelles du CCNI sur I'utilisation du vaccin de la rougeole sont les suivantes:

\section{ENFANTS (DE MOINS DE 18 ANS)}

Il est recommandé que deux doses du vaccin contenant le virus de la rougeole soient administrées dans le cadre de l'immunisation systématique des enfants et de l'immunisation des enfants et des adolescents n'ayant pas suivi le programme d'immunisation systématique contre la maladie. Le vaccin RROV peut être administré aux enfants en bonne santé âgés de 12 mois à 12 ans. Quant aux enfants et adolescents non vaccinés souhaitant recevoir les vaccins qu'ils n'ont pas reçus, I'intervalle minimal entre les doses est de quatre semaines pour le RRO et de six semaines pour le RROV.
Le CCNI recommande d'administrer la première dose du RROV entre 12 et 15 mois et la deuxième dose à 18 mois ou à n'importe quel temps après, généralement avant que l'enfant commence l'école. Tel qu'il est indiqué dans la monographie du produit, les doses peuvent être administrées à intervalles plus rapprochés, mais à au moins six semaines d'intervalle.

Deux doses du vaccin RROV à au moins six semaines d'intervalle peuvent également être administrées aux enfants d'au plus 12 ans comme mesure de rattrapage pour ceux qui n'ont pas déjà été immunisés au moyen du vaccin $R R O$ et des vaccins contre la varicelle et aux cas à risque de ces maladies évitables par l'immunisation.

Les enfants de moins de 12 ans qui ont déjà reçu une dose du vaccin contenant le virus de la varicelle devraient se voir offrir une deuxième dose comme mesure de rattrapage à moins qu'ils soient atteints d'une varicelle confirmée. Si l'enfant a déjà reçu deux doses du vaccin $\mathrm{RRO}$, la deuxième dose du vaccin contre la varicelle devrait être administrée sous la forme d'un vaccin monovalent contre la varicelle. Si un enfant n'a reçu qu'une seule dose du RRO et une dose du vaccin contre la varicelle, on peut alors administrer comme seconde dose le RROV, ou encore le RRO et le vaccin contre la varicelle séparément. Se reporter aux tableaux 2 et 3 de la partie 4 : Vaccins actifs - Vaccin contre la Varicelle du Guide canadien d'immunisation pour obtenir le calendrier précis de l'immunisation de rattrapage.

\section{ADULTES (18 ANS ET PLUS)}

Immunisation systématique : les adultes qui ne présentent pas de contre-indications, qui sont nés en 1970 ou après, qui ne détiennent pas une preuve écrite attestant qu'ils ont reçu deux doses du vaccin à partir de l'âge d'un an, qui ne possèdent pas une preuve d'immunité fournie par un laboratoire ou qui n'ont pas d'antécédents de rougeole confirmés en laboratoire, devraient recevoir une dose du vaccin RRO. II faut vérifier l'immunité à l'égard de la rougeole, des oreillons et de la rubéole chez toutes les femmes en âge de procréer et recommander I'immunisation à celles qui ne sont pas enceintes. II est recommandé que les femmes évitent de devenir enceintes au cours des quatre semaines suivant I'administration d'un vaccin RRO. 
Les adultes nés avant 1970 sont présumés avoir développé une immunité naturelle contre la rougeole et n'ont pas besoin d'être vaccinés, sauf ceux qui présentent un risque.

\subsection{PROGRAMMES D'IMMUNISATION AU CANADA}

Les programmes d'immunisation contre la rougeole ont commencé dans les provinces et les territoires du Canada en 1967 avec I'utilisation d'un vaccin vivant contre la rougeole. En 1983, toutes les provinces et les territoires du Canada avaient mis en œuvre l'immunisation systématique contre la rougeole, la rubéole et les oreillons à l'âge de 12 mois. Les recommandations du $\mathrm{CCNI}$ relatives à un calendrier à deux doses du vaccin RRO ont été publiées en 1996. Entre 1996 et 1997, toutes les provinces et les territoires ont introduit la deuxième dose systématique du vaccin RRO ou du vaccin contre la rougeole et la rubéole administrée à 18 mois ou entre quatre et six ans (âge préscolaire) à leurs programmes d'immunisation financés par l'État. Actuellement, neuf territoires de compétence sur treize administrent une deuxième dose du vaccin contre la rougeole, la rubéole et les oreillons (RRO/RROV) à 18 mois, tandis que le reste des territoires de compétence administrent la deuxième dose du vaccin contre la rougeole, la rubéole et les oreillons entre l'âge de quatre à six ans.

Simultanément, ou à la suite de la mise en œuvre de la deuxième dose du vaccin contenant le virus de la rougeole, de nombreux territoires de compétence ont également mis en œuvre des programmes ou des campagnes de rattrapage au moyen d'une deuxième dose destinés aux cohortes plus âgées. Bien que les recommandations nationales quant à l'utilisation des vaccins spécifiques soient émises par le CCNI, les politiques relatives aux programmes d'immunisation sont établies par les provinces et les territoires qui déterminent les calendriers d'immunisation de leur territoire de compétence en partie en fonction des recommandations du CCNI et d'autres facteurs. Par conséquent, les programmes d'immunisation ne sont pas entièrement harmonisés dans l'ensemble des provinces et des territoires; ainsi, le moment où certains vaccins sont offerts dans le cadre de programmes financés par l'État diffère d'un territoire de compétence à un autre. Les plus récents calendriers d'immunisation systématique qui est offerte aux nourrissons et aux enfants par province et par territoire peuvent être consultés à l'adresse www.phacaspc.gc.ca/im/ptimprog-progimpt/table-1-fra.php.

\subsection{APPROVISIONNEMENT EN VACCINS}

L'état de l'approvisionnement en vaccins RRO et RROV (rougeole, rubéole, oreillons et varicelle) devrait être déterminé avant de prendre des mesures d'immunisation dans un contexte de réponse à une éclosion. Comme dans toute nouvelle initiative d'immunisation, l'approvisionnement en vaccins devrait être coordonné en consultation avec les homologues fédéraux-provinciaux-territoriaux par l'intermédiaire du Groupe de travail sur l'approvisionnement en vaccins et le Comité canadien sur l'immunisation. Bien que I'approvisionnement en vaccins RRO soit demeuré stable au cours des dernières années, certains facteurs, comme la mise en œuvre des programmes d'immunisation de rattrapage contre les oreillons dans certains territoires de compétence, des programmes d'immunisation contre la rougeole et l'utilisation plus étendue du vaccin RROV, pourraient avoir une incidence sur la disponibilité du vaccin RRO.

En cas de pénurie, actuelle ou prévue, du vaccin RRO pendant une éclosion, il est nécessaire de déterminer les groupes prioritaires. Au Royaume-Uni, l'ordre de priorité suivant a été étudié : immunisation systématique des nourrissons et des enfants, immunisation des femmes en âge de procréer susceptibles de contracter la rubéole et immunisation des travailleurs de la santé vulnérables (rougeole, rubéole ou oreillons), suivi de l'immunisation d'autres personnes à risque, telles qu'elles sont définies selon l'épidémiologie de l'éclosion. L'ordre de priorité devrait être établi en consultation avec le Comité canadien sur l'immunisation ( $\mathrm{CCl}$ ) et le Groupe de travail sur l'approvisionnement en vaccins. 


\subsubsection{VACCIN CONTENANT LE VIRUS DE LA ROUGEOLE AU CANADA}

II existe actuellement trois vaccins contenant le virus de la rougeole au Canada. Le vaccin contre la rougeole est seulement disponible sous forme de vaccin contre la rougeole, la rubéole et les oreillons ( $R R O)$ ou de vaccin contre la rougeole, la rubéole, les oreillons et la varicelle (RROV), notamment :

- $\mathbf{M}-\mathbf{M}-\mathbf{R}^{\circledR}$ II (vaccin combiné à virus vivants atténués contre la rougeole, la rubéole et les oreillons), Merck Canada Inc. (vaccin RRO);

- $\quad$ PRIORIX ${ }^{\circledR}$ (vaccin combiné à virus vivants atténués contre la rougeole, la rubéole et les oreillons), GlaxoSmithKline Inc. (vaccin RRO);

- PRIORIX-TETRA ${ }^{\circledR}$ (vaccin combiné à virus vivants atténués contre la rougeole, la rubéole, les oreillons et la varicelle), GlaxoSmithKline Inc. (vaccin RROV).

\section{Conservation des vaccins contre la rougeole}

La température de conservation doit être maintenue pendant l'expédition. La monographie des produits doit être consultée pour obtenir les renseignements les plus récents.

M-M-R ${ }^{\circledR}$ II : Le vaccin doit être protégé de la lumière. Avant le début du processus de reconstitution, il faut conserver les fioles de vaccins à une température variant entre $+2^{\circ} \mathrm{C}$ et $+8^{\circ} \mathrm{C}$ ou à une température moins élevée. Le diluant peut être conservé dans un réfrigérateur ou à la température ambiante et ne doit pas être congelé.

PRIORIX ${ }^{\circledR}$ : Conserver le vaccin au réfrigérateur à une température de $2^{\circ} \mathrm{C}$ à $8^{\circ} \mathrm{C}$. Le diluant peut être conservé séparément à la température ambiante. Le vaccin doit être protégé de la lumière.

PRIORIX-TETRA ${ }^{\circledR}$ : Le vaccin et le diluant doivent être réfrigérés à une température variant entre $2^{\circ} \mathrm{C}$ et $8^{\circ} \mathrm{C}$ et ne doivent pas être congelés. Le vaccin doit être protégé de la lumière. Une fois reconstitué, le vaccin doit être administré sans tarder. Si nécessaire, un vaccin reconstitué peut être réfrigéré à une température variant entre $2^{\circ} \mathrm{C}$ et $8^{\circ} \mathrm{C}$ pendant huit heures au plus.
Une fois reconstitués, tous les vaccins doivent être administrés sans tarder. Si nécessaire, un vaccin reconstitué peut être réfrigéré à une température variant entre $2^{\circ} \mathrm{C}$ et $8{ }^{\circ} \mathrm{C}$ pendant huit heures au plus.

\section{4 ÉCLOSIONS}

Des efforts supplémentaires pour parvenir à un taux élevé de couverture vaccinale contre la rougeole devraient être envisagés, et les interventions de la santé publique, comme les campagnes d'immunisation, devraient être adaptées à l'éclosion particulière et son étendue dans la collectivité. L'étendue d'une campagne d'immunisation devrait être déterminée en fonction de l'objectif de la santé publique (sans cas secondaires ni limite de la propagation dans la collectivité), la faisabilité de la mise en œuvre des interventions et le risque auquel la collectivité est exposée. Ces efforts comportent notamment de réduire les occasions manquées d'être immunisé contre la rougeole, d'améliorer l'accès aux campagnes d'immunisation contre la rougeole (ratissage) ou même aux campagnes de rattrapage pour les personnes qui ne sont pas considérées comme suffisamment immunisées contre la rougeole selon les recommandations actuelles du CCNI ainsi que de sensibiliser davantage la population sur l'importance de I'immunisation contre la rougeole. La couverture vaccinale contre la rougeole devrait être surveillée étroitement, et l'utilisation du vaccin au sein des différents groupes de la population et à l'échelle individuelle devrait être minutieusement consignée. 


\section{CADRE DE COMMUNICATION STRATÉGIQUE DES RISQUES}

\subsection{CONTEXTE}

L'objectif du chapitre sur la communication des risques est de s'assurer que tous les partenaires qui participent à la prévention et au contrôle des éclosions de rougeole au Canada collaborent pour transmettre l'information de façon uniforme, complémentaire et efficace et qui répond aux besoins du public et des parties concernées. Le présent chapitre décrit les protocoles de communication que doivent suivre les gouvernements fédéral, provinciaux et territoriaux de même que les outils qui peuvent être adaptés par tous les utilisateurs des présentes lignes directrices pour faciliter la mise en œuvre des pratiques relatives à la communication des risques.

\subsubsection{OBJECTIF DE LA COMMUNICATION DES RISQUES}

Participer aux activités de communication appropriées et en temps opportun, coordonnées par tous les partenaires pour favoriser la promotion de l'adoption des mesures de contrôle de l'infection et renforcer la confiance du public.

\subsection{PROTOCOLES DE COMMUNICATION FÉDÉRAUX-PROVINCIAUX- TERRITORIAUX}

Dans une situation d'éclosion de la rougeole, les protocoles de communication entre les gouvernements fédéral, provinciaux et territoriaux sont essentiels pour assurer notamment :

- une compréhension claire des rôles et des responsabilités en matière de communication entre les partenaires qui participent à la réponse à une éclosion;

- des relations efficaces et des processus de planification et de communication de l'information parmi le personnel responsable des communications des partenaires concernés;

- I'utilisation efficiente et efficace des ressources de communication.

\subsection{RÔLES ET RESPONSABILITÉS}

Les rôles et les responsabilités qui s'appliquent aux communications portant sur une éclosion de rougeole sont identiques aux rôles et aux responsabilités qui s'appliquent à la gestion de toute éclosion. Si l'éclosion se propage et touche plus d'une province ou plus d'un territoire, I'Agence de la santé publique du Canada dirige les communications destinées au public en collaboration avec les territoires de compétence touchés. L'Agence est également responsable des communications publiques pendant les éclosions qui touchent les modes de transport (trains, autobus, avions et vaisseau-cargo en eaux internationales), car elle est responsable des communications internationales concernant une éclosion de rougeole au Canada.

Peu importe qui est responsable des communications, la communication de l'information pendant une éclosion est essentielle pour assurer la coordination des communications entre tous les territoires de compétence. Par conséquent, il est recommandé de suivre les étapes suivantes:

1. Dès qu'une éclosion (telle qu'elle est définie dans les présentes lignes directrices) est confi mée, le responsable en matière de rougeole devrait communiquer l'information au service des communications de l'Agence de la santé publique du Canada.

2. L'Agence sera chargée d'informer les partenaires de communication de chaque province et territoire au moyen du réseau de communication du Réseau de la santé publique. L'information sera communiquée par courrier électronique.

3. Au besoin, I'ASPC organisera des téléconférences avec les membres afin que le éseau de communication du Réseau de la santé publique (RSP) puisse faire le point sur la situation. Tous les documents informatifs devraient être transmis au groupe de travail. 
4. Lorsque l'Agence n'est pas responsable des communications, les partenaires des communications provinciaux et territoriaux doivent s'efforcer de transmettre leur matériel de communication à l'Agence en vue d'être livré au réseau de communication du Réseau de la santé publique avant que tout avis public ne soit émis.

Lorsque l'Agence dirige les communications concernant une éclosion, elle élabore le matériel de communication destiné au public en consultation avec le réseau de communication du Réseau de la santé publique, puis distribue le matériel définitif à ses membres avant de le rendre public dans la mesure du possible.

En plus de communiquer les messages et le matériel d'information, l'organisme responsable peut également utiliser le réseau de communications du Réseau de santé publique comme ressource pour planifier les activités de communication coordonnées. Les membres de ce groupe se réunissent déjà une fois par mois, mais des réunions supplémentaires peuvent être prévues lorsque des communications particulières sont nécessaires pour contrôler une éclosion.

\section{4 ÉVALUATION}

Des évaluations officielles et non officielles (pendant ou après une éclosion) sont effectuées en fonction des objectifs établis au début de la stratégie de communication des risques. Diverses activités d'évaluation peuvent être entreprises.

L'évaluation postéclosion des plans et des activités de communication sera effectuée par l'organisme responsable pour faciliter les planifications et améliorer la réponse à l'avenir. L'évaluation peut être effectuée une fois que les comptes-rendus après action des joueurs actifs ont été recueillis et analysés.

Pour en savoir davantage sur la communication des risques et les méthodes d'évaluation, veuillez consulter le Cadre de communication stratégique des risques dans le contexte de la gestion intégrée des risques à Santé Canada et à I'ASPC, à l'adresse www.phac-aspc.gc.ca/ publicat/2007/risk-com/index-fra.php.

\subsection{PRINCIPES CLÉS DE LA COMMUNICATION DES RISQUES}

TRANSPARENCE

La communication est souvent la première intervention de la santé publique, particulièrement en contexte d'éclosion. L'information sur les cas, les risques d'exposition et les mesures de prévention et de contrôle de l'infection (se laver les mains, rester à la maison si l'on est malade et surveiller les symptômes) peut être un excellent moyen de réduire la propagation de l'infection avant que les interventions médicales, comme l'immunisation, ne soient offertes.

Dans le cas d'une éclosion de rougeole, la meilleure pratique consiste à informer le public le plus rapidement possible une fois qu'un cas a été déterminé. Conformément aux protocoles fédéraux-provinciauxterritoriaux décrits ci-dessus, les territoires de compétence aviseront l'Agence avant d'annoncer une éclosion au grand public.

\section{RELATIONS AVEC LES PARTIES CONCERNÉES}

La participation des parties concernées dans la communication et la gestion des risques est très avantageuse en ce qui a trait aux communications portant sur une éclosion de rougeole, car elle permet de préconiser des approches coordonnées et uniformes de communication des messages et de l'information qui répondent aux besoins des parties concernées. Elle donne également l'occasion de tirer profit de l'information et des ressources précieuses que les parties concernées peuvent offrir.

Pour faciliter l'ordre de priorité des parties concernées, I'Agence se sert d'une carte des parties concernées (se reporter à l'Annexe I). Dans cette carte, les parties concernées sont catégorisées selon le degré auquel elles sont touchées par le risque et le degré auquel elles peuvent participer à la réduction du risque. 


\section{PRINCIPAUX MESSAGES EFFICACES EN CAS D'ÉCLOSION DE LA ROUGEOLE}

Les messages suivants sont des messages d'ordre général qui peuvent être utiles dans tous les cas d'éclosion de la rougeole:

- La rougeole est une maladie extrêmement contagieuse. Les symptômes de la rougeole sont notamment la fièvre, des écoulements nasaux, de la somnolence, de l'irritabilité et l'apparition de plaques rouges qui se manifestent en premier lieu sur le visage.

- La rougeole touche tous les groupes d'âge, mais elle est généralement plus grave chez les nourrissons et les adultes. Pendant la grossesse, la rougeole peut accroître le risque d'accouchement prématuré et d'insuffisance pondérale à la naissance.

- L'immunisation est le meilleur moyen de défense contre cette maladie. On rappelle aux Canadiens de tenir leurs immunisations à jour.

- Les personnes qui ont pu être exposées, qui ne sont pas immunisées et qui présentent des symptômes devraient communiquer avec leur fournisseur de soins de santé ou les autorités de santé publique pour déterminer le meilleur plan d'action. En règle générale, les personnes malades devraient rester à la maison pour réduire le risque de propagation d'une maladie contagieuse.

\section{COMPOSITION DES MESSAGES}

Pour faciliter la préparation de messages efficaces concernant les risques qui vont au-delà de la sensibilisation à l'égard de l'éclosion et des mesures de prévention et de contrôle de l'infection appropriées, I'Agence a élaboré un outil de composition de messages (se reporter à l'Annexe J) qui décrit les principaux éléments que devrait contenir un message efficace concernant les risques.

Les éléments propres à la composition des messages concernant les risques sont notamment:

- se servir des preuves pour étayer chaque énoncé portant sur les risques ou les avantages;

- reconnaître les incertitudes;

- communiquer les mesures à prendre pour prévenir la maladie.

\section{ÉCOUTE ET POINT DE VUE DES PARTIES CONCERNÉES}

La documentation sur la communication des risques indique que la perception du public quant aux risques a autant d'influence sur leurs comportements que le risque lui-même $(41,42)$. Par exemple, si une personne qui présente un risque élevé de contracter la rougeole ne se sent pas menacée, il est peu probable qu'elle prenne les mesures nécessaires pour se protéger de la maladie.

- Dans une éclosion de rougeole, le point de vue des parties concernées devrait être pris en compte afin de mieux comprendre ce que le public ne saisit pas bien à propos de l'éclosion et déterminer les obstacles qui empêchent le public d'accepter et d'adhérer à l'avis de santé publique. La consultation du contenu des médias sociaux (comme Facebook, Twitter, les blogues et les tribunes) pour relever les questions, les préoccupations et les opinions du public concernant l'éclosion peut s'avérer utile pour connaître ces obstacles.

- Consultez les documents de communication des organismes et des gouvernements pour relever les éléments de confusion ou les conflits.

- Appelez les parties concernées pour connaître les problèmes soulevés dans leurs réseaux.

- Menez des essais auprès de groupes cibles, des recherches sur l'opinion publique, des séances de discussion ouverte et des séances de groupes consultatifs externes pour mieux comprendre la perception du public à l'égard du risque.

En suivant ces principes clés de communication des risques et en établissant la coordination entre tous les partenaires dans la gestion de l'éclosion, nous pouvons rédiger des communications de réponse qui répondent mieux aux besoins des personnes à risque, et finalement, qui servent l'objectif de prévenir et contrôler les éclosions de rougeole. 


\section{ANALYSE DE L'ÉCLOSION}

Une analyse descriptive continue (des personnes, des lieux et des moments) devrait être effectuée à mesure que progresse l'éclosion. L'analyse devrait être effectuée par l'organisme responsable de l'investigation de l'éclosion. Selon la nature de l'éclosion, ces analyses pourraient être communiquées aux autres provinces et territoires ainsi qu'à l'Agence au moyen du système Alertes de santé publique du RCRSP, à I'adresse www.cnphi-rcrsp.ca, ou d'un autre mécanisme établi.

Au terme de l'éclosion, sa nature devrait être pleinement analysée et communiquée. Le territoire de compétence responsable devrait produire un rapport dans l'année qui suit la fin de l'éclosion et publier ce rapport pour les autres territoires de compétence du Canada de sorte qu'ils puissent s'enrichir de la toute récente expérience. Il est recommandé d'évaluer les éléments de données suivants $(4,6)$ :

- le nombre total de cas et le taux d'incidence de I'infection;

- la description épidémiologique du cas de référence;

- I'analyse des chaînes de transmission et leur fonctionnement (y compris le nombre de cas appartenant à chacune des chaînes);

- I'analyse de la classification des cas (importé, lié à un cas importé, de source inconnue ou ayant un lien épidémiologique avec un cas de source inconnue);

- I'analyse des caractéristiques démographiques;

- la définition des facteurs de risque ou des groupes les plus touchés; évaluation de la couverture vaccinale de la région;

- la somme des cas qui auraient pu être évités;
- la caractérisation de la vulnérabilité des cas (cas trop jeunes pour être immunisés, cas nés avant 1970, cas non immunisés selon les recommandations du Comité consultatif national de l'immunisation, cas présentant une contre-indication à l'immunisation, cas ayant un certificat d'exemption pour des motifs religieux ou philosophiques, échec d'immunisation primaire et secondaire); et

- le nombre de cas en âge de procréer estimé.

Si l'éclosion est suffisamment importante, le territoire de compétence pourrait également évaluer les éléments suivants :

- I'efficacité des mesures de prévention et de contrôle de l'infection;

- I'efficacité du vaccin en comparant les taux d'atteinte des cas immunisés avec les taux d'atteinte des cas non immunisés. 


\section{RÉFÉRENCES}

(1) Pratiques de base et précautions additionnelles visant à prévenir la transmission des infections dans les milieux de soins. mai, 2013

(2) National Advisory Committee on Immunization (NACl). Statement on measles-mumps-rubella-varicella vaccine. 2010 .

(3) Dallaire F, De Serres G, Tremblay FW, Markowski F, Tipples G. Long-lasting measles outbreak affecting several unrelated networks of unvaccinated persons. J Infect Dis 2009 Nov 15;200(10):1602-1605.

(4) Pan-American Health Organization (PAHO). Measles elimination field guide. 2005.

(5) Public Health Agency of Canada. Case definitions for diseases under national surveillance. CCDR 2009.

(6) World Health Organization. World Health Organization. Measles fact sheet N²86. 2012; Disponible à : www.who.int/mediacentre/factsheets/ fs286/en. Consulté en octobre 2011.

(7) Nicoara C, Zach K, Trachsel D, German D, Matter L. Decay of passively acquired maternal antibodies against measles, mumps and rubella viruses. Clin Diagn Lab Immunol 1999;6(6):868.

(8) National Advisory Committee on Immunization (NACl). Canadian immunization guide. Part 4: Active Vaccines-Measles Vaccine. 2012; Disponible à : www.phac-aspc.gc.ca/publicat/cig-gci/p04-measroug-eng.php. Consulté en décembre 2012.

(9) World Health Organization. Guidelines for prevention and control. Second Edition. 2006.

(10) Heymann DL,MD. Control of communicable diseases manual. 19th ed.: American public health association; 2008. p. 403.

(11) Public Health Agency of Canada. What you need to know about measles. 2011; Disponible à : www.phac-aspc.gc.ca/im/iyc-vve/faq-dis-mal/measlesrougeole-eng.php. Consulté le 9 novembre 2011.

(12) Manikkavasagan G, Ramsay M. The rationale for the use of measles post-exposure prophylaxis in pregnant women: A review. J Obstet Gynaecol 2009;29(7):572.

(13) Atmar RL, Englund JA, Hammill H. Complications of measles during pregnancy. Clin Infect Dis 1992; 14(1):217.
(14) Soldatou A, Graham Davis E. Respiratory virus infections in the immunocompromised host. Paediatr Respir Rev 2003;4(3):193.

(15) Couch RB, Englund JA. Respiratory viral infections in immunocompetent and immunocompromised persons. Am J Med 1997;102(3):2.

(16) American Academy of Pediatrics. Measles. In: Pickering L, Baker C, editors. Red book: 2012 report of the committee on infectious diseases. $29^{\text {th }}$ ed. Elk Grove Village, IL: American Academy of Pediatrics; 2012. p. 489-499.

(17) Chen RT, Orenstein WA, Frank JA, Sacks JJ, Dales LG, Preblud SR, et al. An explosive pointsource measles outbreak in a highly vaccinated population. Am J Epidemiol 1989;129(1):173.

(18) Davis RM, Orenstein WA, Frank JA, Sacks JJ, Dales LG, Preblud SR, et al. Transmission of measles in medical settings, 1980 through 1984. JAMA 1986;255:1295.

(19) Dales LG, Kizer KW. Measles transmission in medical facilities. West J Med 1985;142:415.

(20) Remington PL, Hall WN, Davis IH, Herald A, Gunn RA. Airborne transmission of measles in a physician's office. JAMA 1985;75:676.

(21) Bloch AB, Orenstein WA, Ewing MW. Measles outbreak in a pediatric practice: airborne transmission in an office setting. Pediatrics 1985;75:676.

(22) Istre GR, McKee PA, West, G.R., O'Mara, D.J., Rettig PJ, Stuemky J, et al. Measles spread in hospital settings: an important focus of disease transmission? Pediatrics 1987;79:356.

(23) Sienko DG, Friedman C, McGee HB, Allen MJ, Simeson WF, Wentworth BB, et al. A measles outbreak at university medical setting involving medical health care providers. Am J Public Health 1987;15:201.

(24) Watkins NM, Smith RP, St. Germain DL, MacKay DN. Measles (rubeola) infection in a hospital setting. Am J Infect Control 1987;15:201.

(25) Raad II, Sheretz RJ, Rains CS, Cusick JL, Fauerbach LL, Reuman PD, et al. The importance of nosocomial transmission in the propagation of a community outbreak. Infect Control Hosp Epidemiol 1989;10:161. 
(26) Rank EL, Brettman L, Katz-Pollack H, DeHertogh D, Nevill D. Chronology of a hospital-wide measles outbreak: lessons learned and shared from an extraordinatory week in late March 1989. Am J Infect Control 1992;209:315.

(27) Atkinson WL. Measles and health care workers. Infect Control Hosp Epidemiol 1994;15:5.

(28) Botelho-Nevers E, Cassir N, Minodier P, Laporte R, Gautret P, Badiaga S, et al. Measles among healthcare workers: A potential for nosocomial outbreaks. Eurosurveillance 2011;16(2):1.

(29) Public Health Agency of Canada. Infection control guidelines: prevention and control of occupational infections in health care. Canadian Communicable Disease Report 2002;28(S1).

(30) Canadian Standards Association. Z317.2-10 Special requirements for heating, ventilation and air conditioning (hvac) systems in health care facilities. 2001.

(31) Canadian Standards Association. Z8000 Canadian health care facilities - planning, design and construction. 2001.

(32) Cutts F, Brown D. The contribution of field tests to measles surveillance and control: A review of available methods. Rev Med Microbiol 1995;5(1):35.

(33) World Health Organization. Manual for the laboratory diagnosis of measles and rubella virus infection. 2007;2.

(34) Bellini WJ, Icenogle J. Measles and rubella viruses. Manual of clinical microbiology. $10^{\text {th }}$ ed. Washington DC: ASM Press; 2011.

(35) Tipples G, Hiebert J. Detection of measles, mumps and rubella viruses. Methods in Molecular Biology 2011;665:183.

(36) Hickman CJ, Hyde TB, Sowers SB, Mercader S, McGrew M, Williams NJ, et al. Laboratory characterization of measles virus infection in previously vaccinated and unvaccinated individuals. J Infect Dis 2011 Jul;204 Suppl 1:S549-58.

(37) Rota JS, Hickman CJ, Sowers SB, Rota PA, Mercader S, Bellini WJ. Two case studies of modified measles in vaccinated physicians exposed to primary measles cases: high risk of infection but low risk of transmission. J Infect Dis 2011 Jul;204 Suppl 1:S559-63.
(38) Cohen B, Audet S, Andrews N, Beeler J, WHO working group on measles plaque reduction neutralization test. Plaque reduction neutralization test for measles antibodies: Description of a standardised laboratory method for use in immunogenicity studies of aerosol vaccination. Vaccine 2007;26(1):59-66.

(39) Markowitz LE, Sepulveda J, Diaz-Ortega J, Valdespino J, Albrecht P, Zell E, et al. Immunization of six-month-old infants with different doses of Edmonston-Zagreb and Schwarz measles vaccines. N Engl J Med 1990;322(9):580-7.

(40) Chen RT, Markowitz LE, Albrecht P, Stewart JA, Mofenson LM, Preblud SR, et al. Measles antibody: reevaluation of protective titers. J Infect Dis 1990 Nov;162(5):1036-1042.

(41) Carman KG, Koorman P. Flu shots, mammograms and the perception of probabilities. Institute for the study of labour 2011;5739(1):1.

(42) Setbon M, Le Pape M, Letroublon C, Caille-Brillet A, Raude J. The public's preventive strategies in response to the pandemic influenza a/H1N1 in France: distribution and determinants. Prev Med $2011 ; 52(2): 178$.

(43) Pan American Health Organization (PAHO). Meeting of the panel of experts for the documentation and verification of measles, rubellal, and CRS elimination. Immunization Newsletter 2009;31(2):1.

(44) Hutse V, Van Hecke K, De Bruyn R, Samu O, Lernout T, Muyembe JJ, et al. Oral fluid for the serological and molecular diagnosis of measles. Int J Infect Dis 2010 Nov;14(11):e991-7.

(45) Gark R. Subacute sclerosing panencephalitis. Postgrad Med J 2002;78:63.

(46) Hummel KB, Lowe L, Bellini WJ, Rota PA. Development of quantitative gene-specific realtime RT-PCR assays for the detection of measles virus in clinical specimens. J Virol Methods 2006 Mar;132(1-2):166-173.

(47) Expanded Programme on Immunization (EPI). Standardization of the nomenclature for describing the genetic characteristics of wild-type measles viruses. Wkly Epidemiol Rec 1998;73(36):265. 


\section{ANNEXE A. \\ PARTICIPANTS À L'ÉLABORATION DES LIGNES DIRECTRICES}

GROUPE DE TRAVAIL POUR L'ÉLIMINATION DE LA ROUGEOLE ET DE LA RUBÉOLE

Gaston DeSerres, Tony Mazzulli, Monika Naus, Marina Salvadori

\section{SANTÉ CANADA}

Gillian Badger, Sahadia Etienne

\section{AGENCE DE LA SANTÉ PUBLIQUE DU CANADA}

Arlette Alcazar, Frederic Bergeron, Heather Deehan, Tracie EisBrenner, Joanne Hiebert, Nashira Khalil, Jacqueline Kosche, Julie Laroche, Mark Lysyshyn, Julie McGihon, Teresa Mersereau, Rana Nemr, Carole Nesbeth, Laurie O’Neil, Joy Pulickal, Myriam Saboui, Alberto Severini, Amanda Shane, Lindsey Sherrard, Lindsey Williams 


\section{ANNEXE B. LOIS PROVINCIALES ET TERRITORIALES RELATIVES À LA DÉCLARATION DES MALADIES TRANSMISSIBLES}

\begin{tabular}{|c|c|c|c|}
\hline PROVINCE OU TERRITOIRE & TITRE DE LA LOI & DERNIÈRE MISE À JOUR & PARTIE \\
\hline Alberta & Public Health Act & 2010 & $\begin{array}{l}\text { Partie III, article 22, article } 23 \text { - Notification } \\
\text { of communicable disease }\end{array}$ \\
\hline Colombie-Britannique & Public Health Act & 2008 & $\begin{array}{l}\text { Section } 3 \text {, article } 10-\text { Mandatory reporting } \\
\text { of infection or exposure }\end{array}$ \\
\hline Manitoba & Public Health Act & 2009 & $\begin{array}{l}\text { Partie IV, section } 1 \text { - Reporting } \\
\text { Requirements for Diseases }\end{array}$ \\
\hline Nouveau-Brunswick & Loi sur la santé publique & 2009 & $\begin{array}{l}\text { Partie III, article } 27 \text { - Déclaration des } \\
\text { maladies à déclaration obligatoire et autres } \\
\text { renseignements }\end{array}$ \\
\hline Terre-Neuve-et-Labrador & $\begin{array}{l}\text { NL Communicable } \\
\text { Diseases Act }\end{array}$ & 2006 & $\begin{array}{l}\text { Article } 4 \text {, article } 5 \text { - Notice by physician, } \\
\text { notice by others }\end{array}$ \\
\hline Territoires du Nord-Ouest & Public Health Act & 2009 & $\begin{array}{l}\text { Articles 6-10 - Disease Surveillance } \\
\text { Regulations }\end{array}$ \\
\hline Nouvelle-Écosse & Health Protection Act & 2004 & $\begin{array}{l}\text { Article } 31 \text { - Notifiable Diseases or } \\
\text { Condition }\end{array}$ \\
\hline Nunavut & Public Health Act & 2008 & $\begin{array}{l}\text { Articles 2, 3,4-Communicable Diseases } \\
\text { Regulations }\end{array}$ \\
\hline Ontario & $\begin{array}{l}\text { Loi sur la protection et la } \\
\text { promotion de la santé }\end{array}$ & 2009 & $\begin{array}{l}\text { Article } 2 \text { - Déclaration des maladies } \\
\text { infectieuses }\end{array}$ \\
\hline Île-du-Prince-Édouard & Public Health Act & 2010 & Article 23 - Regulations \\
\hline Québec & Loi sur la santé publique & 2012 & $\begin{array}{l}\text { Chapitre VIII — Intoxications, infections } \\
\text { et maladies à déclaration obligatoire }\end{array}$ \\
\hline Saskatchewan & Public Health Act & 1994 & $\begin{array}{l}\text { Partie II - Reporting of Communicable } \\
\text { Diseases }\end{array}$ \\
\hline Yukon & Public Health and Safety Act & 2002 & $\begin{array}{l}\text { Article } 2 \text { - Public health and sanitation } \\
\text { regulations }\end{array}$ \\
\hline
\end{tabular}




\section{ANNEXE C. EXIGENCES FÉDÉRALES, PROVINCIALES ET TERRITORIALES RELATIVES À LA DÉCLARATION DES CAS DE ROUGEOLE}

\begin{tabular}{|c|c|c|c|c|}
\hline $\begin{array}{l}\text { TERRITOIRE DE } \\
\text { COMPÉTENCE }\end{array}$ & FORMULAIRE DE DÉCLARATION & DESTINATAIRE & DÉLAl & EXIGENCE \\
\hline \multirow[t]{5}{*}{ Alberta } & $\begin{array}{l}\text { Médecins, professionnels de la santé } \\
\text { et autres }\end{array}$ & Médecin hygiéniste (Alb.) & 1 heure & Obligatoire \\
\hline & $\begin{array}{l}\text { Tous les laboratoires } \\
\text { (régionaux et provinciaux) — Alb. }\end{array}$ & Médecin hygiéniste en chef (Alb.) & 1 heure & Obligatoire \\
\hline & $\begin{array}{l}\text { Tous les laboratoires } \\
\text { (régionaux et provinciaux) — Alb. }\end{array}$ & Médecin hygiéniste (Alb.) & 1 heure & Obligatoire \\
\hline & $\begin{array}{l}\text { Tous les laboratoires } \\
\text { (régionaux et provinciaux) — Alb. }\end{array}$ & Médecin traitant ou médecin requérant & 1 heure & Obligatoire \\
\hline & Médecin hygiéniste (Alb.) & Médecin hygiéniste en chef (Alb.) & 1 heure & Obligatoire \\
\hline \multirow[t]{2}{*}{$\begin{array}{l}\text { Colombie- } \\
\text { Britannique }\end{array}$} & $\begin{array}{l}\text { Médecins, professionnels de la santé } \\
\text { et autres (C.-B.) }\end{array}$ & $\begin{array}{l}\text { British Columbia Communicable Disease } \\
\text { Control }\end{array}$ & 1 heure & Obligatoire \\
\hline & Laboratoire - C.-B. & $\begin{array}{l}\text { British Columbia Communicable Disease } \\
\text { Control }\end{array}$ & 1 heure & Obligatoire \\
\hline \multirow[t]{4}{*}{ Manitoba } & $\begin{array}{l}\text { Tous les laboratoires (régionaux } \\
\text { et provinciaux) - Man. }\end{array}$ & $\begin{array}{l}\text { Manitoba Health Public Health } \\
\text { Surveillance Unit }\end{array}$ & 1 heure & Obligatoire \\
\hline & Laboratoires régionaux - Man. & Cadham Provincial Laboratory & 7 jours & Obligatoire \\
\hline & $\begin{array}{l}\text { Médecins, professionnels de la santé } \\
\text { et autres }\end{array}$ & $\begin{array}{l}\text { Administrateur en chef de la santé } \\
\text { publique - Man. }\end{array}$ & 1 heure & Obligatoire \\
\hline & $\begin{array}{l}\text { Tous les laboratoires } \\
\text { (régionaux et provinciaux) — Man. }\end{array}$ & $\begin{array}{l}\text { Administrateur en chef de la santé } \\
\text { publique - Man. }\end{array}$ & 1 heure & Obligatoire \\
\hline Nouveau-Brunswick & $\begin{array}{l}\text { Médecins, professionnels de la santé } \\
\text { et autres }\end{array}$ & Médecin hygiéniste & 1 heure & Obligatoire \\
\hline \multirow{3}{*}{$\begin{array}{l}\text { Terre-Neuve-et- } \\
\text { Labrador }\end{array}$} & Professionnels de la santé & Médecin hygiéniste régional (T.-N.-L.) & 1 heure & Obligatoire \\
\hline & $\begin{array}{l}\text { Laboratoires provinciaux de santé } \\
\text { publique (T.-N.-L.) }\end{array}$ & Médecin hygiéniste régional (T.-N.-L.) & 1 heure & Obligatoire \\
\hline & Médecin hygiéniste régional (T.-N.-L.) & Bureau provincial (T.-N.-L.) & 1 heure & Obligatoire \\
\hline $\begin{array}{l}\text { Territoires du } \\
\text { Nord-Ouest }\end{array}$ & $\begin{array}{l}\text { Médecins, professionnels de la santé } \\
\text { et autres }\end{array}$ & $\begin{array}{l}\text { Administrateur en chef de la santé } \\
\text { publique (T.N.-O.) }\end{array}$ & 24 heures & Obligatoire \\
\hline \multirow[t]{3}{*}{ Nouvelle-Écosse } & $\begin{array}{l}\text { Médecins, praticiens de la santé } \\
\text { et autres (N.-É.) }\end{array}$ & Médecin hygiéniste - N.-É. & 1 heure & Obligatoire \\
\hline & Directeur d'école — N.-É. & Médecin hygiéniste — N.-É. & 1 heure & Obligatoire \\
\hline & Administrateur d'établissement & Médecin hygiéniste - N.-É. & 1 heure & Obligatoire \\
\hline
\end{tabular}




\begin{tabular}{|c|c|c|c|c|}
\hline $\begin{array}{l}\text { TERRITOIRE DE } \\
\text { COMPÉTENCE }\end{array}$ & FORMULAIRE DE DÉCLARATION & DESTINATAIRE & DÉLAI & EXIGENCE \\
\hline Nunavut & $\begin{array}{l}\text { Médecins, professionnels de la santé } \\
\text { et autres - Nun. }\end{array}$ & Médecin hygiéniste en chef — Nun. & 1 heure & Obligatoire \\
\hline \multirow[t]{4}{*}{ Ontario } & $\begin{array}{l}\text { Médecins, professionnels de la santé } \\
\text { et autres }\end{array}$ & Médecin hygiéniste — Ont. & heures & Obligatoire \\
\hline & Administrateur d'hôpital — Ont. & Médecin hygiéniste — Ont. & heures & Obligatoire \\
\hline & Technicien de laboratoire - Ont. & Médecin hygiéniste — Ont. & heures & Obligatoire \\
\hline & Directeur d'école - Ont. & Médecin hygiéniste — Ont. & heures & Obligatoire \\
\hline $\begin{array}{l}\text { Île-du-Prince- } \\
\text { Édouard }\end{array}$ & $\begin{array}{l}\text { Médecins, professionnels de la santé } \\
\text { et autres - Î.-P.-É. }\end{array}$ & Médecin en chef — Î.-P.-É. & heures & Obligatoire \\
\hline \multirow[t]{2}{*}{ Québec } & Laboratoires (Qué.) & $\begin{array}{l}\text { Directeur régional de la santé publique } \\
\text { (Qué.) }\end{array}$ & 48 heures & Obligatoire \\
\hline & Médecins (Qué.) & $\begin{array}{l}\text { Directeur régional de la santé publique } \\
\text { (Qué.) }\end{array}$ & 48 heures & Obligatoire \\
\hline \multirow[t]{3}{*}{ Saskatchewan } & Laboratoires (tous) — Sask. & Médecin hygiéniste — Sask. & 48 heures & Obligatoire \\
\hline & Enseignant ou directeur — Sask. & Médecin hygiéniste — Sask. & 48 heures & Obligatoire \\
\hline & $\begin{array}{l}\text { Médecins, professionnels de la santé } \\
\text { et autres - Sask. }\end{array}$ & Médecin hygiéniste — Sask. & 48 heures & Obligatoire \\
\hline Yukon & $\begin{array}{l}\text { Médecins, professionnels de la santé } \\
\text { et autres - Yn }\end{array}$ & Yukon Communicable Disease Control & 1 heure & Obligatoire \\
\hline Canada (fédéral) & $\begin{array}{l}\text { Territoires de compétence provinciaux } \\
\text { et territoriaux }\end{array}$ & $\begin{array}{l}\text { Système canadien de surveillance } \\
\text { des maladies à déclaration obligatoire, } \\
\text { Agence de la santé publique du Canada }\end{array}$ & Annuel & Facultatif \\
\hline Canada (fédéral) & $\begin{array}{l}\text { Territoires de compétence provinciaux } \\
\text { et territoriaux }\end{array}$ & $\begin{array}{l}\text { Système canadien de surveillance de } \\
\text { la rougeole et de la rubéole, Agence } \\
\text { de la santé publique du Canada }\end{array}$ & 7 jours & Facultatif \\
\hline Canada (fédéral) & Agence de la santé publique du Canada & Organisation panaméricaine de la santé & 7 jours & Facultatif \\
\hline
\end{tabular}




\section{ANNEXE D.}

\section{FORMULAIRE NATIONAL DE DÉCLARATION DE CAS DE ROUGEOLE}

\section{Cochez une case : $\square$ ROUGEOLE a RUBÉOLE a SYNDROME DE RUBÉOLE CONGÉNITALE/INFECTION RUBÉOLEUSE CONGÉNITALE}

\begin{tabular}{|c|c|}
\hline \multicolumn{2}{|c|}{ IDENTIFICATION } \\
\hline $\begin{array}{l}\text { Numéro du cas } \\
\text { Attribué par la province ou le territoire }\end{array}$ & $\begin{array}{l}\text { Unité de services de santé, Ville et trois premiers caractères } \\
\text { du code postal }\end{array}$ \\
\hline $\begin{array}{l}\text { Date de naissance } \\
\text { Si inconnue, indiquez l'ÂGE }\end{array}$ & $\begin{array}{l}\text { Date de la déclaration à l'unité de services de santé } \\
\text { AAAA-MM-JJ }\end{array}$ \\
\hline $\begin{array}{l}\text { Sexe } \square \text { FEMME } \square \text { HOMME } \\
\text { Si FEMME, enceinte? } \square \text { Oui } \square \text { Non }\end{array}$ & $\begin{array}{l}\text { Date de début de l'investigation } \\
\text { AAAA-MM-JJ }\end{array}$ \\
\hline \multicolumn{2}{|c|}{ CONTEXTE, EXPOSITION ET DONNÉES CLINIQUES } \\
\hline $\begin{array}{l}\text { La période d'incubation du virus de la ROUGEOLE est de } 7 \\
\text { à } 21 \text { jours précédant l'apparition de l'éruption cutanée, et la } \\
\text { période de transmission est de } 4 \text { jours avant à } 4 \text { jours après } \\
\text { l'apparition de l'éruption cutanée }\end{array}$ & $\begin{array}{l}\text { La période d'incubation du virus de la RUBÉOLE est de } 14 \text { à } \\
21 \text { jours précédant l'apparition de l'éruption cutanée, et la } \\
\text { période de transmission est de } 7 \text { jours avant à au moins } 4 \text { jours } \\
\text { après l'apparition de l'éruption cutanée }\end{array}$ \\
\hline $\begin{array}{ll}\text { Date de l'apparition de l'éruption } & \text { AAAA-MM-JJ } \\
\text { Maladie clinique et lien } & \\
\text { épidémiologique avec un } & \square \text { Oui } \square \text { Non } \\
\text { cas confirmé en laboratoire } & \end{array}$ & $\begin{array}{ll}\text { Antécédents d'immunisation } & \square \text { Oui } \square \text { Non } \square \text { Inconnu } \\
\text { Date dose } 1 & \text { AAAA-MM-JJ } \\
\text { Date dose } 2 & \text { AAAA-MM-JJ } \\
\text { Date dose } 3 & \text { AAAA-MM-JJ }\end{array}$ \\
\hline $\begin{array}{l}\text { Hospitalisé } \quad \square \text { Oui } \square \text { Non } \square \text { Inconnu } \\
\text { pour la rougeole ou la rubéole ou en raison de complications } \\
\text { de la maladie }\end{array}$ & Outbreak associated $\square$ Oui $\square$ Non $\square$ Inconnu \\
\hline \multicolumn{2}{|c|}{$\begin{array}{ll}\text { Source: } & \square \text { extérieur du Canada } \\
\text { OU } & \square \text { au Canada, lié à un cas ou une chaîne importé } \\
\text { OU } & \square \text { au Canada, lié à un cas ou une chaîne de source inconnue } \\
\text { OU } & \square \text { source inconnue }\end{array}$} \\
\hline \multicolumn{2}{|c|}{$\begin{array}{l}\text { Dans l'espace ci-dessous ou sur une pièce jointe : } \\
\text { - indiquez tous les pays, dates de voyage et milieu de l'exposition pendant les périodes d'incubation et de transmission } \\
\text { - s'il s'agit d'un nouveau résident canadien, inscrivez son pays de naissance ou l'année d'immigration } \\
\text { - autres données laboratoires ou données sur l'exposition }\end{array}$} \\
\hline \multicolumn{2}{|c|}{ DONNÉES DU LABORATOIRE } \\
\hline 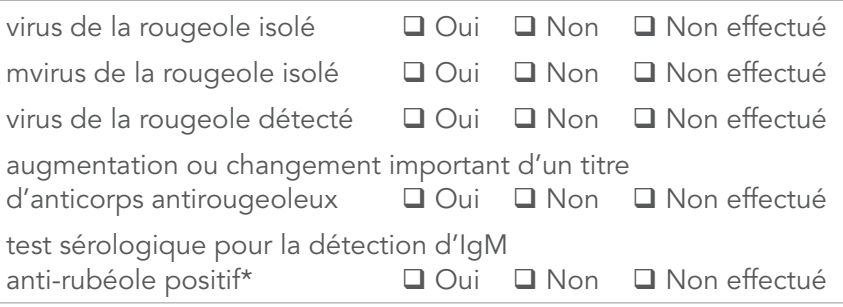 & 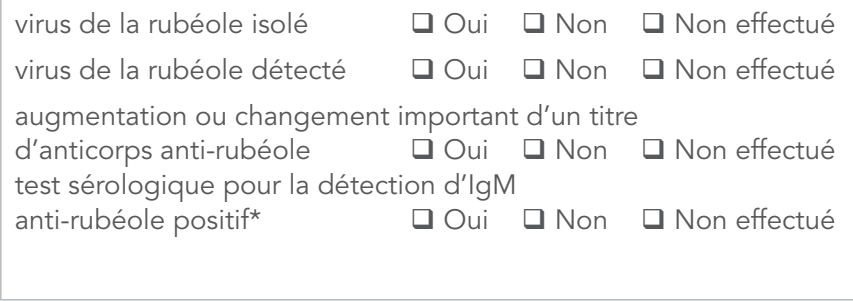 \\
\hline \multicolumn{2}{|c|}{$\begin{array}{l}\text { * Les cas n'ayant aucun lien épidémiologique avec un cas confi mé en laboratoire ni les cas n'ayant pas récemment voyagé dans une région où la maladie } \\
\text { est active ne doivent être confi més en laboratoire par isolement du virus ou test sérologique en phase de convalescence. }\end{array}$} \\
\hline \multicolumn{2}{|c|}{ Tous les cas diagnostiqués au Canada, peu importe leur citoyenneté, devraient être déclarés à l'Agence de la santé publique du Canada. } \\
\hline \multicolumn{2}{|c|}{$\begin{array}{l}\text { VEUILLEZ ENVOYER VOTRE FORMULAIRE PROVINCIAL OU TERRITORIAL POUR DÉCLARER } \\
\text { UN SYNDROME DE RUBÉOLE CONGÉNITALE/INFECTION RUBÉOLEUSE CONGÉNITALE }\end{array}$} \\
\hline RÉSERVÉ À L'USAGE DE L'ASPC : DATE de réc. & DATE de déc. \\
\hline
\end{tabular}




\section{ANNEXE E. FORMULAIRE D'ANALYSE D'ÉCHANTILLON DE CAS DE ROUGEOLE}

\section{Formulaire d'investigation de cas associés à une éclosion de rougeole}

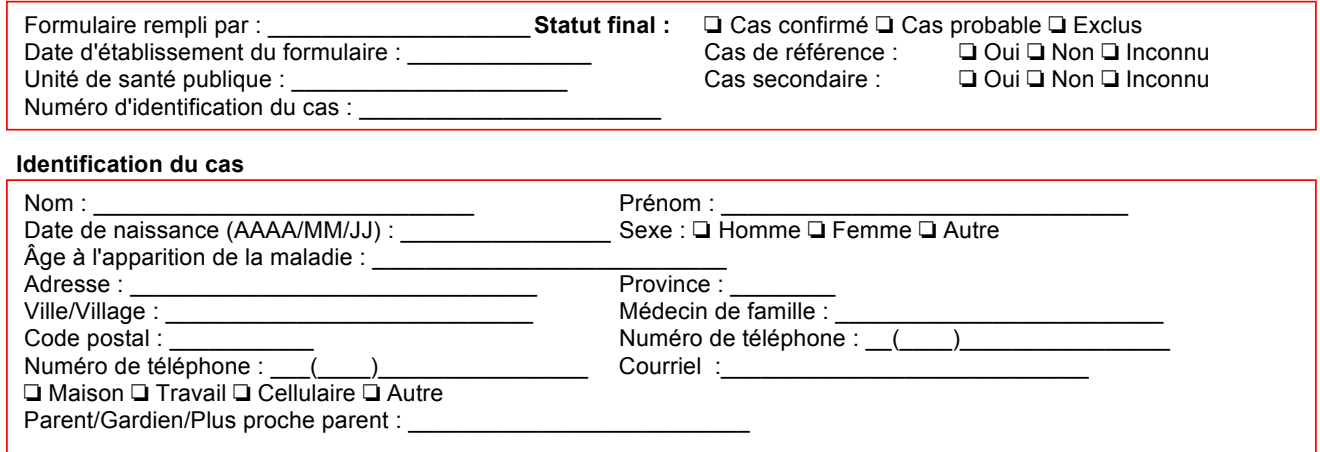

\section{Données cliniques}

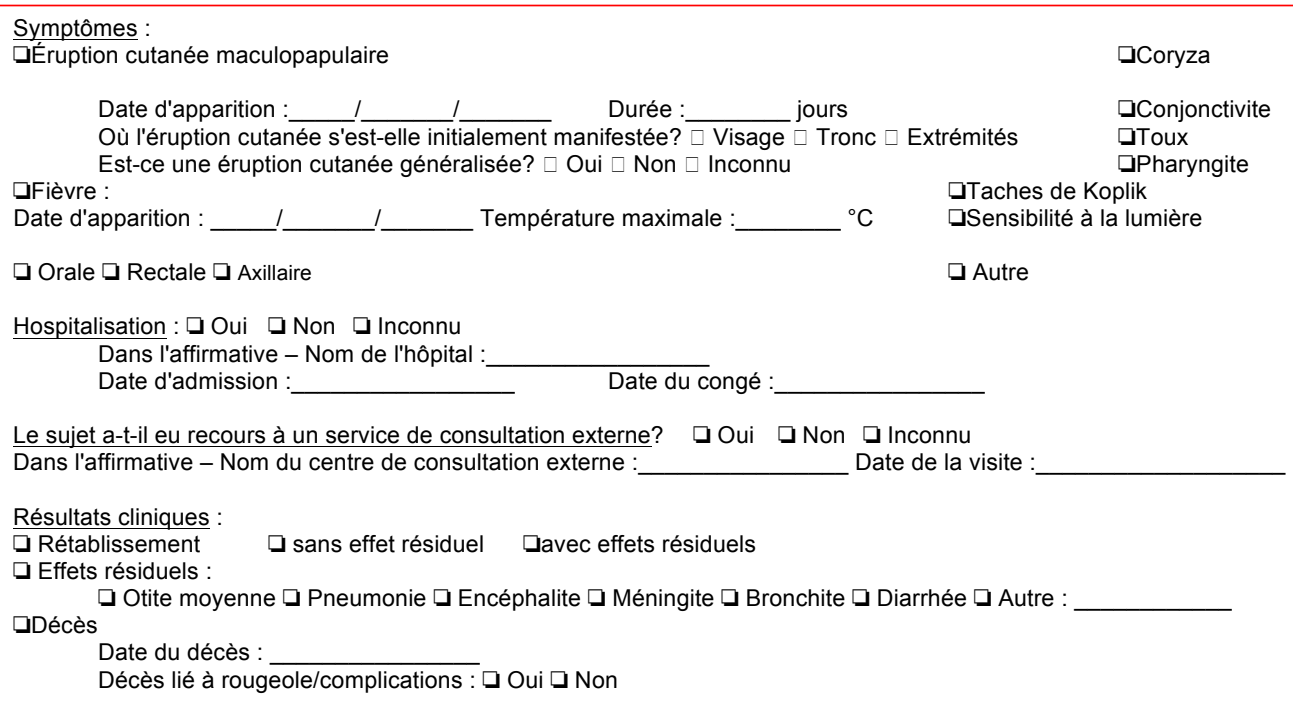

Calcul de la période d'incubation et de la période de contagion

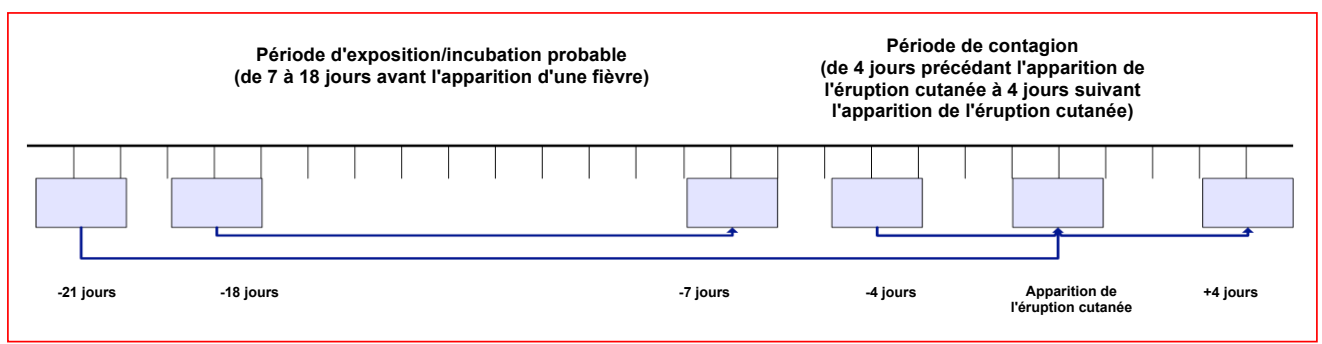


Antécédents d'immunisation

Antécédents de rougeole : $\square$ Oui $\square$ Non $\square$ Inconnu

Le patient a-t-il déjà reçu un vaccin contenant le virus de la rougeole? $\quad \square$ Oui $\quad \square$ Non $\square$ Inconnu Si aucune immunisation n'a eu lieu, indiquer la raison :

\begin{tabular}{||l|l|l|l|l|}
\hline Nom du vaccin & $\begin{array}{l}\text { Date } \\
\text { d'administration } \\
\text { (AAAA/MM/JJ) }\end{array}$ & $\begin{array}{l}\text { Âge } \\
\text { (années) }\end{array}$ & $\begin{array}{l}\text { Province/Territoire } \\
\text { ou pays }\end{array}$ & $\begin{array}{l}\text { Numéro de lot } \\
\text { (si connu) }\end{array}$ \\
\hline 1. & & & & \\
\hline 2. & & & & \\
\hline 3. & & & & \\
\hline
\end{tabular}

Renseignements liés au laboratoire

\begin{tabular}{|c|c|c|c|c|}
\hline & Échantillon 1 & Échantillon 2 & Échantillon 3 & Échantillon 4 \\
\hline $\begin{array}{l}\text { Type } \\
\text { d'échantillon }\end{array}$ & $\begin{array}{l}\square \text { Écouvillonnage du } \\
\text { nasopharynx/Aspirat } \\
\text { rhinopharyngé } \\
\square \text { Écouvillonnage de la } \\
\text { gorge } \\
\square \text { Échantillon de sérum } \\
\square \text { Échantillon d'urine } \\
\square \text { Autre: }\end{array}$ & $\begin{array}{l}\square \text { Écouvillonnage du } \\
\text { nasopharynx/Aspirat } \\
\text { rhinopharyngé } \\
\square \text { Écouvillonnage de la } \\
\text { gorge } \\
\square \text { Échantillon de sérum } \\
\square \text { Échantillon d'urine } \\
\square \text { Autre: }\end{array}$ & $\begin{array}{l}\square \text { Écouvillonnage du } \\
\text { nasopharynx/Aspirat } \\
\text { rhinopharyngé } \\
\square \text { Écouvillonnage de } \\
\text { la gorge } \\
\square \text { Échantillon de } \\
\text { sérum } \\
\square \text { Échantillon d'urine } \\
\square \text { Autre : }\end{array}$ & $\begin{array}{l}\square \text { Écouvillonnage du } \\
\text { nasopharynx/Aspirat } \\
\text { rhinopharyngé } \\
\square \text { Écouvillonnage de } \\
\text { la gorge } \\
\square \text { Échantillon de } \\
\text { sérum } \\
\square \text { Échantillon d'urine } \\
\square \text { Autre: }\end{array}$ \\
\hline \multicolumn{5}{|l|}{$\begin{array}{l}\mathrm{N}^{\circ} \\
\mathrm{d}^{\prime} \text { 'identification }\end{array}$} \\
\hline $\begin{array}{l}\text { Date de } \\
\text { prélèvement }\end{array}$ & Jour/Mois/Année & Jour/Mois/Année & Jour/Mois/Année & Jour/Mois/Année \\
\hline \multicolumn{5}{|l|}{ Date d'envoi } \\
\hline \multicolumn{5}{|c|}{ POUR UTILISATION EN LABORATOIRE } \\
\hline Date de réception & Jour/Mois/Année & Jour/Mois/Année & Jour/Mois/Année & Jour/Mois/Année \\
\hline \multicolumn{5}{|l|}{$\begin{array}{l}\mathbf{N}^{\circ} \\
\text { d'identification } \\
\text { en laboratoire }\end{array}$} \\
\hline Type de test & $\begin{array}{l}\square \text { Épreuve } \\
\text { immunoenzymatique - } \\
\text { lgM } \\
\square \text { Épreuve } \\
\text { immunoenzymatique } \\
\text { indirecte - IgM } \\
\square \text { Épreuve } \\
\text { immunoenzymatique - } \\
\text { lgG } \\
\square \text { Isolement du virus } \\
\square \text { Réaction en chaîne de } \\
\text { la polymérase } \\
\square \text { Autre test }\end{array}$ & $\begin{array}{l}\square \text { Épreuve } \\
\text { immunoenzymatique - } \\
\text { lgM } \\
\square \text { Épreuve } \\
\text { immunoenzymatique } \\
\text { indirecte - IgM } \\
\square \text { Épreuve } \\
\text { immunoenzymatique - } \\
\text { lgG } \\
\square \text { Isolement du virus } \\
\square \text { Réaction en chaîne } \\
\text { de la polymérase } \\
\square \text { Autre test }\end{array}$ & $\begin{array}{l}\square \text { Épreuve } \\
\text { immunoenzymatique } \\
\text { - IgM } \\
\square \text { Épreuve } \\
\text { immunoenzymatique } \\
\text { indirecte - IgM } \\
\square \text { Épreuve } \\
\text { immunoenzymatique } \\
\text { - IgG } \\
\square \text { Isolement du virus } \\
\square \text { Réaction en } \\
\text { chaîne de la } \\
\text { polymérase } \\
\square \text { Autre test }\end{array}$ & $\begin{array}{l}\square \text { Épreuve } \\
\text { immunoenzymatique } \\
\text { - IgM } \\
\square \text { Épreuve } \\
\text { immunoenzymatique } \\
\text { indirecte - IgM } \\
\square \text { Épreuve } \\
\text { immunoenzymatique } \\
\text { - IgG } \\
\square \text { Isolement du virus } \\
\square \text { Réaction en } \\
\text { chaîne de la } \\
\text { polymérase } \\
\square \text { Autre test }\end{array}$ \\
\hline Résultats & $\begin{array}{l}\square \text { Positif } \\
\square \text { Négatif } \\
\square \text { Indéterminé } \\
\square \text { Échantillon inadéquat } \\
\square \text { Non traité }\end{array}$ & $\begin{array}{l}\square \text { Positif } \\
\square \text { Négatif } \\
\square \text { Indéterminé } \\
\square \text { Échantillon inadéquat } \\
\square \text { Non traité }\end{array}$ & $\begin{array}{l}\square \text { Positif } \\
\square \text { Négatif } \\
\square \text { Indéterminé } \\
\square \text { Échantillon } \\
\text { inadéquat } \\
\square \text { Non traité }\end{array}$ & $\begin{array}{l}\square \text { Positif } \\
\square \text { Négatif } \\
\square \text { Indéterminé } \\
\square \text { Échantillon } \\
\text { inadéquat } \\
\square \text { Non traité }\end{array}$ \\
\hline $\begin{array}{l}\text { Dates des } \\
\text { résultats }\end{array}$ & Jour/Mois/Année & Jour/Mois/Année & Jour/Mois/Année & Jour/Mois/Année \\
\hline Commentaire & & & & \\
\hline
\end{tabular}


Renseignements sur l'exposition :

Êtes-vous entré en contact avec une personne chez qui on a diagnostiqué un cas de rougeole? $\quad \square$ Oui $\square$ Non Dans l'affirmative, indiquer le nom de cette personne

Activités sociales lors des 7 jours précédant l'apparition de symptômes chez le sujet

\begin{tabular}{|c|c|c|}
\hline Activités sociales lors des 7 derniers jours & $\begin{array}{c}\text { Date }(s) \\
\text { (AAAA/MM/JJ) }\end{array}$ & Détails sur les activités \\
\hline \multicolumn{3}{|l|}{$\square$ A utilisé le transport en commun } \\
\hline \multicolumn{3}{|l|}{$\begin{array}{l}\square \text { A visité un hôpital ou a fait du bénévolat dans un } \\
\text { hôpital }\end{array}$} \\
\hline \multicolumn{3}{|l|}{$\square$ A assisté à une activité ecclésiale/religieuse } \\
\hline \multicolumn{3}{|l|}{$\mathrm{A}$ assisté à une réunion de famille } \\
\hline \multicolumn{3}{|l|}{$\square$ A assisté à une réunion ou à une téléconférence } \\
\hline \multicolumn{3}{|l|}{$\begin{array}{l}\text { A assisté à un concert, à une pièce de théâtre ou à } \\
\text { un événement sportif }\end{array}$} \\
\hline \multicolumn{3}{|l|}{$\square$ S'est adonné à une séance de magasinage } \\
\hline \multicolumn{3}{|l|}{$\square$ A participé à une activité récréative } \\
\hline \multicolumn{3}{|l|}{$\begin{array}{l}\square \text { A mangé dans un café-restaurant, une cafétéria ou } \\
\text { une aire de restauration }\end{array}$} \\
\hline \multicolumn{3}{|l|}{$\square$ A mangé dans un restaurant } \\
\hline \multicolumn{3}{|l|}{$\square$ A fréquenté un bar ou une boîte de nuit } \\
\hline \multicolumn{3}{|l|}{$\square$ Autres activités } \\
\hline Voyages lors des 7 derniers jours & $\begin{array}{c}\text { Date }(s) \\
\text { (AAAA/MM/JJ) }\end{array}$ & Lieu \\
\hline \multicolumn{3}{|l|}{$\square$ À l'intérieur du pays } \\
\hline$\square \AA \grave{~ l ' e ́ t r a n g e r ~}$ & & \\
\hline
\end{tabular}

Renseignements sur la profession

Profession :

Nom de l'employeur :

Garderie/École/Établissement d'enseignement

Fréquentez-vous une garderie, une école ou un établissement d'enseignement postsecondaire? $\square$ Oui $\square$ Non

$\mathrm{Si}$ la réponse est $\mathrm{OUI}-\mathrm{Nom}$ de l'école/établissement :

Horaire (joindre en pièce jointe, le cas échéant) :

Année scolaire/Niveau/Année d'étude :

Conditions de logement

Dans quel type de résidence habitez-vous?

$\square$ Maison $\square$ Appartement $\square$ Résidence universitaire $\square$ Hôtel/Motel $\square$ Foyer de groupe ou établissement de soins de longue durée $\square$ Autre (préciser) :

Partagez-vous un logement ou une chambre avec quelqu'un? $\square$ Oui $\square$ Non

Si la réponse est OUI - Avec combien de personnes?

Recevez-vous des soins à domicile? $\quad$ Oui $\square$ Non

Renseignements sur les contacts étroits

Veuillez indiquer ci-dessous tous les contacts étroits, y compris votre conjoint ou votre conjointe, votre partenaire, vos frères ou sœurs, vos enfants, les membres de votre famille, vos colocataires et toute autre personne avec qui vous habitez. 


\begin{tabular}{|c|c|l|l|l|l|}
\hline $\begin{array}{c}\text { Nom du contact } \\
\text { (Prénom, Nom) }\end{array}$ & $\begin{array}{c}\text { Numéro de } \\
\text { téléphone du } \\
\text { contact }\end{array}$ & Relation & $\begin{array}{c}\text { État vaccinal } \\
\text { Date de } \\
\text { naissance } \\
\text { (AAAA/MM/JJ) } \\
\text { ou } \\
\text { âge } \\
\text { Vacciné -1 } \\
\text { dose (1) } \\
\text { Vacciné -2 } \\
\text { doses (2) } \\
\text { Antécédents } \\
\text { de rougeole (8) }\end{array}$ & Profession \\
\hline & & & & & \\
\hline & & & & & \\
\hline
\end{tabular}

Commentaires/Notes :

\section{Classification}

Cas de rougeole confirmé en laboratoire

Cas probable de rougeole

Exclus

$\square$

Base de la classification : $\square$ Analyses de laboratoire $\square$ Lien épidémiologique

Responsable de l'investigation : 


\section{ANNEXE F.}

\section{RECOMMANDATIONS POUR LA PRISE EN CHARGE DES CAS DE ROUGEOLE DANS LES MILIEUX DE SOINS}

Un milieu de soins est un établissement ou un lieu où des soins de santé sont dispensés, notamment les soins d'urgence, les soins préhospitaliers, les soins de courte durée, les soins de longue durée, les soins aux malades chroniques, les soins complexes, les soins à domicile et les soins ambulatoires, ainsi qu'un établissement ou un lieu communautaire où des soins sont dispensés (p. ex. les infirmeries scolaires, les établissements résidentiels ou correctionnels). Certains milieux de soins n'ont pas de service la santé au travail ni de service de prévention et de contrôle des infections. Lorsqu'ils sont mentionnés, ils se rapportent aux personnes responsables de la santé au travail et de la prévention et du contrôle des infections du milieu de soins en question.

Les travailleurs de la santé sont les personnes qui dispensent des soins de santé ou des services de soutien, comme les infirmières, les médecins, les dentistes, les infirmières praticiennes, les ambulanciers paramédicaux et, parfois, les premiers intervenants, les professionnels paramédicaux, les fournisseurs de soins de santé non réglementés, les enseignants cliniques et les étudiants, les bénévoles et le personnel d'entretien.

Le terme "patient » peut s'entendre des patients hospitalisés, des patients externes, des résidents d'établissements de soins de longue durée, etc., ainsi que des patients qui reçoivent des soins à la maison ou dans un établissement communautaire.

\section{ÉVALUATION DES TRAVAILLEURS DE LA SANTÉ AVANT L'EMPLOI}

1. Le service de la santé au travail devrait consigner I'état immunitaire du travailleur de la santé selon I'examen avant l'emploi. Un travailleur de la santé devrait être considéré comme immunisé s'il :

a) dispose des documents attestant l'administration de deux doses du vaccin contenant le virus de la rougeole; ou b) dispose des documents attestant des antécédents de rougeole confi més en laboratoire; ou

c) obtient un résultat positif au test de détection d'anticorps lgG antirougeoleux (se reporter à la section 6 et à l'Annexe $\mathrm{H}$ pour l'interprétation des résultats sur les lgG).

\section{TRAVAILLEUR DE LA SANTÉ EN POSTE}

1. Le service de la santé au travail devrait administrer le vaccin $\mathrm{RRO}$ à tous les travailleurs de la santé, à moins que le travailleur de la santé :

a) dispose des documents attestant l'administration de deux doses du vaccin contenant le virus de la rougeole; ou

b) dispose des documents attestant des antécédents de rougeole confi més en laboratoire; ou

c) obtient un résultat positif au test de détection d'IgG antirougeoleux; ou

d) présente une contre-indication valide au vaccin RRO.

\section{MESURES DE PRÉVENTION ET DE CONTRÔLE DE L'INFECTION À L'ÉGARD DES CAS SUSPECTS OU CONFIRMÉS}

1. Les milieux de soins devraient être avisés lorsque des cas de rougeole sont présents dans la collectivité et informés des cas reconnus sur le plan clinique et diagnostiqués en laboratoire.

2. Les services d'urgence et les milieux de soins ambulatoires devraient être avisés de procéder au triage des cas suspects le plus rapidement possible et de les transférer dans une CIITA pour éviter I'exposition des autres personnes qui se trouvent dans les salles d'attente. 
3. Les cliniques de consultation externe et les organismes de soins à domicile devraient être dotés d'un système d'identification des cas suspects ou confi més de rougeole.

4. Les rendez-vous pris pour des cas suspects ou confi més de rougeole devraient être reportés, à moins que les cas puissent être placés dans une chambre $d^{\prime}$ 'isolement pour infections à transmission aérienne.

\section{TRAVAILLEURS DE LA SANTÉ ÉTANT DES CAS SUSPECTS OU CONFIRMÉS DE ROUGEOLE}

1. Les travailleurs de la santé étant des cas suspects de rougeole devraient être pris en charge comme des cas de rougeole confi més jusqu'à ce qu'une preuve d'immunité soit fournie par un laboratoire.

2. Les cas devraient être avisés d'informer immédiatement le service de santé au travail ou le service de prévention et de contrôle des infections de leur milieu de soins.

3. L'information sur la rougeole et ses symptômes devrait être fournie aux travailleurs de la santé.

4. Les cas devraient être avisés de rester à la maison pendant au moins quatre jours après l'apparition de l'éruption cutanée.

5. Les cas devraient être avisés d'informer le service de santé au travail ou le service de prévention et de contrôle des infections de leur milieu de soins pour déterminer si leur état de santé leur permet de retourner au travail.

6. Les cas devraient être signalés aux autorités de santé publique de la région, conformément à la politique de l'organisme.

\section{TRAVAILLEURS DE LA SANTÉ ÉTANT DES CONTACTS (AYANT ÉTÉ EXPOSÉS AU VIRUS DE LA ROUGEOLE)}

Les mesures suivantes s'appliquent aux cas de contacts dans la collectivité (se reporter à la section 4.2) et des contacts dans les milieux de soins (les contacts sont les personnes ayant passé jusqu'à deux heures dans une pièce ou un espace clos dans lequel un cas en période infectieuse était présent) :

1. Les travailleurs de la santé devraient être avisés d'informer immédiatement le service de santé au travail ou le service de prévention et de contrôle des infections de leur milieu de soins.
2. L'information sur les contacts ayant été exposés à la rougeole devrait être fournie aux travailleurs de la santé.

3. L'information sur la rougeole et ses symptômes devrait être fournie aux travailleurs de la santé.

4. Les antécédents de déficience immunitai e et le stade de grossesse des travailleuses de la santé devraient être évalués (se reporter à la section 7.c ci-dessous).

5. L'immunité contre la rougeole des travailleurs de la santé devrait être évaluée si elle n'a pas été évaluée avant l'emploi. Le travailleur de la santé est immunisé s'il :

a) dispose des documents attestant l'administration de deux doses du vaccin contenant le virus de la rougeole; ou

b) dispose des documents attestant des antécédents de rougeole confi més en laboratoire; ou

c) obtient un résultat positif au test de détection d'lgG antirougeoleux; ou

6. Le travail devrait être interdit aux contacts à risque à compter du cinquième jour, et ce, jusqu'au $21^{\mathrm{e}}$ jour suivant la dernière exposition, même s'ils ont reçu le vaccin ou les immunoglobulines contre la rougeole après leur exposition.

7. Les travailleurs de la santé qui ont été exposés et qui ne disposent pas des documents attestant leur immunité avant l'emploi devraient être pris en charge de la façon suivante:

a) faire un prélèvement sanguin pour test sérologique pour la détection d'lgG antirougeoleux;

b) administrer une dose du vaccin RRO (immédiatement après le prélèvement de l'échantillon), à moins d'une contre-indication à l'immunisation;

c) envisager l'administration d'immunoglobulines dans les six jours suivant l'exposition des travailleuses de la santé séronégatives enceintes ou gravement immunovulnérables(29);

d) interdire le travail aux travailleurs de la santé pendant la période de transmissibilité à compter du cinquième jour suivant la dernière exposition, et ce, jusqu'au $21^{e}$ jour suivant la dernière exposition, à moins qu'un test sérologique n'indique leur immunité à la rougeole; et 
e) en se reportant à la section 6 et à l'Annexe $\mathrm{H}$ pour I'interprétation des résultats liés aux lgG :

(i) si le résultat du test de détection d'lgG est positif, considérer le travailleur de la santé comme immunisé et apte à retourner au travail;

(ii) si le résultat du test de détection d'lgG est négatif, considérer le travailleur de la santé comme étant à risque lui administrer une deuxième dose du vaccin RRO 28 jours après la première dose et lui interdire le travail à compter du cinquième jour, et ce, jusqu'au $21^{e}$ jour suivant la dernière exposition.

\section{PATIENTS ÉTANT DES CAS SUSPECTS OU CONFIRMÉS DE ROUGEOLE}

1. Les patients étant des cas suspects de rougeole devraient être pris en charge comme des cas de rougeole confi més jusqu'à ce qu'une preuve d'immunité soit fournie par un laboratoire.

2. Les patients devraient être immédiatement isolés dans une CIITA.

3. Si aucune CIITA n'est disponible (p. ex. dans les milieux de soins de longue durée), les patients devraient être placés dans une chambre individuelle, loin des patients à risque, jusqu'à leur transfert dans un milieu doté d'une CIITA.

4. Seuls les travailleurs de la santé immunisés peuvent entrer dans la chambre d'un patient d'un patient à risque en phase contagieuse. Lorsqu'un travailleur de la santé non immunisé ne peut éviter d'entrer dans la chambre, il devrait porter un appareil de protection respiratoire.

5. Les rendez-vous pris pour des cas suspects ou confi més de rougeole devraient être reportés, à moins que les cas puissent être placés dans une CIITA.

6. Les patients de soins à domicile qui sont des cas suspects ou confi més de rougeole ne devraient être soignés que par des travailleurs de la santé immunisés contre la rougeole.

7. Le service de prévention et de contrôle des infections ou le travailleur de la santé devrait remettre I'information sur la rougeole et ses symptômes aux patients et à leur famille.
8. Les patients hospitalisés devraient rester dans une CIITA pendant au moins quatre jours après l'apparition de l'éruption cutanée. Les patients immunovulnérables atteints de la rougeole devraient rester dans la CIITA tant qu'ils présentent des symptômes de la rougeole.

9. Les cas devraient être signalés aux autorités de santé publique de la région, conformément à la politique de l'organisme.

\section{PATIENTS ÉTANT DES CONTACTS (EXPOSÉS AU VIRUS DE LA ROUGEOLE)}

Les mesures suivantes s'appliquent aux cas de contacts dans la collectivité (se reporter à la section 4.2) et des contacts dans les milieux de soins (les contacts sont les personnes ayant passé jusqu'à deux heures dans une pièce ou un espace clos dans lequel un cas en période infectieuse était présent) :

1. Le milieu de soins devrait informer le service de prévention et de contrôle des infections du cas de contact possible à la rougeole.

2. Le service de prévention et de contrôle des infections devrait remettre l'information sur la rougeole et ses symptômes à la personne et aux travailleurs de la santé.

3. Le service de prévention et de contrôle des infections devrait évaluer les antécédents de déficience immunitaire et le stade de grossesse des travailleuses de la santé (se reporter à la section 6.c ci-dessous).

4. Le service de prévention et de contrôle des infections devrait évaluer l'immunité à la rougeole des patients exposés. Considérer l'immunisation du patient comme établie si le patient :

a) dispose des documents attestant l'administration de deux doses du vaccin contenant le virus de la rougeole; ou

b) dispose des documents attestant des antécédents de rougeole confi més en laboratoire; ou

c) obtient un résultat positif au test de détection d'anticorps lgG antirougeoleux (se reporter à la section 6 et à l'Annexe $G$ pour l'interprétation des résultats sur les lgG). 
5. Les patients à risque étant des contacts devraient être isolés dans le milieu de soins à compter du cinquième jour, et ce, jusqu'au $21^{\mathrm{e}}$ jour suivant la dernière exposition, même s'ils ont reçu le vaccin ou les immunoglobulines contre la rougeole après leur exposition.

6. Les patients qui ont été exposés et qui ne disposent pas des documents attestant leur immunité à la rougeole devraient être pris en charge de la façon suivante :

a) faire un prélèvement sanguin pour test sérologique pour la détection d'lgG antirougeoleux;

b) administrer une dose du vaccin RRO (immédiatement après le prélèvement de l'échantillon), à moins d'une contre-indication à l'immunisation;

c) envisager l'administration d'immunoglobulines dans les six jours suivant l'exposition des patientes séronégatives enceintes ou gravement immunovulnérables;

d) isoler les patients exposés pendant la période de transmissibilité à compter du cinquième jour suivant la dernière exposition, et ce, jusqu'au $21^{e}$ jour suivant la dernière exposition, à moins qu'un test sérologique n'indique leur immunité à la rougeole; et

e) en se reportant à la section 6 et à l'Annexe $\mathrm{H}$ pour I'interprétation des résultats liés aux lgG :

i) Si le résultat du test de détection d'lgG est positif, considérer le patient comme immunisé et qu'il est inutile de l'isoler.

ii) Si le résultat du test de détection d'IgG est négatif, considérer le patient comme étant à risque, lui administrer une deuxième dose du vaccin RRO 28 jours après la première dose et l'isoler dans une CIITA à compter du cinquième jour, et ce, jusqu'au $21^{e}$ jour suivant la dernière exposition.

\section{PATIENTS EXTERNES OU PATIENTS ÉTANT DES CONTACTS AYANT REÇU LEUR CONGÉ (EXPOSÉS AU VIRUS DE LA ROUGEOLE)}

1. Le service de prévention et de contrôle des infections devrait informer les autorités de santé publique de la région des patients externes ou ayant reçu leur congé qui sont des contacts. 


\section{ANNEXE G. ALGORITHMES POUR MILIEUX DE SOINS}

Algorithme A. Évaluation de la réceptivité des travailleurs de la santé au virus de la rougeole

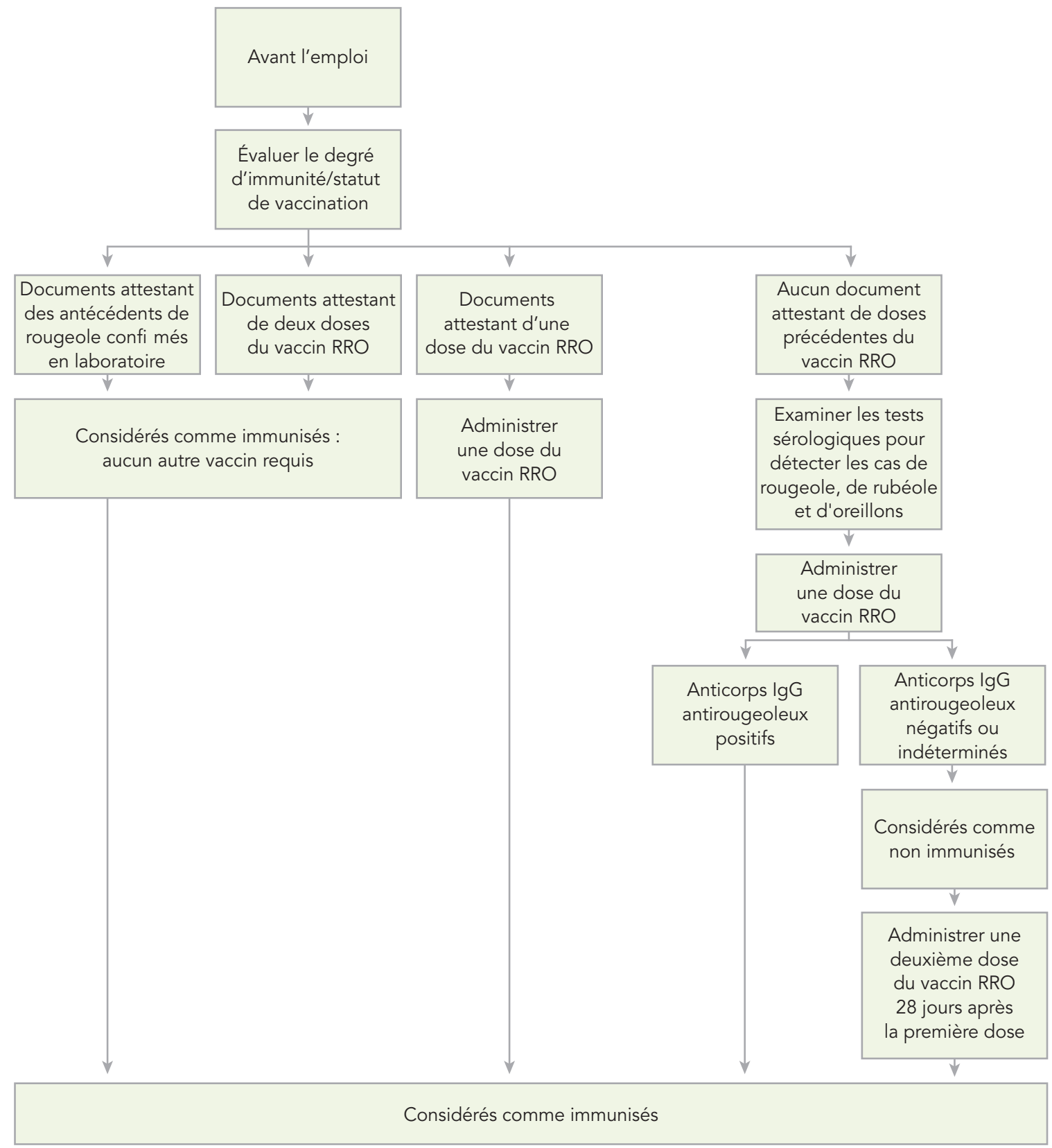


Algorithme B. Prise en charge des travailleurs de la santé ayant été en contact direct avec un cas de rougeole

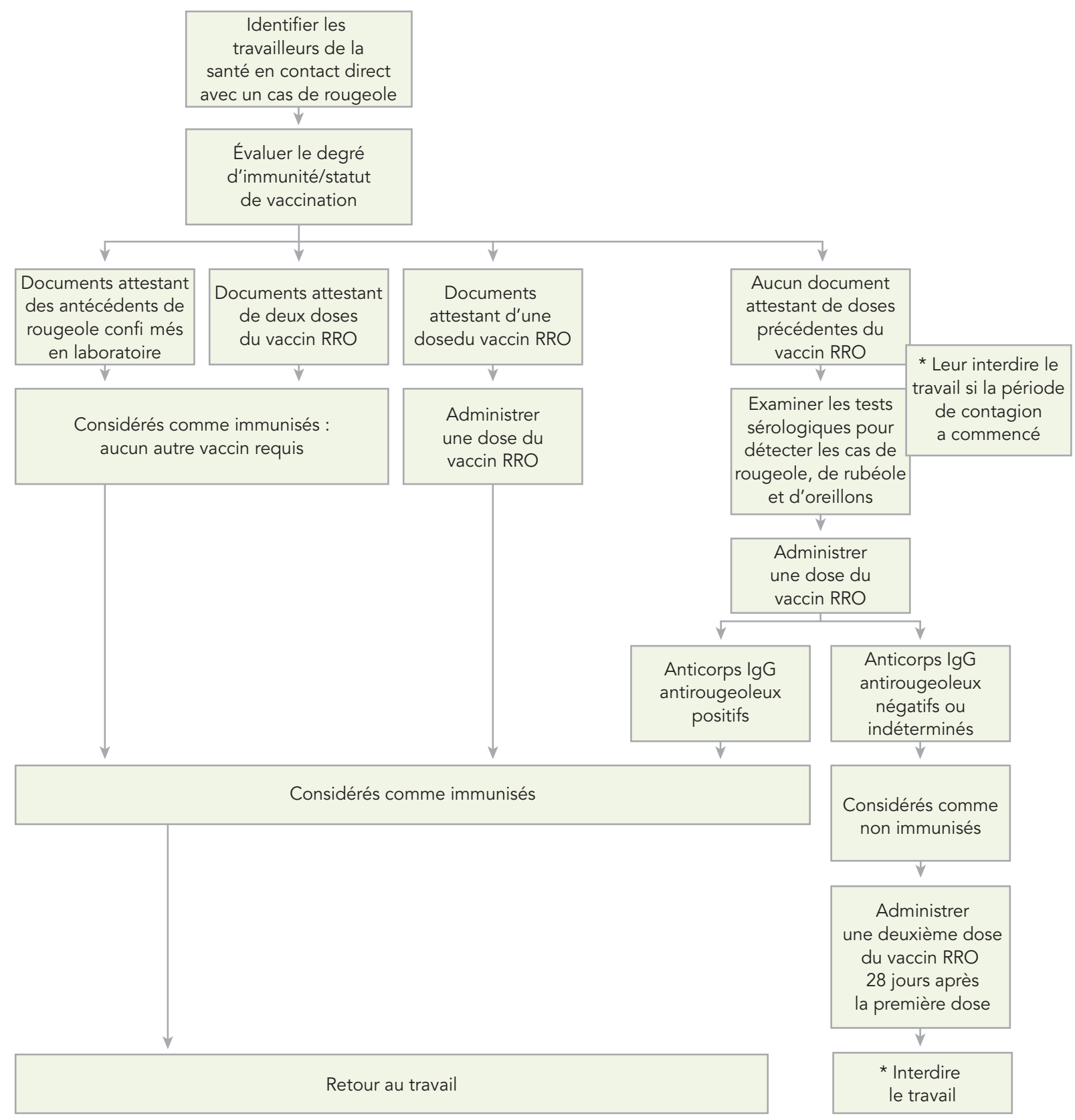

* Le retour au travail doit être interdit aux contacts à compter du $5^{e}$ jour, et ce, jusqu'au $21^{e}$ jour suivant l'exposition. 
Algorithme C. Prise en charge des patients ayant été en contact direct avec un cas de rougeole

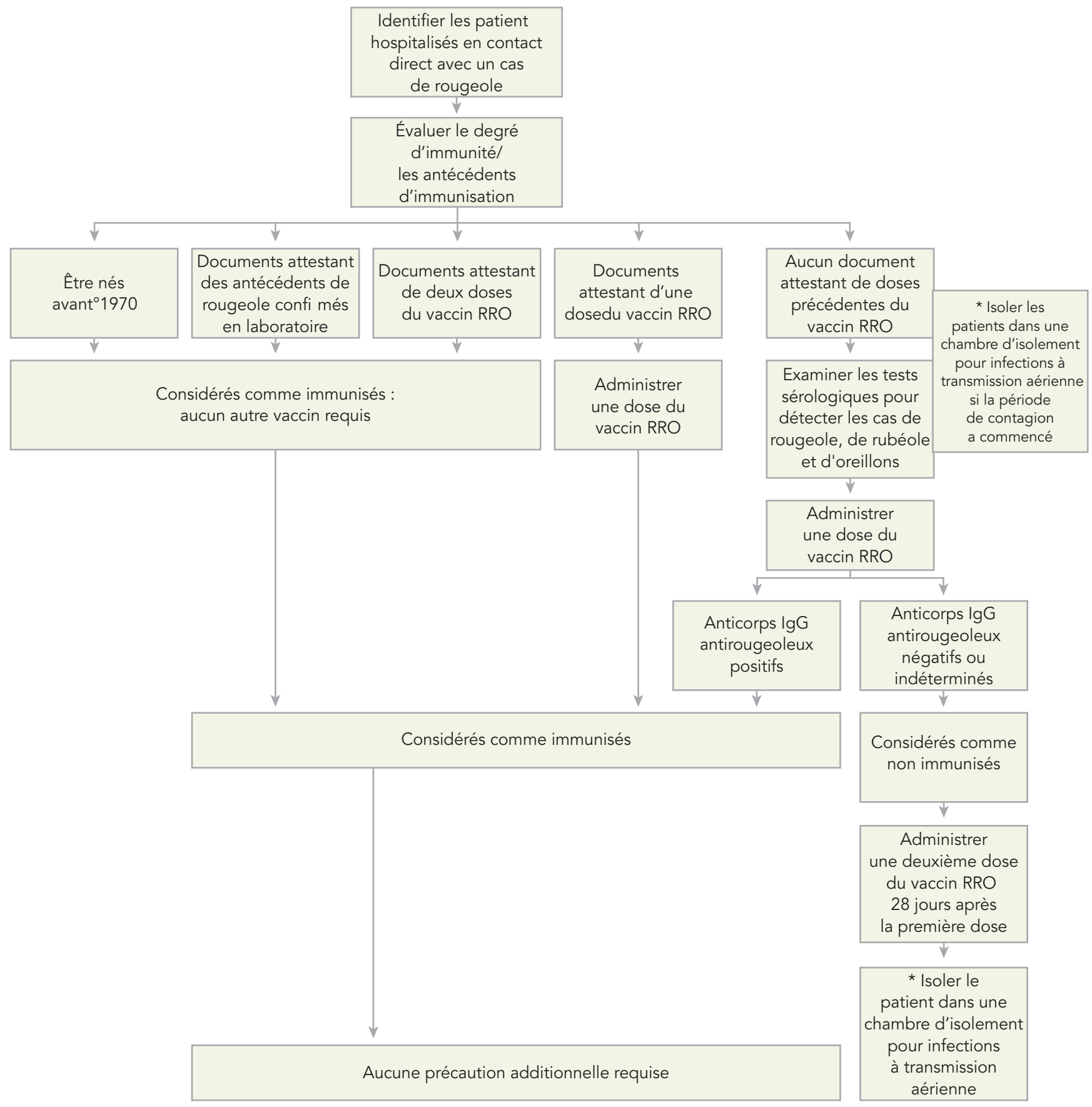

* Les patients ayant des contacts doivent être isolés à compter du $5^{e}$ jour, et ce, jusqu'au 21 jour suivant l'exposition 


\section{ANNEXE H. LIGNES DIRECTRICES POUR LE DIAGNOSTIC DE LA ROUGEOLE EN LABORATOIRE}

\subsection{INTRODUCTION}

L'objectif des présentes directrices qui s'appliquent aux tests en laboratoires est de fournir l'information sur la collecte, le transport, l'analyse en laboratoire et l'interprétation des résultats des tests effectués en laboratoire sur les échantillons prélevés pour des cas de rougeole suspects. Une description complète des diagnostics de la rougeole est fournie dans le Manual of Clinical Microbiology (34), et les détails techniques figurent dans le (35). L'information présentée est fondée sur l'expérience récente en matière de diagnostic de la rougeole au Canada et partout dans le monde ainsi que sur les lignes directrices de l'Organisation mondiale de la Santé qui s'appliquent aux tests en laboratoire(33).

\subsection{RÉSUMÉ}

La technique de l'amplification par la polymérase après transcription inverse (RT-PCR) est le test le plus fiable pour confirmer le diagnostic d'une infection par le virus de la rougeole, mais sa sensibilité peut être influencée par les facteurs suivants :

- moment du prélèvement de l'échantillon par rapport à l'apparition des symptômes;

- intégrité de l'échantillon et conditions de conservation;

- antécédents d'immunisation.

Les échantillons de sécrétions nasopharyngiennes et les échantillons de la gorge prélevés dans les quatre premiers jours suivant l'apparition de l'éruption cutanée sont les échantillons de choix pour la détection du virus par technique de transcription inverse suivie d'une réaction en chaîne de la polymérase.

Les échantillons d'urine prélevés dans les sept premiers jours suivant l'apparition de l'éruption cutanée sont également appropriés pour la détection du virus par technique de transcription inverse suivie d'une réaction en chaîne de la polymérase.
Le test de détection sérologique d'un échantillon de sérum prélevé pendant la phase aiguë pour trouver la présence d'anticorps IgM propres à la rougeole convient au diagnostic de la rougeole, mais pas dans les cas sporadiques n'ayant pas voyagé ou sans lien épidémiologique avec un cas confirmé de rougeole dont le résultat pourrait être un faux résultat positif. De faux résultats négatifs pourraient également être obtenus, selon le moment du prélèvement de l'échantillon. Les cas de rougeole chez les patients qui ont déjà été vaccinés peuvent ne pas être accompagnés d'une élaboration $d^{\prime}$ 'anticorps IgM étant donné que les infections ne sont pas principalement causées par une exposition à la rougeole.

Le résultat d'un échantillon de sérum prélevé pendant la phase aiguë et d'un échantillon de sérum prélevé pendant la phase de convalescence de 10 à 30 jours plus tard peut indiquer une séroconversion des anticorps IgM ou lgG chez les cas pour lesquels les résultats de la RT-PCR et du test de détection d'lgM sont négatifs ou indéterminés au début de la maladie, ce qui permet de détecter des cas additionnels.

Le résultat du test sérologique chez les personnes qui ont déjà été vaccinées (échec de l'immunisation secondaire) ne s'inscrira probablement pas dans le paradigme associé à la présence d'une infection aiguë chez les personnes qui n'ont pas été immunisées. La réponse des anticorps IgM antirougeoleux peut être faible ou indétectable, et une augmentation rapide du titre d'anticorps IgG antirougeoleux devrait entraîner des résultats fortement positifs au test de détection d'lgG antirougeoleux dans le sérum prélevé en phase aiguë et l'absence probable d'un titre d'anticorps lgG quatre fois plus élevé dans le sérum prélevé en phase de convalescence $(36,37)$.

Un résultat négatif de la RT-PCR pourrait ne pas suffire à écarter la possibilité d'une infection par le virus de la rougeole. Un seul résultat de détection d'IgM, négatif ou positif, pourrait ne pas suffire pour confirmer ou invalider un diagnostic de la rougeole, particulièrement dans les cas sporadiques. Par conséquent, il est important d'évaluer les 
résultats de la RT-PCR et de la séroconversion des résultats $d^{\prime} \operatorname{lgM}$ et d'lgG dans le contexte des données cliniques et épidémiologiques. L'OPS recommande de classer les cas par un comité d'analyse des cas après l'examen des résultats laboratoire et la confirmation d'une éclosion(43) (recommandation disponible à l'adresse www.paho.org/ French/AD/FCH/IM/SNF3102.pdf).

\subsection{PRÉLÈVEMENT D'ÉCHANTILLON}

\subsection{DÉTECTION (PAR TECHNIQUE DE L'AMPLIFICATION PAR LA POLYMÉRASE APRĖS TRANSCRIPTION INVERSE) OU ISOLEMENT (CULTURE) DU VIRUS}

Les échantillons de sécrétions nasopharyngiennes et les échantillons de la gorge devraient être prélevés au moyen d'un écouvillon approuvé pour l'isolement du virus. Les écouvillons devraient être placés dans un milieu de transport viral (MTV). Les écouvillons doivent être conservés dans une petite quantité (de 1 ou $2 \mathrm{ml}$ ) d'un MTV pendant au moins une heure pour permettre l'élution du virus. Les écouvillons peuvent avoir un bout en dacron, en nylon ou en rayonne et être soit floqués ou non floqués. Les écouvillons en alginate de calcium ne sont pas acceptables, car ils inhibent les réactions en chaîne de la polymérase. Les écouvillons avec charbon de bois ou milieu d'Ames qui sont utilisés pour la recherche de pathogènes bactériens tels que le streptocoque du groupe A ne sont pas acceptables. Les échantillons à tige d'aluminium ou de bois ne sont également pas acceptables.

Les échantillons devraient être prélevés le plus rapidement possible après l'apparition de l'éruption cutanée, c'est-àdire dans les cinq jours pour l'isolement du virus et dans les sept jours pour la technique de transcription inverse suivie d'une réaction en chaîne de la polymérase. La sensibilité décline dramatiquement après ce temps, particulièrement pour ce qui est de l'isolement du virus.

Les échantillons placés dans un MTV devraient être conservés à $4{ }^{\circ} \mathrm{C}$, puis expédiés au laboratoire sur de la glace, dans les 48 heures suivant leur prélèvement. Sinon, les échantillons élués peuvent être congelés indéfiniment à $-70^{\circ} \mathrm{C}$, et expédiés au laboratoire sur de la glace sèche afin de prévenir la décongélation, ce qui réduirait le titre du virus infectieux pour l'isolement et qui pourrait également réduire la sensibilité de la technique de transcription inverse suivie d'une réaction en chaîne de la polymérase.

Échantillons d'urine Le virus de la rougeole est détecté dans les cellules exfoliées de l'urine et peut être isolé ou détecté par RT-PCR avec une sensibilité élevée si l'urine est prélevée le plus rapidement possible, au plus tard le septième jour suivant l'apparition de l'éruption cutanée.

- La quantité idéale d'urine est de $50 \mathrm{ml}$ (minimum $10 \mathrm{ml}$ ) et devrait être prélevée dans un contenant stérile.

- Les échantillons devraient être conservés à $4{ }^{\circ} \mathrm{C}$.

- L'urine devrait être centrifugée à 2500 x g pendant 15 minutes à $4{ }^{\circ} \mathrm{C}$ le plus rapidement possible, c'est-àdire dans les 24 heures suivant son prélèvement, et le sédiment sera remis en suspension dans 1 à $2 \mathrm{~mL}$ d'un milieu de transport physiologique stérile, puis expédié au laboratoire sur de la glace. Sinon, le sédiment remis en suspension peut être congelé à $-70^{\circ} \mathrm{C}$ et expédié au laboratoire sur glace sèche afin de prévenir la décongélation, ce qui réduirait le titre du virus infectieux pour l'isolement et qui pourrait également réduire la sensibilité de la transcription inverse suivie d'une réaction en chaîne de la polymérase.

Échantillons de liquide buccal L'obtention du liquide buccal par le prélèvement de fluide gingival entre les gencives et les dents est une méthode de prélèvement non invasive et facile qui permet de détecter la présence d'anticorps IgM et du virus par transcription inverse suivie d'une réaction en chaîne de la polymérase. L'analyse du liquide buccal a été utilisée avec succès dans des milieux qui disposaient de peu de ressources, et certains pays qui disposent de ressources importantes commencent également à utiliser cette méthode. La sensibilité et la spécificité pour la détection d'anticorps IgM et du virus s'approchent de la sensibilité et de la spécificité des tests sérologiques et de la RT-PCR dans les milieux de recherche(44), mais la qualité des résultats varie sur le terrain. Actuellement, cette technique n'est pas recommandée pour le diagnostic systématique des cas de rougeole au Canada. 


\subsection{SÉROLOGIE}

Le premier échantillon de sérum (en phase aiguë) devrait être prélevé le plus tôt possible dès la manifestation des symptômes de la rougeole.

Pour mettre en évidence une séroconversion lgG, un deuxième échantillon de sérum (en phase de convalescence) devrait être prélevé de 10 à 30 jours après le premier échantillon.

Pour le test sérologique d'IgM, un échantillon prélevé trois jours avant l'apparition des symptômes et 28 jours après l'apparition des symptômes peut entraîner de faux résultats négatifs.

\subsection{CONSERVATION ET TRANSPORT DES ÉCHANTILLONS}

Les échantillons non traités peuvent être expédiés à une température de $4{ }^{\circ} \mathrm{C}$ de manière à pouvoir être reçus au laboratoire dans les 48 heures suivant leur prélèvement. Si les analyses subséquentes sont retardées, les échantillons traités peuvent être congelés à $-70^{\circ} \mathrm{C}$ et expédiés sur glace sèche. Si les analyses subséquentes sont retardées, les échantillons traités peuvent être congelés à $-70{ }^{\circ} \mathrm{C}$ et expédiés sur glace sèche. Idéalement, il faut conserver les échantillons de sérum pour la détection d'anticorps à $4{ }^{\circ} \mathrm{C}$ et éviter leur congélation et décongélation. L'expédition des échantillons devrait être assurée par une personne accréditée aux termes de la Réglementation sur le transport de marchandises dangereuses. Pour en savoir davantage sur la classification des échantillons aux fins d'expédition, veuillez-vous reporter à la Partie II et I'Annexe 3 du Règlement sur le transport de marchandises dangereuses ou à la section 3.6.2 de la Réglementation IATA pour le transport des marchandises dangereuses, selon le cas.

\subsection{SÉROLOGIE}

\subsection{IGM}

La présence d'anticorps IgM propres à la rougeole indique une infection primaire aiguë par le virus de la rougeole lorsqu'elle est accompagnée de symptômes cliniques de la rougeole et d'antécédents laissant supposer une exposition au virus de la rougeole. La confirmation des résultats d'IgM par la détection du virus de la rougeole au moyen de la RT-PCR est recommandée chaque fois que cela est possible, car un faux résultat pour les IgM suivants peut être obtenu :

\section{Résultats positifs pour les IgM, sans infection aiguë par le virus de la rougeole}

Un résultat pour les IgM positif chez un cas présentant une éruption cutanée sans antécédents de voyage dans une région endémique ni lien épidémiologique avec un cas suspect est fort probablement un faux résultat positif. Les nécessaires d'essai pour la détection d'IgM peuvent donner de faux résultats positifs d'anticorps IgM antirougeoleux chez les patients présentant un facteur rhumatoïde, d'autres infections aiguës accompagnées de titres élevés d'anticorps IgG antirougeoleux, et apparemment testés de façon aléatoire, pour des raisons inconnues.

Un résultat pour les IgM propres à la rougeole positif peut être obtenu chez les patients qui ont reçu le vaccin RRO jusqu'à six semaines avant le moment du test. Aucun test sérologique ne permet de déterminer si les résultats pour les IgM sont positifs en raison l'administration du vaccin ou d'une souche sauvage de la rougeole.

\section{Résultats pour le IgM négatifs, avec infection aiguë par le virus de la rougeole}

Des résultats négatifs peuvent être obtenus lorsque l'échantillon de sérum a été prélevé au-delà de trois jours avant l'apparition de l'éruption cutanée, dans quel cas les IgM ne se sont pas développés à un titre suffisamment élevé pour être détectés au moyen des tests par EIA.

Au sein d'une population dont le taux d'immunisation est élevé, l'infection par le virus de la rougeole peut se développer chez des personnes qui ont déjà été immunisées et dont les résultats n'indiquent pas une réponse des IgM.

\subsection{IGG}

La présence d'IgG antirougeoleux indique une exposition récente ou antérieure au virus de la rougeole, qu'il soit de souche sauvage ou vaccinale. Aucun test ne permet de déterminer si la présence d'lgG est le résultat de l'administration du vaccin ou d'une infection naturelle.

La séroconversion (c.-à-d. le passage de résultats négatifs à des résultats positifs) ou une augmentation du titre d'anticorps lgG par facteur de quatre ou davantage entre le sérum prélevé en phase aiguë et le sérum prélevé en phase de convalescence indique la présence d'une infection par le virus de la rougeole. Pour le prélèvement 
d'un deuxième échantillon de sérum (en phase de convalescence), il faut prévoir un délai de 10 jours suivant le prélèvement du premier échantillon de sérum (en phase aiguë). Cependant, il peut s'agir de la seule façon de démontrer de façon concluante une infection par le virus de la rougeole lorsqu'il n'est pas possible de procéder à une RT-PCR et que le résultat pour les lgM est négatif ou peu fiable.

Les épreuves immunoenzymatiques permettent de mesurer le titre d'IgG comme valeur de densité optique constante (parfois convertie en unité internationale). Il est par conséquent important d'effectuer des dosages avec points de fin de titrage plutôt que des analyses avec dilution unique d'un échantillon afin de déterminer de façon concluante si les titres ont augmenté par un facteur de quatre ou plus entre la phase aiguë et la phase de convalescence.

Les personnes qui ont déjà été vaccinées (échec de l'immunisation secondaire) peuvent représenter une exception dans l'augmentation par facteur de quatre du titre d'IgG antirougeoleux qui devrait entraîner des résultats fortement positifs au test de détection d'lgG antirougeoleux dans le sérum prélevé en phase aiguë et l'absence probable d'un titre d'anticorps IgG antirougeoleux quatre fois plus élevé dans le sérum prélevé en phase de convalescence(36,37).

L'identification du titre d'anticorps propres à la rougeole est utilisée pour mesurer le degré d'immunité d'une personne, la plupart du temps pour des raisons de santé au travail. La présence d'anticorps IgG propres à la rougeole, déterminée par une EIA, constitue un bon indicateur d'immunité contre la maladie, mais n'a pas nécessairement de lien direct avec la présence d'anticorps protecteurs et neutralisants quantifiés par l'étalon de référence, le TSNRP(38). L'absence d'IgG antirougeoleux détectables au moyen de l'EIA peut refléter la plus faible sensibilité de l'EIA comparativement à une épreuve plus sensible, particulièrement chez les jeunes enfants.

Le titre d'anticorps IgG antirougeoleux protecteur a été estimé entre 120(39) et 200 mUI(17), mais n'est pas connu avec précision.

\subsection{PANENCÉPHALITE SCLÉROSANTE SUBAIGUË (PSS)}

La panencéphalite sclérosante subaiguë (PSS) est une complication rare, mais mortelle, d'une infection par le virus de la rougeole persistante du système nerveux central (SNC). Le virus ne peut pas être facilement détecté par RT-PCR dans le LCR, mais les taux d'lgG antirougeoleux relatifs dans le sérum et le LCR peuvent être utilisés pour confirmer le diagnostic, s'ils sont accompagnés des symptômes cliniques, neurologiques et pathologiques caractéristiques de la PSS(45).

Ce test est effectué par le LMN et nécessite le prélèvement d'un échantillon de LCR et d'un échantillon de sérum jumelés. Les concentrations totales d'lgG et d'albumine ( $\mathrm{mg} / \mathrm{l})$ dans le sérum et dans le LCR doivent être déterminées et communiquées. L'échantillon de sérum et l'échantillon de LCR jumelés sont analysés au moyen de la trousse Euroimmun pour les anticorps de la classe lgG dirigés contre le virus de la rougeole dans le LCR. Le rapport entre les anticorps propres à la rougeole dans le LCR et le sérum, en comparaison avec le rapport des IgG totaux ou de l'albumine totale dans le LCR et le sérum, sert à déterminer s'il y a une indication de la production d'anticorps propres à la rougeole dans le système nerveux central.

\subsection{DÉTECTION DU VIRUS DE LA ROUGEOLE}

\subsection{TECHNIQUE DE TRANSCRIPTION INVERSE SUIVIE D'UNE RÉACTION EN CHAÎNE DE LA POLYMÉRASE (RT-PCR)}

La technique de transcription inverse suivie d'une réaction en chaîne de la polymérase (RT-PCR) est la méthode diagnostique la plus sensible et la plus précise pour la confirmation d'une infection par le virus rougeole, tant qu'un échantillon approprié est prélevé le plus rapidement possible après l'apparition de l'éruption cutanée. On obtient la meilleure sensibilité lorsque l'échantillon est prélevé dans les sept jours suivant l'éruption cutanée. La détection est quand même possible après ce délai, mais le virus perd rapidement de sa sensibilité. 
Des trousses commerciales de détection du virus de la rougeole par RT-PCR sont offertes, mais les laboratoires de référence utilisent des méthodes d'essai internes. Le LMN utilise deux méthodes de RT-PCR en temps réel qui ciblent la nucléoprotéine $(\mathrm{N})$ et l'hémagglutinine $(\mathrm{H})$, fondées sur les méthodes décrites par Hummel et al.(46).

Les protocoles détaillés peuvent être demandés au LMN. Le LMN soutiendra les laboratoires qui souhaitent mettre en œuvre la RT-PCR en leur fournissant les protocoles, la formation connexe et un panel des analyses moléculaires pour la rougeole annuellement.

Bien que la sensibilité analytique de la RT-PCR se situe entre 10 et 100 copies de génome, la sensibilité clinique globale est influencée par des facteurs préanalytiques (voir la section 3 ci-dessus), notamment les facteurs suivants :

- moment du prélèvement de l'échantillon par rapport à l'apparition de la maladie;

- type et qualité de l'échantillon;

- transport rapide de l'échantillon au laboratoire;

- traitement rapide de l'échantillon : il est recommandé que les échantillons pour la détection du virus soient traités dans les 48 heures suivant leur prélèvement. Les retards entraînent une baisse importante de la sensibilité;

- conservation adéquate de l'échantillon;

- congélation-décongélation des échantillons non traités à éviter.

\subsection{ISOLEMENT DU VIRUS DE LA ROUGEOLE}

L'isolement du virus de la rougeole exige des cellules B95a ou des cellules Vero/SLAM en prolifération qui sont inoculées par l'échantillon. L'effet cytopathogène est habituellement détecté entre quatre et cinq jours après l'inoculation, moment à partir duquel le virus de la rougeole peut être détecté par immunofluorescence ou par RT-PCR.

L'isolement du virus de la rougeole n'est pas aussi sensible ni aussi rapide que la RT-PCR et dépend beaucoup plus de la qualité et des conditions de conservation de l'échantillon. Le délai de traitement est notamment beaucoup plus long que celui de la RT-PCR. Pour ces raisons, I'isolement de cultures cellulaires est de moins en moins utilisé pour le diagnostic d'une infection primaire causée par le virus de la rougeole. Néanmoins, il est utile d'isoler les souches du virus de la rougeole des nouvelles éclosions et des cas sporadiques afin d'élaborer un répertoire des souches qui peut être utile pour le génotypage plus précis et l'établissement du lien épidémiologique. Le LMN tente d'isoler le virus de la rougeole de chaque éclosion et cas sporadique.

\subsection{GÉNOTYPAGE DU VIRUS DE LA ROUGEOLE}

Le génotypage du virus de la rougeole est utilisé pour distinguer une éruption cutanée postimmunisation d'une infection par un virus sauvage. Le génotypage est également un outil de surveillance important pour déterminer la source des cas importés et lier les cas dans les éclosions. La séquence des nucléotides du virus de la rougeole change peu au moment de la transmission dans un contexte d'éclosion; par conséquent, il s'agit d'un outil fiable pour confirmer ou écarter les liens épidémiologiques. Le réseau de laboratoires pour la surveillance de la rougeole et de la rubéole de l'OMS recommande le génotypage du plus grand nombre de cas de rougeole possible par les laboratoires de référence nationaux, mais d'au moins $80 \%$ des cas sporadiques et $80 \%$ des cas d'éclosion. II n'est pas nécessaire d'obtenir le génotype de tous les cas d'une éclosion importante, mais il est tout de même recommandé d'obtenir le génotype du plus grand nombre de cas possible pour détecter les événements d'importation qui s'entrecoupent et pour étudier l'évolution naturelle de l'éclosion.

Le génotypage de la rougeole a été normalisé (l'Organisation mondiale de la Santé) selon les directives de l'OMS(47) et est offert par le LMN. Une partie de la séquence du gène sur nucléoprotéines est amplifiée par la RT-PCR, puis l'amplicon est séquencé. Le génotypage est déterminé par la comparaison des 450 nucléotides qui codent l'extrémité carboxylique de la nucléoprotéine avec les séquences de référence de génotypage normalisées de l'Organisation mondiale de la Santé. Les séquences d'échantillons du virus de la rougeole peuvent être analysées davantage au cours du même génotypage en les comparant aux séquences des différentes souches du virus de la rougeole déterminées dans des régions données. Cette analyse peut servir de confirmation de la source importée ou d'un lien épidémiologique avec d'autres cas.

Le LMN verse tous les résultats de génotypage dans la base de données de l'OMS et dépose les séquences dans la base de données Measles Nucleotide Surveillance (MeaNS). La base de données MeaNS est une ressource précieuse pour surveiller par épidémiologie moléculaire les éclosions à l'échelle mondiale, et les professionnels de la santé peuvent s'inscrire à la page http://who-measles.org pour obtenir les données et les rapports publics. 
Dans le cas du génotypage, le type et la manutention de l'échantillon sont les mêmes que ceux qui sont nécessaires à la RT-PCR. II est recommandé qu'une aliquote de tous les échantillons prélevés pour la RT-PCR du virus de la rougeole soit envoyée au LMN aux fins de son génotypage.

\subsection{INTERPRÉTATION DES RÉSULTATS DES ANALYSES DE LABORATOIRE}

- Un résultat positif à la RT-PCR ou un résultat positif au test de détection d'IgM chez un patient qui présente les symptômes cliniques types ou qui a voyagé dans une région où la rougeole est endémique ou qui a un lien épidémiologique avec un cas confirmé sont des critères qui permettent de poser le diagnostic de la rougeole.

- Un résultat négatif à la RT-PCR peut être évalué en tenant compte du moment où l'échantillon a été prélevé (dans les sept jours suivant l'apparition de l'éruption cutanée), les antécédents d'immunisation et les conditions de conservation et d'expédition au laboratoire.

- Une séroconversion du titre d'lgG ou une augmentation par facteur de quatre du titre d'lgG chez un patient qui présente une éruption cutanée peut confirmer le diagnostic de la rougeole, mais l'interprétation des résultats sur les lgG est problématique lorsque le titre n'a pas augmenté jusqu'à quatre fois (par exemple chez les patients déjà vaccinés) ou lorsqu'il n'a pas été mesuré par dilution de l'événement cible.

- Un résultat d'IgM positif chez un patient présentant une éruption cutanée et sans antécédents d'exposition au virus de la rougeole peut être un faux positif et devrait être confirmé par RT-PCR ou la mise en évidence d'une séroconversion.

- Un résultat d'IgM positif chez un patient ayant reçu le vaccin RRO jusqu'à six semaines avant le test peut être causé par le vaccin. La séroconversion n'est également pas un test de diagnostic utile dans un tel cas. La détection du virus de la rougeole par RT-PCR est nécessaire pour confirmer le diagnostic. Le génotypage est nécessaire pour écarter une infection de souche vaccinale si le vaccin a été administré de deux à trois semaines avant l'apparition de l'éruption cutanée ou si le patient est immunovulnérables.
- Un résultat d'IgM négatif peut être obtenu chez un cas de rougeole si l'échantillon a été prélevé trop tôt après l'apparition de l'éruption cutanée (avant trois jours). Un deuxième échantillon peut être prélevé 10 jours plus tard et être testé pour détecter la présence d'IgM, si un échantillon pour RT-PCR n'est pas disponible.

- Il est possible d'obtenir un résultat d'IgM négatif chez les personnes qui ont déjà été vaccinées. Chez ces personnes, la détection du virus de la rougeole par RT-PCR est nécessaire.

- Pendant les éclosions, le diagnostic des cas de rougeole est parfois posé à partir d'un résultat d'lgM positif seulement, s'il y a eu exposition seulement ou en fonction du tableau clinique. Ces diagnostics ne sont toutefois pas acceptables pour confirmer les cas sporadiques, lesquels devraient toujours être confirmés par des données laboratoires ou des données laboratoires et épidémiologiques. L'OMS recommande le classement des cas par un comité d'analyse des cas après l'examen des résultats laboratoire et la confirmation d'une éclosion (document de l'OPS disponible à l'adresse www.paho.org/French/AD/FCH/ IM/SNF3102.pdf).

\subsection{TESTS DE DÉTECTION DU VIRUS DE LA ROUGEOLE AU LABORATOIRE NATIONAL DE MICROBIOLOGIE}

Le LMN offre les services suivants :

- détection du virus par RT-PCR (deux cibles);

- génotypage du virus de la rougeole et détermination de la nature sauvage ou vaccinale de la souche;

- tests sérologiques pour la confirmation d'une PSS;

- épreuves de compétences pour tests sérologiques pour la détection d'anticorps lgG et IgM antirougeoleux et tests moléculaires;

- isolement de culture du virus de la rougeole (à des fins autres que diagnostiques).

Pour en savoir davantage, veuillez consulter le guide des services du LMN à l'adresse www.nml-Inm.gc.ca/english/ guide/default.asp. 


\section{ANNEXE I. \\ CARTE DES PARTIES CONCERNÉES}

Voici un exemple de carte des parties concernées complète. Cette carte a été élaborée en janvier 2012 par un groupe d'experts en communication, en épidémiologie, en surveillance et en maladies infectieuses de I'ASPC. La carte des parties concernées répartit les intervenants en quatre groupes:

- Décideurs : Peut s'agir des ministères, des directions générales ou des territoires de compétence ayant un rôle essentiel ou contributif dans la réglementation du risque.
- Intervenants : Parties concernées qui sont le plus touchées par le risque et la gestion de celui-ci, et qui ont un lien transactionnel quelconque avec le risque en question.

- Parties intéressées : Personnes ou groupes ayant un intérêt dans ce qui est en cause, sans toutefois être directement touchés.

- Publics cibles : Peut s'agir des médias en général, $d^{\prime}$ 'autres ministères et $d$ 'autres associations et organismes intéressés qui ne jouent pas un rôle déterminant dans le problème ni dans la gestion du problème.

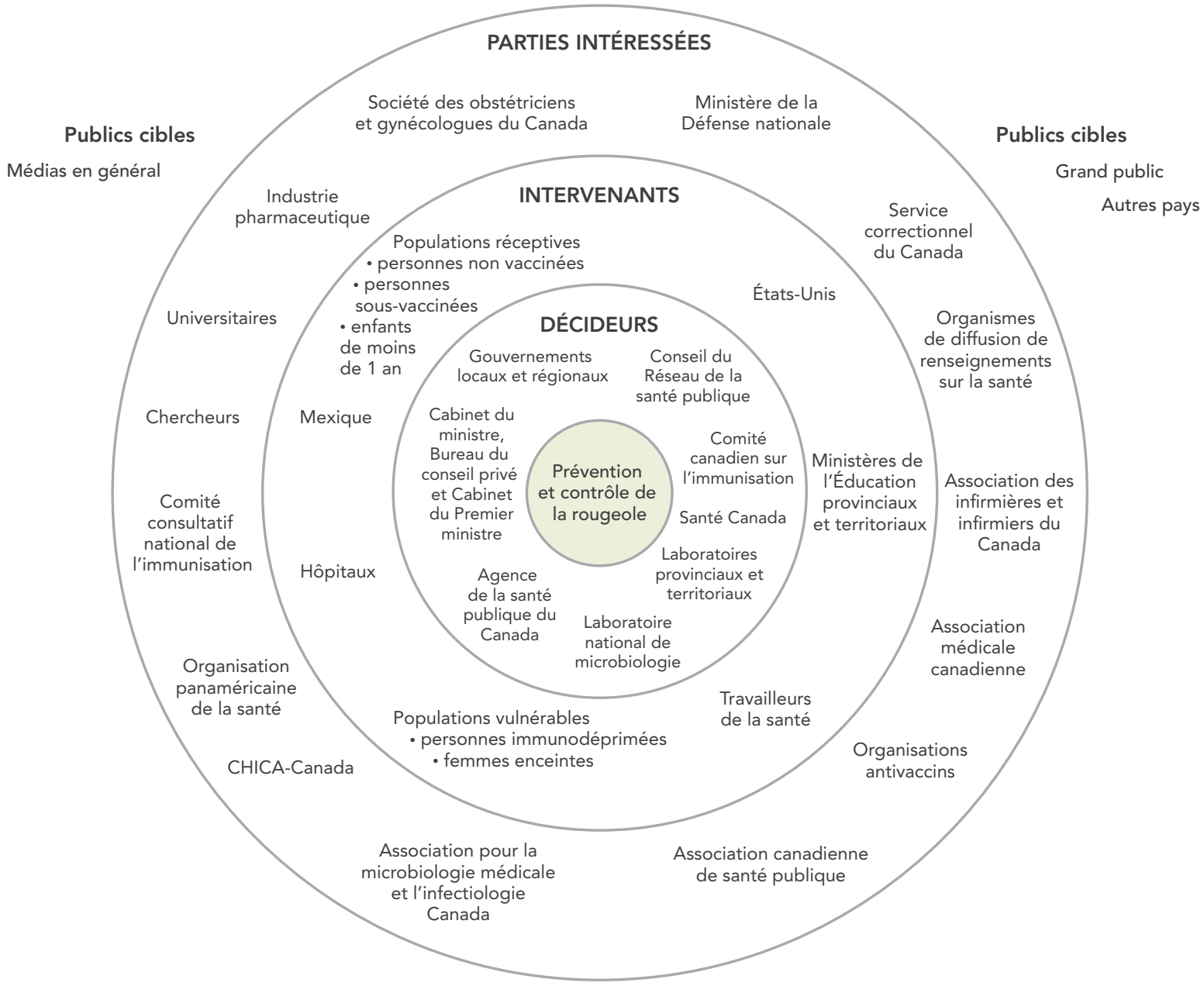




\section{ANNEXE J. EXEMPLE DE COMPOSITION D'UN MESSAGE}

\section{OBJET : LA ROUGEOLE EST UNE MALADIE GRAVE}

\begin{tabular}{|c|c|}
\hline Message clé & $\begin{array}{l}\text { La rougeole est une maladie extrêmement contagieuse qui affecte en premier lieu le nez } \\
\text { et la gorge. Les conséquences de la maladie peuvent être graves. }\end{array}$ \\
\hline Fait $n^{\circ} 1$ & $\begin{array}{l}\text { La plupart des personnes se rétablissent de la rougeole sans complications, mais la maladie } \\
\text { peut être plus dangereuse chez les nourrissons, les adultes et les femmes enceintes. }\end{array}$ \\
\hline Fait $n^{\circ} 2$ & $\begin{array}{l}\text { Parmi les complications de la rougeole, on compte notamment la pneumonie, l'accouchement } \\
\text { prématuré et l'insuffisance pondérale à la naissance }\end{array}$ \\
\hline Difficultés et incertitudes & $\begin{array}{l}\text { Bien que nous sachions que certains groupes de personnes sont particulièrement à risque } \\
\text { de présenter des complications, nous ne pouvons prédire quelles sont les personnes qui } \\
\text { souffriront de complications graves de l'infection par le virus de la rougeole. D'ailleurs, nous } \\
\text { ne pouvons pas plus prédire le nombre de personnes à risque qui seront touchées par cette } \\
\text { éclosion. C'est pourquoi il est si important que chacun prenne les mesures nécessaires pour } \\
\text { prévenir la propagation de la rougeole. }\end{array}$ \\
\hline Mesure personnelle & $\begin{array}{l}\text { Voici les meilleures façons de vous protéger contre la rougeole : } \\
\text { - Veillez à ce que vos vaccins soient à jour. } \\
\text { - Couvrez-vous le nez et la bouche au moment de tousser et d'éternuer. } \\
\text { - Gardez les surfaces fréquemment utilisées propres et désinfectées. } \\
\text { - Restez à la maison lorsque vous êtes malade. } \\
\text { - Nettoyez-vous les mains fréquemment, soit en vous lavant bien les mains avec de l'eau } \\
\text { et du savon, soit en utilisant un désinfectant pour les mains à base d'alcool. }\end{array}$ \\
\hline
\end{tabular}

